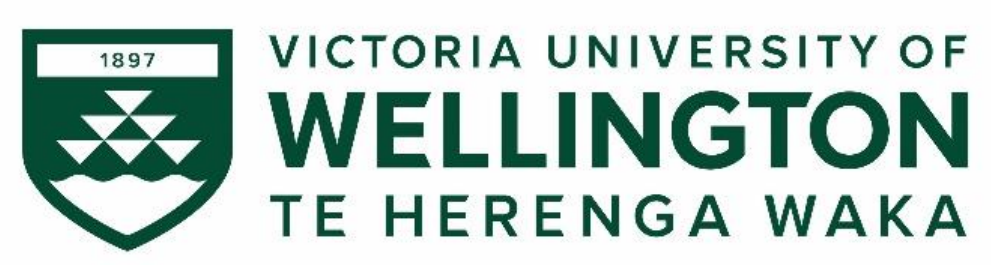

\title{
Ownership, Decentralization and Development in Papua New Guinea: Sub National Participation in Aid Effectiveness
}

Thesis submitted in partial fulfilment of the degree of Master of Development Studies

Edward Kapi 


\section{Abstract}

The debate on aid effectiveness and ineffectiveness continues to remain as a core issue for international development. The endorsement of the Paris Declaration on the principles of aid effectiveness in March 2005 by states and international agencies was a significant milestone in this regard. This declaration involved specific commitments for donors and partner countries and marked a paradigm shift for improving aid effectiveness. The overall aim was to improve the quality of aid and its impact on development and, in particular, recipient countries taking ownership of their development. The ownership principle has been echoed and reaffirmed in the subsequent series of high level forums on aid effectiveness.

This thesis provides a critical examination of Papua New Guinea's commitment to aid effectiveness. It examines and analyses aid and development effectiveness at the subnational levels of government. It finds that there is a substantial disjunction between national and subnational levels of government with regard to development ownership. This is demonstrated in current policies and practices, and it largely echoes studies elsewhere in the Pacific region on aid and development. However, in this wider literature, there is little evidence on important policy issues regarding leadership and effective aid and development coordination in a decentralized system of government, and this is where Papua New Guinea (PNG) offers some important new insights. This thesis argues that the subnational levels of government continue to remain isolated from the aid effectiveness discussion despite development ownership efforts and government objectives to practice ownership and leadership through all tiers of government. 


\section{Acknowledgement}

First and most importantly, I would like to express my solemn gratitude to Professor John Overton for his overwhelming expertise, assistance, guidance and forbearance throughout the process of writing this thesis. Without your support, this thesis would not be possible.

Special thanks to the New Zealand's Ministry of Foreign Affairs and Trade for giving me the once in a lifetime opportunity to be the recipient of the Maanaki New Zealand Scholarship. Through the scholarship, this study has come to fruition. I would also like to give special thanks to those who have assisted me in providing information during my data collection.

Also, I would like to extend my sincere appreciation to the staff and management of the Department of National Planning and Monitoring for supporting me financially, which eventually released some of my pressures imposed by the coronavirus pandemic whilst studying.

Last of all, I would like to express my sincere gratitude to my immediate family members, especially my old father for his unconditional love, and keeping me close to his heart in prayers. Without your faithfulness in praying for spiritual guidance and inspiring words, it would not have been an easy journey for me. Even so, I would also like to thank those who have given me headaches, heartaches and arguments and inflicted pain on me amidst the coronavirus pandemic. They were indeed great lessons for me to be resilient, determined and courageous, which eventually led me to complete this study. It is through such hard experiences, I saw the leading hand of the almighty God. I offer my sincere thank you for His unfailing love and faithfulness. 
TABLE OF CONTENTS

\begin{tabular}{|c|c|c|}
\hline \multirow{2}{*}{\multicolumn{2}{|c|}{ List of Tables }} & Pages \\
\hline & & $\mathrm{v}$ \\
\hline List 0 & Figures & vi \\
\hline \multicolumn{3}{|c|}{ CHAPTER ONE: INTRODUCTION } \\
\hline \multicolumn{3}{|c|}{ 1.1. Introduction } \\
\hline & 1.1.1. Background of the Study & 1 \\
\hline & Research Problem & 3 \\
\hline & Research Question and Objectives & 3 \\
\hline 1.4. & Proposed Conceptual Framework & 4 \\
\hline & Significance of the Study & 4 \\
\hline & Limitations of the Study & 5 \\
\hline & Thesis Outline & 5 \\
\hline \multicolumn{3}{|c|}{ CHAPTER TWO: LITERATURE REVIEW } \\
\hline 2.1. & Introduction & 7 \\
\hline & Origin of Aid Effectiveness & 8 \\
\hline & 2.2.1. Rome Declaration 2003 & 9 \\
\hline & 2.2.2. Paris Declaration 2005 & 10 \\
\hline & 2.2.3. Accra Agenda for Action 2008 & 10 \\
\hline & $\begin{array}{l}\text { 2.2.4. Busan Partnership for Effective Development Co-operation } \\
2011\end{array}$ & 11 \\
\hline & Experiences of Development Ownership & 12 \\
\hline 2.4 . & Paradigm Shift of Aid Effectiveness in PNG & 14 \\
\hline & Participatory Approach to Development & 17 \\
\hline \multicolumn{3}{|c|}{ CHAPTER THREE: METHODOLOGY } \\
\hline 3.1 & Introduction & 20 \\
\hline 3.2 & Research Design & 20 \\
\hline 3.3 & Participants & 22 \\
\hline 3.4 & Methods & 24 \\
\hline 3.5 & Procedures & 25 \\
\hline 3.6 & Data Analysis & 27 \\
\hline 3.7 & Ethical Considerations & 28 \\
\hline 3.8 & Conclusion & 30 \\
\hline \multicolumn{3}{|c|}{$\begin{array}{l}\text { CHAPTER FOUR: PAPUA NEW GUINEA'S POLICY AND } \\
\text { DEVELOPMENT CONTEXT }\end{array}$} \\
\hline 4.1. & Introduction & 32 \\
\hline 4.2. & Papua New Guinea's Political and Social Context & 33 \\
\hline 4.3. & Development and Legislative Framework & 34 \\
\hline 4.4 . & Institutions of the Government & 39 \\
\hline 4.5 . & Papua New Guinea's Aid and Development & 42 \\
\hline 4.6. & $\begin{array}{l}\text { Challenges and Issues in the Aid and Development Industry in } \\
\text { PNG }\end{array}$ & 49 \\
\hline & Recent Policy and Legislative Reforms & 53 \\
\hline & Paradigm shift to Retro-literalism: Private Sector a Key Player & 54 \\
\hline 4.9. & Bridging the Gap: Development Ownership & 57 \\
\hline 4.10. & Conclusion & 57 \\
\hline \multicolumn{3}{|c|}{ CHAPTER 5: FINDINGS } \\
\hline & Introduction & 59 \\
\hline 5.2. & General Aid Management and Performance in Papua New Guinea & 63 \\
\hline
\end{tabular}




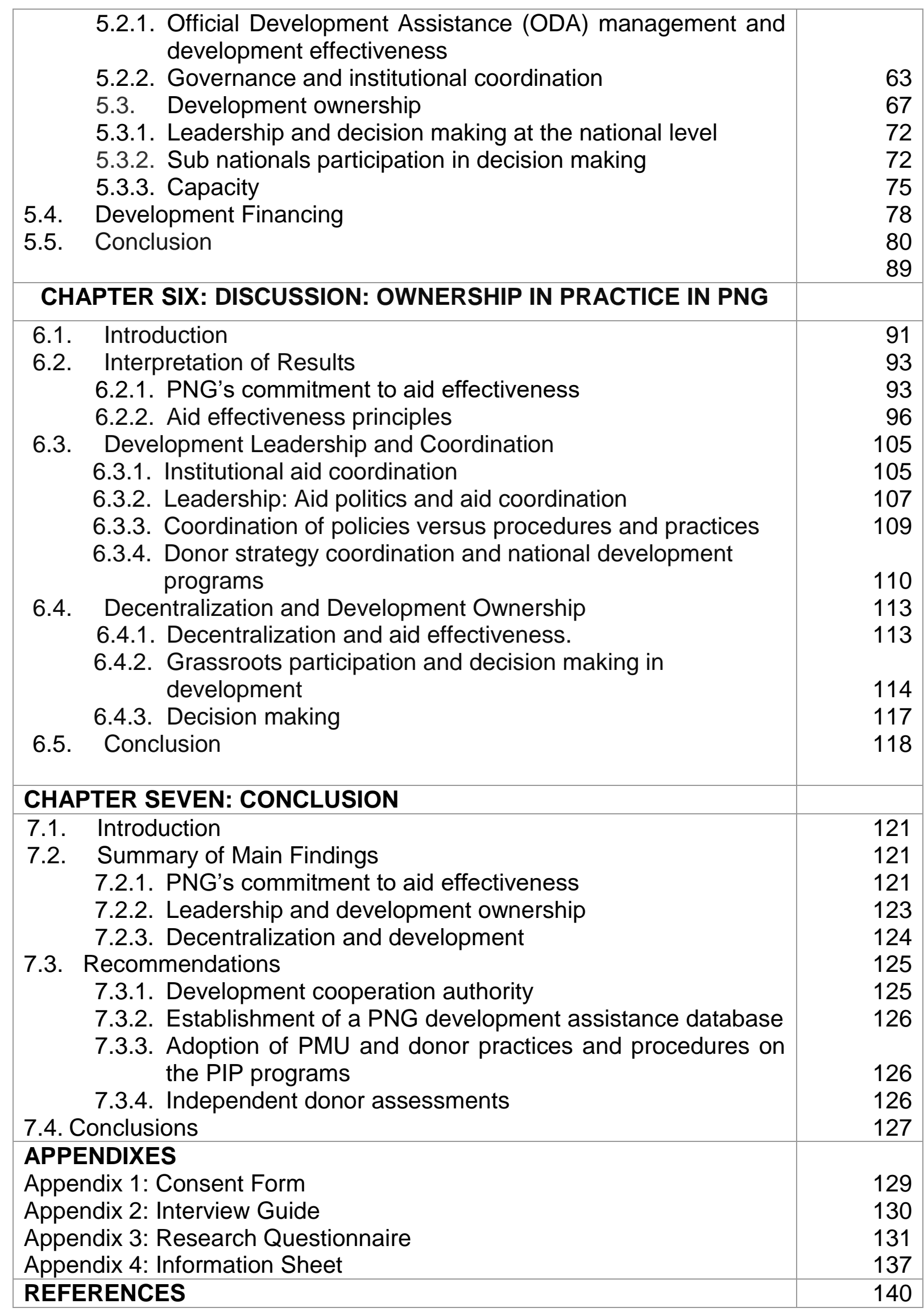




\section{LIST OF TABLES}

\begin{tabular}{llc}
\hline Table No. & Title & Page \\
\hline Table 2.1 & Government's Central and Sector Agencies & 15 \\
Table 3.1 & List of Participants & 22 \\
Table 4.1 & Agencies of the Government of PNG & 40 \\
Table 4.2 & Kavieng Declaration & 44 \\
Table 4.3 & Sample of Donors in PNG & 47 \\
Table 4.4 & Sample of ODA to Oceania by recipient country (1970- & \\
& 2017) & 48 \\
Table 5.1 & Summary of the Findings & 60 \\
Table 5.2 & Public Investment Program Appropriation from 2008-2018 & 82 \\
Table 5.2a & Expenditure by Funding Source & 85 \\
Table 5.2b & Sample of the Budget 2011-2012 & 85 \\
Table 5.3 & Final Budget Outcome Summary from 2008-2018 & 86
\end{tabular}




\section{LIST OF FIGURES}

\begin{tabular}{llr}
\hline Figure & \multicolumn{1}{c}{ Title } & Page \\
\hline Figure 4.1 & The Provinces of Papua New Guinea & 32 \\
Figure 4.2 & Development Planning Framework of Papua New & 37 \\
& Guinea & 88 \\
Figure 5.1 & The upsurge of subnational budgetary allocation in & \\
& PNG (Kina million) & 98 \\
Figure 6.1 & Donors and GoPNG Contribution towards & 102 \\
& Development Budget (2007-2013) \\
Figure 6.2 & Trend in Donor Funding to GoPNG 2007-2013 & 111
\end{tabular}




\section{INTRODUCTION}

"Papua New Guinea is changing, we are growing and as a nation of 8 million people we want to move beyond handouts and work with our partners to strengthen capacity... Development assistance has become a billion dollar 'industry' where so much of the goodwill ends up in the pockets of middlemen and expensive consultants" Peter O'Neill- Former PNG Prime Minister, $2015^{1}$.

"We will move from an introduced culture of dependency and complacency, where we rely on overseas aid and inward investment alone, to one where we become a vibrant economic powerhouse and are totally economically independent by expansion and diversification of our economic base." James Marape- PNG Prime Minister, $2019^{2}$

\subsection{Introduction}

\subsubsection{Background of the Study}

In the past two decades, debate in the international development community has been focused on foreign aid effectiveness. A pressing question that should concern every development practitioner, policy analyst, and development financier is whether or not the foreign aid from Western donors has helped to promote economic growth and development in lesser developed country economies. With regard to this question

\footnotetext{
${ }^{1}$ ABC News, 2015. Papua New Guinea PM says aid money wasted on 'middlemen'; calls for development support rethink. PNG's Prime Minister Peter O'Neill released a press statement calling for a rethink to aid support. https://www.abc.net.au/news/2015-08-03/papua-new-guinea-plans-rethink-ofdevelopment-support-delivery/6667642

2 James Marape. Papua New Guinea will not be dependent on Australia in 10 years, Remarks address at the Lowy Institute, Australia
} 
about foreign aid effectiveness, researchers and development practitioners have been relatively silent on the issue of aid effectiveness at the lower levels of government where there is a decentralised system of government. This does not necessarily mean that no research has been conducted on aid effectiveness in Papua New Guinea or at the regional and global scale; instead, research on this subject has focused primarily on a different research question, one related to the determinants (rather than the effects) of Western aid allocations, largely at the macro- and national scales.

This thesis study focuses not on the determinants and the effectiveness of what is already available to the recipient countries; rather it examines whether or not recipients effectively take ownership of their own development in practice. This zooms down to the sub national levels of government to examine how they participate in foreign aid effectiveness.

Papua New Guinea has been an aid-recipient and dependent country since independence in 1975. Despite the country performing well economically compared with other developing countries in the South Pacific region, the country still depends on development assistance. Despite promising indications that PNG is taking greater ownership of its development by instituting improved policy frameworks and systems, the efforts to increase development ownership throughout all levels of government has been somewhat disappointing.

My personal experiences working with the Government of Papua New Guinea shares the same sentiments that are held by many researchers, development practitioners and donors. I have been working with the Department of National Planning and Monitoring (DNPM) as a senior aid coordinator, and my relationships with donors and government agencies have revealed interesting insights with regard to development ownership. The country's political leaders have articulated a vision for moving away from a culture of dependency and complacency, where the country relies on overseas aid and inward investment alone, to one where we become a vibrant and robust economic powerhouse in the region and are much more economically independent through the expansion and diversification of our economic base. However, there are increasing concerns that development assistance has become a billion dollar 'industry' where it is centralised at the national level and involves only a few who have direct 
influence on the development process, while the sub national levels of government have little or no say in development financing, planning and prioritization.

\subsection{Research Problem}

With the country dependent on foreign aid, efforts to exert greater aid and development ownership at the sub national levels of government have been minimal. These are demonstrated in the struggles to improve service delivery that are not adequately reaching the lower levels of government. The feeling of disconnectedness by the local levels point to the ineffectiveness of aid and development effectiveness. Other compelling issues, such as lack of capacity to absorb resources flowing down to the lower levels of government, as well as misappropriation, corruption and many other governance issues, result in development ineffectiveness. Therefore, with such issues in mind, this study has been designed to examine and analyse whether or not the sub national levels of government sufficiently participate in development and aid effectiveness.

\subsection{Research Questions and Objectives}

The aim of this research is to focus on how aid and development ownership is exerted at the subnational levels of government. Its objectives are as follows:

i. To analyse whether or not the subnational levels of government of PNG participate in aid effectiveness.

ii. To assess if development ownership is achieved at the lower levels of government.

iii. To provide policy and practical recommendations to improve on the efforts to achieve aid effectiveness in PNG.

The primary research question for this study is to answer the question: do the sub national levels of government participate in aid effectiveness?

This main question is supported by secondary research questions: 
- What are the current practices of aid and development effectiveness?

- Are the functions of aid management and coordination effective?

- Do the sub national levels of government make informed decisions in relation to development planning and financing?

\subsection{Proposed Conceptual Framework}

The study will be adopting a broad analytical framework to assess the 'decision space' and 'capacity' of the sub national levels of the government to participate in aid effectiveness. There are certain key thematic areas this conceptual framework encompasses. These include the country's commitment to aid effectiveness, leadership and coordination of aid and development, and finally decentralization. Country commitment to aid effectiveness entails a planning framework and the localization of the 2005 Paris Declaration on aid effectiveness. Ownership is demonstrated by the level of strong leadership in coordination and management of aid and development. Yet of particular concern is how sub national levels of government - provinces, districts and wards - are capacitated and provided with strategic leadership and direction to take ownership of their own development.

Also, the study engages with the values of the participatory approach to development through examining the principles underpinning aid effectiveness and in particular 'development ownership'. Ownership requires participation from all stakeholders, including donors, government at all levels, and civil society (churches and NonGovernmental Organizations) who, one way or another, influence the development process of a community, district, provinces and the country as a whole.

\subsection{Significance of the Study}

This study has the potential to contribute towards the body of knowledge on the aid effectiveness agenda. Particularly, the testimonies, experiences and lessons examined in this study can generate some new sources of information and perspectives on the ways aid effectiveness works or does not work in practice. 
The study also aims to provide some practical recommendations on how to improve on the current concerted efforts to achieve aid and development effectiveness in Papua New Guinea. The recommendations provided in this study are provided in order to feed into policy reviews and reforms.

\subsection{Limitations of the Study}

This research has been undertaken against the background of the global Covid-19 pandemic. The original plan for the research was to conduct research face-to-face in Papua New Guinea with a range of development practitioners. However, when the research started in March 2020, the outbreak of the pandemic immediately forced major changes.

It has been a tough time for me during this period. The pandemic led to mounting pressures at home as well as at the university, affecting the data collection due to cancellation of the home-based field research trip. It was difficult to deal with significant family issues and news from home whilst based in Wellington. The research also had to be redesigned and be based on online and phone interviews. I had to extend my study for another three months as it was very challenging to complete. Although interviews were completed, I felt they were less detailed and illuminating than if they had been conducted in person.

Certain ethical considerations also had to be managed throughout this study. For example, there were elements of potential conflict of interest, as I was a government officer interviewing some of the key government departmental heads and donors whom I have been working with, such as officials at the Department of National Planning and Monitoring, and the Department of Treasury.

\subsection{Thesis Outline}

There are total of seven chapters of this study. The chapters are structured in the following manner. 
This first chapter sets a brief outline of the thesis background and aims. This is followed by the literature review, which examines the key foundations for the topic in the wider global literature on aid effectiveness. The third chapter sets out the research methodology and the method this study has employed and reflects on how these worked in practice. The fourth chapter provides the backgrounds and the context of this study. This entails the cultural, political and economic context of Papua New Guinea. The development planning framework and importantly, the localization of Paris Declaration of Aid Effectiveness will be discussed in this chapter. Chapter Five presents the findings of the research and presents data from the interviews organised around certain themes that emerged from the research. Chapter Six then analyses the findings and discusses relevant themes. The seventh and final chapter of the study is the conclusion. In this chapter, there will be several key policy and practical recommendations for improving aid management, coordination and implementation for aid and development effectiveness in the country. 


\section{LITERATURE REVIEW}

\subsection{Introduction}

The issue of aid effectiveness has been a major topic of interest in Development Studies over the last 20 years, and the practices of development cooperation have been rapidly changing. In the past decade, there has been an increase in the number of actors in the aid industry, such as private companies and philanthropic organizations, and increased domestic resource capacities. As such, it has been suggested that this has lessened the relative importance of aid contributed by Official Development Assistance (ODA) (Mawdsley et al., 2014).

However, although these changes have introduced major changes to the aid world what has been called an era of 'retroliberalism' (Murray \& Overton 2016, Mawdsley et al., 2018) - the previous 'neostructural' period with a focus on poverty alleviation and aid effectiveness still exerts an influence on the way aid is managed (Murray \& Overton, 2011). There is also recognition that aid continues to have an important role to play.

Despite critiques of aid assistance and the developments that are driven from external projects such as the Millennium Development Goals (MDGs) and the Sustainable Development Goals (SDGs), foreign aid resources have been seen to help lift many countries from extreme poverty and address economic growth and social inequalities (Harman \& Williams, 2011). The use of practices such as Poverty Reduction Strategy Papers (PRSP) and concerted efforts to improve aid effectiveness by aid donors and aid recipient countries have continued

Among those many aid effectiveness priorities, ownership of development by aid recipient countries has been on top of every donor roundtable policy agenda. This principle, as will be seen below, was the first of the so-called 'Paris Principles' coming out of the OECD-sponsored Paris Declaration on aid effectiveness of 2005. It has been 
viewed that the Paris process was strengthened by concrete, evidence-based insight about predicted importance of 'country ownership' going forward. However, the shift in practices and focuses compromised its initial insights. The essence of countries taking leadership over their own development has been pushed forward by donors and foreign aid recipient countries.

This research will adopt a conceptual framework in which I am more interested in looking at how effective the principle of ownership has been adopted by aid recipient countries, and for this case, Papua New Guinea (PNG). The thesis will be focused on how the subnational governments and project beneficiaries at the grassroots level are adopting the principle of ownership in practice, while the state in the form of the central PNG government is the main stakeholder taking leadership of the country's development. Moreover, this thesis will also try to ask how the best practices of the development partners are institutionalised into mainstream government service delivery efforts, according to their own country's comparative advantages and relevance. It will also look at why ownership is important for development and aid effectiveness through reviewing the various literatures on high level forums of aid effectiveness.

This chapter reviews relevant literature in two main aspects. Firstly it traces the emergence of the aid effectiveness agenda in the first decade of the 2000s and examines the main principles. Secondly it examines the wider literature on participatory development to gain insights into the way greater involvement of people at all levels can improve the ability of development activities to achieve their desired results.

\subsection{Origin of Aid Effectiveness}

The genesis of foreign aid began following the end of World War 2, when the US President Harry Truman introduced the European economic recovery plan, the Marshall plan, which was named after the president's economic adviser, George Marshall. The plan was designed purposely to provide financial resources to those severely damaged economies of Europe which took part in the two world wars to rebuild their countries and their collapsing economies (Hogan \& Hogan, 1989; 
Dabelstein, 2012). The conversion of the then Organisation for European Economic Cooperation (OEEC) to the Organisation for Economic Cooperation and Development (OECD) in 1947 was purposely to run the US's Marshall Plan targeting the reconstruction of European economies. Its goal was to help European governments recognize their economic interdependence. Since the culture of countries donating resources particular from developed countries to developing countries or the third world countries in simplest terms, the effort of aid effectiveness became greater and importance in the aid architecture of global development governance. The Development Assistance Committee was the committee of the OECD who discuss on shaping policies that foster prosperity, equality, opportunity and well-being for all. But most importantly, the DAC ensures that the aid effectiveness is achieved on all the aid resources that are being transferred to the developing countries.

Following global commitments to increase aid volumes with the launch of the Millennium Development Goals (MDGs) in 2000, donors became increasingly concerned with the issue of whether their growing volumes of aid were achieving those important goals. To ensure aid resources were having meaningful contribution to the development of the recipient countries, the DAC member countries through their concerted efforts held a series of High Level Forums (HLF) for aid effectiveness. Senior cabinet ministers and leaders from more than 100 countries, representatives of multilateral aid institutions such as the European Commission (EuropeAid), the World Bank (WB), the United Nations (UN), private foundations and civil society organizations have attended these forums convened by DAC-OECD.

\subsubsection{Rome Declaration 2003}

The first HLF was the Rome Declaration on Harmonization in 2003. This forum was smaller than the other three forums but set the foundation for later agreements. Only a few traditional donors attended and committed themselves to promote donor harmonization, in which United Kingdom was leading the agenda. However, some observers pointed to the fact that, for the first time, aid effectiveness was the main policy dialogue proclaimed by a ministerial level declaration, despite the World Bank's objective to have a conference outcome. 
The second forum (HLF-2) was the Paris Declaration held in 2005 (Dabelstein 2012). In this HLF, they agreed to certain principles enshrined in the Paris Declaration on Aid Effectiveness and pledged their commitment to work together to achieving aid effectiveness. This forum was the continuation from the first HLF, explicitly defining the principles of aid effectiveness, and this time emphasizing country ownership. The commitments are in principle, ownership, in which the importance of recipient countries taking ownership of their development through development plans and strategies, around which development partners are to "align" themselves (Bourguignon \& Sundberg, 2007; Bissio, 2013). The aid principles included:

- Recipient countries taking ownership of their development through leadership in policy, planning, institutional reforms and governance,

- Harmonization of donor coordination by sharing information to ensure that resources channelled are not duplicated with other donors,

- Alignment of donor assistance strategies with those of the recipient countries development priorities through using local systems and process to improve aid effectiveness,

- Results-oriented management of aid resources in which both the recipient and donors are satisfied on the expected development outcome,

- Mutual accountability of both donors and recipients for development outcomes.

\subsubsection{Accra Agenda for Action 2008}

After three years, the third HLF on Aid Effectiveness (HLF-3) was held in Accra, Ghana from September 2-4, 2008. The primary aim of this forum was to build on the work of the Rome and Paris HLF by taking stock of progress so far and to accelerate the momentum of change. Many observers claim that in this forum a number of paradigm shifts occurred in the global development landscape and aid industry, including the shift of China and India from aid recipients to aid donor countries while taking greater control of their aid process. Importantly, emphasis was made on increasing the role of developing countries and civil societies in the role of development, and extended the scope to stress the importance of results on the progress of past commitments while 
attracting new ones. This forum did not only assess the past commitments, rather it emphasised additional commitments such as prioritizing the option of using country systems and processes; making aid more predictable and transparent; adding greater emphasis on mutual accountability; and reduction of aid fragmentation though division of labour domestically or internationally.

\subsubsection{Busan Partnership for Effective Development Co-operation 2011}

The fourth and final HLF was held in Busan, South Korea in 2011. In this forum, there was a reaffirmation of commitment to assist countries transition from developing to developed while shifting the focus from conventional aid effectiveness to development effectiveness (Martini et al., 2012). And such was promoted by new and emerging donor such as host country South Korea (Kim \& Lee, 2013). Interestingly, the role played by the host country itself followed the similar trend of the two countries (China and India) in the third HLF. A point worth noting is that this forum has shifted the focus from aid effectiveness to development effectiveness.

While looking at these series of high level forums, one primary focus on aid effectiveness that stood tall in all dialogue was country ownership. All these HLFs had one agenda in common: to make foreign aid more effective by giving meaning to its purpose. The causes of failures and successes in the implementation of such reforms at various HLFs are often tracked back to weak or strong ownership by the recipient/implementing agency (Castel-Branco, 2008). There are comprehensive and reflective reviews on aid governance and the Paris Declaration optimistically perceived that the principle of ownership has been achieved but still had room for improvement. As such, the Paris Declaration urged the commitments from all partner countries to three primary objectives of ownership. Firstly, partner countries were encouraged to exercise leadership in developing and implementing their national development strategies through broad consultative processes. The second objective was to translate these into prioritised results-oriented operational programs as expressed in medium-term expenditure frameworks and annual budgets. And the final objective of ownership emphasised the need for countries to harmonise donor partnership with civil society and private sectors by playing a leading role in coordinating aid at all levels together with other development resources. 


\subsection{Experiences of Development Ownership}

While examining experiences from various countries such as Bolivia, Honduras and Nicaragua (Dijkstra 2011), one finds that within the effort to achieving aid effectiveness, ownership particularly is somewhat disappointing. Of the five principles of PRSP, the most important principles which all countries committed to achieve were (i) country-driven, involving broad-based participation, and (iv) based on a long-term perspective. Through the experiences of these three countries of Latin America, lack of participation from civil society, lack of prioritization between development and economic growth, and domestic ownership were major contributing factors to aid ineffectiveness.

There is some literature that covers positive experiences of aid and development ownership globally. Among those is Uganda's leading example of the successes of new approaches to partnership in one of the projects in the education sector (Higgins \& Rwanyange, 2005). What is interesting in this case study was the local experiences of planning for change in the education sector, in which both government and donor funds support its Poverty Eradication Action Plan (PEAP) through a sector wide approach (SWAP) of aid financing modality. Uganda's successful exemplification of adopting SWAP in the local government and political structure is worth noting in the efforts of aid effectiveness. It is also widely acknowledged that ownership of developments or reforms entails robust engagement and participation by those involved in implementation.

Another interesting area of literature on aid ownership and how aid resources have been effective in a decentralised political structure is the case of Ethiopia. Furtado and Smith (2007) did a deep analysis of aid, ownership and sovereignty in Ethiopia. They found several attributes of Ethiopian systems that make it different from other donor recipients and also influences the flow of donor-government and governmentdonor relationships. One of the interesting attributes which makes the country unique from others is the federal system, under which seven regional states have a greater deal of autonomy for delivering services, such as health, education, water supply, and transport services. These are the sectors in which more activities are financed through aid resources; primarily the budget is transferred in the form of block grants (Furtado 
\& Smith, 2007). The administration and governance become highly decentralised while the policy and decision making were centralised. What is worth noting is that the central function of aid management and coordination has been transferred to the municipal states in which aid resources are directly managed by the autonomous government structure, while in many other cases outside Ethiopia, that function is still with the central government. An interesting part of donor coordination was that the government did not want anyone in the kitchen, while it drives its own development agenda with limited donor influence over development prioritization, which allows Ethiopia to achieve its own development aspirations. This means that there is a more domestically-owned agenda or a state-centred view of development.

On the other hand, there are some disappointing experiences on country ownership of development which forms part of the literature review. The Paris principles themselves have received attention in the field, for example the notion of ownership (Buiter, 2007) and harmonization (Eyben, 2007). Studies of the experiences of Bolivia, Honduras (Dijkstra, 2011) and Nicaragua revealed problems in implementing the principles, including lack of participation from civil societies, lack of prioritization between development and economic growth, and limited domestic ownership (Dijkstra, 2011). On the other hand, there are notable positive experiences such as Uganda's successful exemplification of adopting a SWAP model in the local government and political structure (Higgins \& Rwanyange, 2005).

Despite these shortfalls, it is also widely acknowledged that ownership of developments or reforms entails robust engagement and participation by those involved in implementation at the lower levels of government. An interesting example in the literature on aid ownership is the way aid resources have been effective in a decentralised political structure is the case of Ethiopia as referenced above, in which the administration and governance become highly decentralised while the policy and decision making remain centralised (Furtado \& Smith, 2007). What is worth noting here is that the central function of aid management and coordination has been transferred to the municipal states in which aid resources are directly managed by the autonomous government structure, while in many other cases, the function is still with the central government. The results seemed favourable. 


\subsection{Paradigm Shift of Aid Effectiveness in PNG}

When looking at the evolution of aid effectiveness thinking and various cases of ownership, this thesis asks how effectively can the global best practices of ownership be institutionalised in the context of PNG. PNG's commitment to aid and development effectiveness has been encouraging through their policy reforms and leadership dating back to 2005. In particular, the country made a notable effort to localise the Paris Declaration principles in its own Kavieng Declaration of 2008 (Government of PNG, 2008). This document, agreed to by the major donors to PNG, sought to define the principles that were appropriate to the country and spell out how donors and the government of PNG would work together to achieve them.

However, despite this higher level agreement, this research aims to look at how effective the idea of ownership trickles down to all levels of government through their budgeting, policy and programming. How the best practices would be adopted and institutionalised in the domestic and local political structure, and for this case, the national, provincial and local level government. Moreover, is the sense of ownership felt at the grassroots level? And importantly, do the lower levels of government have the capacity to adopt these practices?

The present reforms and continued effort of aligning development priorities through various country assistance strategies and country assistance partnerships reflect the ambition to contribute towards aid effectiveness. However, while looking at the various cases of aid effectiveness and in particular the ownership issue, PNG is in a complex state given its government system, and the cultural and geographical diversity in which people perceive and practice of development is not uniform throughout the country. For instance, some of this diversity is reflected in the varied ways of dealing with issues of land ownership, environmental and social safeguard issues, women in development, culture and development, state legitimacy and the social contract, and law and order. These variations have resulted in people distinguishing development differently from state vs donor interventions. The visibility of a donor is more common that the state's own development initiatives. Such leads to certain issues such as lack of development ownership, distrust of the state, breakdown of social contract, and compromised project qualities as there is no sense of ownership nor any sustainability. 
This research poses questions regarding how effectively the domestic ownership of development can inform the national ownership of development in the context of PNG. It is important to look at how effectively the ideal of ownership trickles down to all levels of government through their budgeting, policy and programming in a country that has three levels of government. These levels are the central/national government comprised of sector agencies and the central agencies (see table 1), the provincial governments (22 provinces), and the district and local level governments (89 districts, 326 LLGs and 6122 wards). Subnational agencies are the real agencies who implement and manage ODA resources at the local level and not the central government agencies such as Department of National Planning \& Monitoring (DNPM), Department of Treasury (DOT), Department of Finance (DOF) or Department of Foreign Affairs \& Trade (DFAT). The central government only makes high-level policy decisions and does not directly implement projects and programs.

\section{Table 2.1. Government's Central and Sector Agencies}

\begin{tabular}{|c|c|}
\hline $\begin{array}{l}\text { CENTRAL GOVERNMENT } \\
\text { AGENCIES }\end{array}$ & SECTOR/LINE AGENCIES \\
\hline $\begin{array}{l}\text { Department of Prime Minister \& } \\
\text { National Executive Council } \\
\text { (PM\&NEC), } \\
\text { Department of Treasury (DOT), } \\
\text { Department of National Planning \& } \\
\text { Monitoring (DNPM), } \\
\text { Department of Finance (DOF), } \\
\text { Department of Personnel } \\
\text { Management (DPM), and } \\
\text { Department of Provincial and Local } \\
\text { Level Government Affairs } \\
\text { (DPLGA) }\end{array}$ & $\begin{array}{l}\text { Department of Works and Implementation } \\
\text { (DOW), } \\
\text { National Department of Health (NDOH), } \\
\text { Department of Education (DOE), } \\
\text { Department of Law and Justice Sector } \\
\text { (DLJS), } \\
\text { Department of Commerce (DC), } \\
\text { Department of Foreign Affairs and Trade } \\
\text { (DFAT), } \\
\text { Department of Environment and Conservation } \\
\text { (DEC), } \\
\text { Department of Community Development, } \\
\text { Youth and Religious Affairs (DCDYRA), } \\
\text { Department of Lands and Physical Planning } \\
\text { (DLPP), } \\
\text { Department of Higher Education, Research, } \\
\text { Science and Technology (DHERST), } \\
\text { Department of Information and } \\
\text { Communication (DIC), } \\
\text { Department of Mineral Policy and Geohazard } \\
\text { Management (DMP\&GM, } \\
\text { Department of Defence (DOF), } \\
\text { Department of Mineral and Hazard } \\
\text { Management (DMHM } \\
\text { Department of Transport (DOT). }\end{array}$ \\
\hline
\end{tabular}


PNG's commitment to aid and development effectiveness have been encouraging through their policy reforms and leadership since the Kavieng Declaration. For instance, the Government formulated its first development cooperation policy in 2015 for its commitment to the Paris Principles for country ownership of their own development. Recent reforms such as creating the National Procurement Commission (NPC), while doing away with Central Supplies and Tenders Board, has helped promote the principle of alignment. In addition, the government has outsourced the auditing for all donor fund projects to private firms and introduced the Public Expenditure \& Financial Accountability (PEFA) assessment. The formulation of the PEFA Roadmap and the subsequent PEFA Assessment Report have progressed the process of having a strengthened government system supported by the strategic Medium Term Development Plan 3 (MTDP III) and the PNG Development Cooperation Policy (DCP) 2018-2022. These are intended to give confidence to Development Partners (DPs) that the government is increasing its efforts to achieve aid and development effectiveness. Also, the 100 percent financing for all loan funded projects has been agreed upon while doing away with traditional 20/80 financing modality. The present reforms and continued effort to align development priorities through various country assistance strategies and country assistance partnership has the ambition to contribute towards aid effectiveness.

However, from personal experience working in the aid unit of the government of PNG, it is apparent that the practices of good aid delivery have been seen by donors as a stand-alone effort. Once the donor-funded projects are completed, the best practices are not institutionalised into the mainstream processes. There are practices of upscaling the programs but only through continuous loans and aid dependency. There is little or no vision of sustainability if and when the donors pull out their resources and priorities in the sectors of support. There is a clear risk when the projects are seen as just discrete projects with no long-term evaluation. Furthermore, the issue of poor governance still exists. The Government's own reporting on financial expenditure is poor when compared to donor-funded projects. Donor audits are done on a timely basis while the Government's own funded project audits have often been delayed by two or three years. For example, the audits of the Provincial Service Improvement Programs and District Service Improvement Programs were three years late. 
On top of these issues, new aid approaches are complicating the issue of aid effectiveness. From a retro-liberal perspective, the private sector is increasingly seen as an equal player in driving development. This is also seen as part of the whole paradigm shift in aid delivery where donors are engaging their own companies to provide services. However, how do the principles of aid effectiveness apply to forms of development sponsored by foreign direct investment (FDI) and operations by the private sector? In addition, private companies are dealing directly with the provinces and districts when providing basic services to the communities as part of their corporate responsibilities and community relations.

\subsection{Participatory Approach to Development}

The proponents of the participatory development approach (Michener, 1998; Shah \& Baporikar, 2012) argued that the meaning and intention of participation are well articulated as espoused at academic and policy levels. However, when it comes to implementing "genuine" participation, different stakeholders employ participation suiting their own advantage, and the realities of the field act as barriers to participatory development. In other words, it is apparent that the concept of people's participation in development is well defined, but different development organizations and social sciences have different definitions of participation.

Participation describes active involvement by people in civic and developmental organizations, political parties and local government, with the purpose of influencing decisions that affect their lives (Roodt, 2001). Rahman (1993) put forward the idea that participation is the exercise of people's power in thinking and acting, as well as in controlling their action in a collective framework. Mikelsen (1995) argued that participation is the sensitization of people to increase their receptivity and ability to respond to development projects. Roodt (2001) concurs with this notion, and uses the term coined by Paulo Freire, conscientization, a process whereby poor and oppressed people become politically and socially aware that their living conditions are not "natural" but the result of the exploitative policies implemented by the state and their country's elites. Central to this concept is that this awareness is achieved through active participation in educational/political/social organizations in conjunction with 
fellow citizens and will enable oppressed people to actively change their lot (Roodt, 2001, p. 472). In the context of this research, the term participation is regarded as the ability of the community to identify their challenges and needs and then take charge of their scenario. Participation also refers to "empowering people to mobilize their own capacities, be social actors, rather than passive subjects, manage the resources, make decisions, and control the activities that affect their lives" (International Institute for Environment and Development, IIED, 2010, p. 13). Change agents are only there as catalysts, and the community members are at the centre of development.

There are notable studies in the literature available on participation by lower levels of government and grassroots for development in Zimbabwe, for example, Sibanda's (2011) exploration of the role of community participation in development initiatives there. The study was conducted to examine the level and extent of community participation in the Danga Ecological Sanitation Project carried out in the Zvishavane district of Zimbabwe. In this study, they used Mvuramanzi Trust, a non-governmental organization established purposely to contribute to the development and growth of the Rural and Peri-Urban areas in Zimbabwe by providing technical support, training, education and consultancy services in the sustainable use of water resources, sanitation facilities and related social services.

The Mvuramanzi Trust relied mostly on ward councillors and other government officials for mobilizing the community members. Despite activities initiated by community members like those in places such as the Kufuma Ishungu Garden Group, all projects had to be endorsed by the ward councillor, village head and traditional chief. According to the study, as it was recorded, Mr. Mandebvu, a villager, complained that "every one of them wants to be felt; they want a piece of us." This means the Danga Ecological Sanitation Project was no exception, and the Mvuramanzi Trust had to go through the leadership hierarchy before reaching the 84 communities. As a consequence, community participation remains minimal and the top-down approach continues to dominate. This implies that organizations can plan, but when they go to the community there are some unforeseen stumbling blocks that will force them to abandon their initial plan. Although their approach is based on SARAH, Mvuramanzi Trust had to go through the local traditional leadership and local councillors before being able to implement the project. This replicates the top-down approach in 
development where civil sociality participation is minimal. Another classic example of a failure in asserting a participatory development approach that led to technocratic participation, absence of democratic participation and absence of social learning is the role of a participatory approach in the outcome of the Finnish sustainable development indicator (SDI) exercise in 1998-2002 (Rosenström \& Kyllönen, 2007). The process was analysed through three main objectives: to achieve stronger democracy, better quality of the end product and a more effective process.

Furthermore, there are many notable experiences (Van Meensel et al., 2012) where a participatory development approach is seen as key for development effectiveness. It is widely viewed that the participatory approach influences the selection of stakeholders, objective setting, and monitoring and evaluation of projects and programs for development effectiveness. 


\section{CHAPTER THREE:}

\section{METHODOLOGY}

\subsection{Introduction}

This chapter gives an outline of research methods that were followed in the study. It describes the research design that was chosen for the purpose of this study and the reasons for this choice. The instrument that was used for data collection is also described and the procedures that were followed to carry out this study are included. The researcher further discusses the methods used to analyse the data. The chapter provides information on the participants, that is, the criteria for inclusion in the study, who the participants were and how they were sampled. Lastly, the ethical issues that were followed in the process are also discussed.

The focus of this study is to look at the country ownership of development from a Papua New Guinea perspective. Papua New Guinea has a decentralised system of government with national, provincial and district administrative systems. The objective is to look at how the subnational levels of government are taking part in aid effectiveness, specifically in ownership of their own development, while currently the function of aid management coordination and implementation is being centralised.

The study adopts mixed methods to collect data. Qualitative methodology is the predominant approach while quantitative methods are only used in a minor and secondary way. This research has applied two analytical frameworks: the decision space and the capacity to achieve development ownership.

\subsection{Research Design}

This research is exploratory in nature as it attempts to examine the experiences of government officials of Papua New Guinea regarding aid and development ownership in the country. Their subjective perceptions on topics such as ownership, decentralization, and development in the sector of aid effectiveness formed the core data of the study. Their independent perspectives were treated with respect and formed the basis of this study. Hence, the study needs methods that would deal with this topic in a largely qualitative way. 
Given that this study is concerned with the way people experience and perceive the notion of ownership, it adopts a social constructivist epistemology. In other words, it recognises that people generate knowledge and meaning about this topic based on their social and cultural context. This epistemological approach then, in turn, requires the use of largely qualitative methodologies, though it accepts that there is also room to use some more quantitative approaches to present certain 'facts' about aid flows.

Thus, for the purpose of this study, the research paradigm that was followed is a mixture of qualitative nature, using semi-structured interviews as discussed later in the chapter, and quantitative data to describe the flows of aid resources into the subnational level. The latter instrument was used to do a litmus test on the existing hypothesis of aid resources that the central government is channelling towards the sub national levels with a lesser degree or absence of the sense of development ownership. Recently there have been several calls for the use of mixed method designs in implementation research (Proctor et al., 2009; Landsverk et al., 2012; Palinkas et al., 2011a; Aarons et al., 2011). This has been precipitated by the realization that the challenges of implementing evidence-based and other innovative practices, treatments, interventions and programs are sufficiently complex that a single methodological approach is often inadequate (Palinkas et al., 2015).

Leedy (1993) explains that qualitative research is based on the belief that first-hand experiences provide the most meaningful data when looking at people's attitudes and behaviours. It is also believed that qualitative data gives good quality data from a limited number of people. It is aimed at understanding the world of participants from their frame of reference (Walker, 1985). It would have been impossible to make a quantitative evaluation on this study because it is based on the perceptions of people, regarding key concepts such as 'ownership', which cannot be readily measured. The study contends that the test of effective development ownership will be whether subnational officials and agencies adopt best practices regarding local participation. The study focuses particularly on the subnational level by examining the World Bank's Productive Partnership in Agriculture Project.

Therefore, a constructivist approach has been undertaken to examine possible contributions towards the effort of understanding development ownership as far as aid effectiveness is concerned. Not much has been written on this subject in PNG, but it 
is hoped that the study will help identify practices to promote local ownership considering the development context in the country.

\subsection{Participants}

With the focus on qualitative approaches and the need to interview officials involved in development work, this research has targeted a number of officials who have worked on aid-funded activities at a subnational level in PNG. The study selected its participants from five key central and sector agencies of the government, a provincial government (in the province where the case study project, the Productive Partnership in Agriculture Project, is taking place), three local ward leaders and three major donors who actively participated in development financing and aid dialogue. There were a total of 16 individuals participating jointly or individually in the data collection who contributed in either being interviewed or submitting relevant documents and information. However, due to Covid-19, most of the participants originally targeted were not able to be interviewed, and this affected the study. The following table 3.1 captures the participants interviewed.

Table 3.1. List of Participants

\begin{tabular}{|l|c|l|}
\hline $\begin{array}{l}\text { Central \& Sector } \\
\text { Agencies }\end{array}$ & $\begin{array}{l}\text { Provinces and Districts } \\
\text { (Subnational) }\end{array}$ & Donor Agencies \\
\hline $\begin{array}{l}\text { Department of Treasury } \\
(2)\end{array}$ & $\begin{array}{c}\text { Eastern Highlands } \\
\text { Provincial Government (1) }\end{array}$ & World Bank (1) \\
\hline $\begin{array}{l}\text { Department of National } \\
\text { Planning and Monitoring } \\
(2)\end{array}$ & $\begin{array}{c}\text { Coffee Industry } \\
\text { Corporation - } \\
\text { PPAP/Coffee Project } \\
\text { Management Unit (2) }\end{array}$ & $\begin{array}{l}\text { Asian Development Bank } \\
(1)\end{array}$ \\
\hline Department of Agriculture \\
and Live Stock (1) & $3 \times$ ward councillors & World Vision (1) \\
\hline PNG customs (1) & & \\
\hline Department of Works (1) & & \\
\hline
\end{tabular}


The selection of participants was based on the key tasks they do in relation to foreign aid management, coordination, and implementation. Most central agencies who have been interviewed were all directly involved in foreign aid and aid effectiveness dialogue. One of the key advantages in selecting the participants was the researcher's pre-existing working relationships with the government and donor agencies. This made the participant selection easier, particularly as contact had to be made through email, phone and social media channels.

According to Neuman and Wiegand (2000), the focus of the qualitative researcher is more on the selected participants' ability to clarify and deepen the understanding of social life than its representativeness. The authors further indicated that the qualitative researcher should be concerned with obtaining cases that can enhance the learning process in a specific context, and that is the reason why they tend to use a nonprobability sampling method, such as deliberate selection.

There were some inclusion criteria used for participating in the study. Participants were selected based on their ability to represent at least one of the following groups:

- Key central agencies of the government which mobilises, coordinates and manages official development assistances.

- Sector agencies which have direct experience on implementing aid funded projects and programs.

- Officers with first-hand knowledge on aid and development

- Senior officers who can be able to provide relevant information and who can be able to make decision for policy reforms.

- Officers that have the capacity to make change or undertake policy decisions at the higher authority level.

- Someone who has the technical knowledge of how aid funded projects work and can make distinct comparative analysis on the government initiatives.

- Officers with whom the researcher has close working relation who may not hesitate to participate considering the Covid-19 situation.

- Highly educated on government policies and development priorities.

The participants were first invited through email to participate in the research project. Once they agreed to participate, I sent another official email containing the consent form, information sheet, questionnaire and the interview guide. Once they received the 
information package, I gave them at least three to four days to go through the information, while also asking them to set a date and time suitable for them for a phone call interview. Setting of date and time was driven by the participants when a phone or similar conversation could take place. During the interview, I asked them to give verbal consent to participate in the interview as well as for recording the entire interview. Most gave verbal consent. I then used Adobe Audition (audio software) to record all phone call interviews and code them for transcribing. However, there were some issues encountered during data collection which will be discussed in the later part of this chapter.

\subsection{Methods}

For the purpose of this study, I used semi-structured in-depth analytical interviews, which involved both direct questioning using open-ended questions and also the analytical determinations of the policy documents as they refer to promoting and localizing global agenda of aid effectiveness. Chill et al., (2008) support this method and holds the view that the flexibility of this approach, particularly compared to structured interviews, allows for the discovery or elaboration of information that is important to participants. In addition to open-ended questions, there were more closed questions that were used to obtain the understanding and views of aid architecture in the country. The questions were not very technical in nature. Each interviewee was given the liberty to ask further questions for clarity. Sometimes the interview questions were adapted to contextualize the agencies each participant represents.

The questionnaire was divided into two sections (see Appendix 3). The first section of the questionnaire covered the participation and ownership of development. It also investigated the general consensus on decision making as well as sought their understanding on the principles and indicators of aid effectiveness. The second section explored the test of development ownership by investigating whether or not best practices had been adopted by all or any levels of the government. Also, it explored the actions that were taken by the central agencies on the localization of aid effectiveness principles. Since this is an exploratory study, the use of a semistructured interview allowed me some flexibility in the wording of the questions for each individual participant. It also gave me the opportunity to probe for more information and clarification where necessary (Kvale, 1996; Walker, 1985). According 
to Neuman (2000), the researcher needs to have a skill to match the research question to an appropriate technique. This author further stated that for exploratory research, open-ended questionnaires are the most effective. This view supports that of Riessman (1993, p.54), when he pointed out that it is useful "to ask questions that open up the topic and allow respondents to construct answers in collaboration with the listeners, in ways they find meaningful."

These interviews and questionnaires formed the basis of the research for this study and provided the bulk of the data for analysis. Additionally, some research was also conducted that focused on documentary sources where the policies and strategies of government and development agencies were in written form. These sources included government policy documents such as Development Cooperation Policy 2018-2022, Medium Term Development Plan 2018-2022 (MDTP), the National Planning Act, the National Constitution, Organic Law on Provincial and Local Level Government $\left(\mathrm{OLPLLG}^{3}\right.$ ), and Strategy for Responsible Sustainable Development. Also there were project review reports and country portfolio reports from the donor-funded projects that were consulted to support this study.

\subsection{Procedures}

Given the focus on interviews with aid and development officials, it was important to carefully consider the way these people were approached and their participation sought and agreed to. In addition, the research was significantly affected by issues relating to the Covid-19 pandemic. Being based in Wellington, I was unable to travel to $P N G$ to conduct the research in person as originally planned. Therefore, some quick changes had to be made in the research approach and procedures so that interviews could be conducted online. This was far from ideal, because in-person interviews would have been much preferred, particularly in PNG where personal relationships are important. It also affected practical issues, such as arranging for suitable times to make calls, and sometimes the quality of the audio recordings.

One of the first important issues in this research was working through the different agencies and securing appropriate permissions for staff to participate in interviews.

\footnotetext{
${ }^{3}$ Organic Law on Provincial and Local Level Government provides for the legislative framework of decentralisation and created the system of Provincial and Local Level Governments in PNG.
} 
Initial contacts were made with the professionals either in charge of the institutions or work for the organization that have extensive knowledge on aid and development. Letters were sent out through email explaining the research aims to them and requesting assistance with obtaining the data through interviews. Some agencies never responded even when the follow-up was made through emails and text messages, whereas others were willing to assist but did not have people who met the criteria for participating as described earlier in the chapter. In other instances, officers who would have been contacted were either reluctant to participate or declined or gave wrong addresses.

Most of the policy data sources were submitted via email by the participants. Other legislation in documents, such as OLPLLG and the National Constitution, were extracted from the Pacific Islands Legal Information Institute (PACLII n.d) ${ }^{4}$. There were some reliable sources found on the website of the donor agencies. However, most government agencies do not update their website regularly for publicity purposes. As such, the study found it difficult both to verify and compare whether the data was consistent or not and to obtain up-to-date data.

The criteria used to select the materials was purely based on the area of interest, in this case, ownership, decentralization and development. As such, the materials selected were specifically on how counterpart funding was being given to the subnational level and how loan and grant funded projects have produced results through project reports and reviews. Also, there were other documents being consulted written by individuals who were involved very closely with donors to improve service delivery in a sectoral level. Those documents are in the public domain and have been utilised by many donors and government agencies.

Most of the interviews were focused on the Government's central agencies, while a few key donor agencies were interviewed including the World Bank Acting Country Manager, Transport Specialist for the Asian Development Bank, and the Project Manager for Productive Partnership in Agriculture Project funded by World Bank and International Fund for Agriculture Development. Other donors such as the European Union and Australia's Department of Foreign Affairs and Trade (DFaT) were contacted but were not available for interview. Key central PNG Government agencies including

\footnotetext{
${ }^{4}$ http://www.paclii.org/pg/legis/consol_act/cotisopng534/
} 
the Department of Treasury (DoT), Department of National Planning and Monitoring (DNPM), Department of Agriculture and Live Stock (DAL), PNG Customs and the Eastern Highlands Provincial Administrator were interviewed. Most of the data were collected from the DNPM, which is the key agency responsible for coordination, mobilization, management and implementation of ODAs and is also central agency in charge of setting development frameworks for the country.

Once permissions were gained and contact made with potential participants, times were arranged for interviews. In practice, this step often proved difficult as many times had to be re-scheduled and some participants eventually were not able to take part, despite initial agreement. Interviews took place and were audio recorded and later transcribed for analysis. In practice, interviews took place in English or Tok Pisin or a mixture. This allowed for conversations to flow more easily and to reflect the relationship between participants and myself, many of whom I knew personally and professionally.

\subsection{Data Analysis}

Analysis of qualitative data involves interpretation and an attempt in understanding the subjects' development ownership "as they construct it" (Jones, 1985b, cited in Hooper 1992 , p. 29). This is done through the process of organizing the data from the transcripts in a way that would increase a researcher's understanding and also for better presentation of the findings (Bogdan and Bicklen, 1982, cited in Carter, 1990). I had a mounting task for transcribing the recorded audio of around 15 interviews. Single interview audio was approximately one hour 30 minutes. Others were more than two hours. When I transcribed, each transcription was more than 5 pages. Mthembu (2000) refers to these notes and transcripts as raw data that need to be converted into refined data for better analysis by the researcher. I transcribed the interviews from the audio recorded and saved wav files in the language that was used and those that were conducted in other languages were translated into English. The transcripts were then read several times and in the process the list of various themes that emerged was made. On several occasions I had to re-listen to the audio whilst reading the transcript so as to identify the participants' feelings that came with certain responses. 
The themes were then grouped according to their similarities, and common or recurring themes were identified for the purpose of making sense of them in relation to concepts discussed in the literature review. The above procedure is in line with what authors like Marshall (1995, cited in Mthembu, 2000) and Neuman (2000) suggest about qualitative data analysis. These authors indicate that in qualitative research the data is analysed through reading and re-reading of data notes, reflecting on what is read and organizing those into similar themes and patterns. I made several key themes for my data analysis. This includes organizing the questionnaires as well. The themes are: PNG's commitment to aid effectiveness, Leadership and development ownership, and Decentralisation.

\subsection{Ethical Considerations}

My positionality in this study was quite challenging particularly in the data collection. This raised potential ethical issues, given previous work in government and existing relationships with most participants. However, I tried my best to move away from being a career public servant to working as a university-based researcher. The most challenging part was the working relationship with some of the government's central and line agencies. When contacted for their participation, several candidates did not want to participate due to many reasons. This included but was not limited to conflict of interest, protection of information or confidentiality, trust and also lack of knowledge. Other challenges included finding a suitable time for interview. The coronavirus pandemic also placed a huge obstacle to this study with most government officers working from home for much of the research period in 2020. This made the receiving of emails very late and procrastination of interview scheduling. The pandemic had other effects including a delay in gaining human ethics approval by the university as well as other family problems and worries that deeply affected my wellbeing and commitment.

The Covid-19 pandemic has greatly affected my home country as a field of study. The initial plan was to carry out a field study in Papua New Guinea for data collection. This was not possible due to the global pandemic that affected the entire world. The New Zealand Government though the Ministry of Foreign Affairs and Trade issued a travel ban on all scholarship students who have home country-based field study. As such, I changed the research methods while the topic and analytical framework remained 
unchanged. I quickly responded to the global situation and decided to conduct interviews from New Zealand through phone call interviews (qualitative method) and other existing data that was available online (quantitative methods). Initial methods such as face-to-face interviews and focus group interviews were discarded.

Interviews seemed challenging when there were elements of power being played by either side (interviewer and the interviewee). Looking at the agencies and the position they occupied, had different experiences on the level of power grapple extent to which the dynamisms in power shifts influence data collection and analysis in the interview methodology (Anyan, 2013). According to Anyan (2013), power asymmetry seems to be an exasperating circumstance in the interview methodology. Such asymmetry was experienced in this study, demonstrated by the researcher giving into following lines of questioning that the participant prefers instead of adhering to the planned interview rubric. In other instances, the interviewee has to set a time and even disrupts the interview schedule. A classic example of this exasperating circumstance was when a senior participant declined to go through information sheet and questionnaires, but went straight into the discussion without giving the interviewer a change to ask questions.

After interviewing, transcription was the hardest task this study encountered. This study has explored many ways to make effective transcription. It consulted the supervisor for further assistance in this regard. Procrastination of interview schedule was another one of the challenges the study faced in this research method. Most of the time, I did not conduct the interview during the initial schedule. The participants delayed their interviews due to many genuine reasons. It was quite frustrating, but I responded to their situation, and finally got all the interviews done. Sometimes it was frustrating to the interviewees while I was persistently asking them of their availability, but all of this was managed amicably. Also, one interviewee tried a WhatsApp call while I was running out of credit. Sometimes, due to poor network coverage, a conversation was cut off. Such made the whole interview session rather lengthy. Most of the issues, however, were largely overcome due to my personal knowledge of the sector and work experiences, as well as good working relationships with donors and agencies and the focus area, which was the field that I have been working in for four years. 
Despite the many issues and challenges, this study managed to complete its data collection with extended time and reduced participants. Most of its participants were willing to take part in the interview. I had good working relationships with the agencies for four years as a senior aid coordinator with the Department of National Planning and Monitoring. This eased the burden of selecting participants in the data collection. Not only this past experience but the advantage of currently working in the aid industry also helped the study a lot in both data collection and analyzing.

However, despite the value of these personal relationships, the study still had to conform to the ethical principles expected of such research. I applied for and received approval from the Victoria University of Wellington's Human Ethics Committee. This process involved developing a full information sheet, outlining my role and the rights and expectations of participants, and a consent form (see Appendixes 1 and 4). I also had to carefully consider how I would approach and ask for permission and consent for participants to take part. These processes were followed carefully during the research process, although most participants preferred giving oral consent (which was recorded) rather than using signed consent forms.

\subsection{Conclusion}

This chapter focused on the methodology that was used in this study. An explanation of qualitative research as a method for data collection and analysis was given. Measures followed during the data collection were discussed in this chapter. Further, it discussed the methodological issues and reflected on the data collection process.

Investigating country ownership by employing a mixed methodology continues to remain a key priority for this study as far as aid effectiveness is concerned. Papua New Guinea's effort to development ownership at the subnational level has been examined. Localizing country ownership at the subnational levels featured in the questionnaires and the interviews, and a body of data has been produced from the interviews and existing documents.

Despite many changes resulting from the Covid-19 pandemic, the study seemed to work satisfactorily. Data were collected successfully but outside of the planned schedule. The mixed methods approach in data collection was moderately satisfactory due to the cancelling of home country field study. However, working relationships with 
the agencies and sector knowledge were advantageous for this study to progress without major hiccups.

What follows is an account of the PNG aid effectiveness and its context in which development plans and policies are framed. The next chapter will further examine the policy framework and development practices in which aid resources are captured in development plans, policies and legislation. 


\section{PAPUA NEW GUINEA'S POLICY AND DEVELOPMENT CONTEXT}

\subsection{Introduction}

Having described in the previous chapter the methodology employed in this study, this chapter presents the development and policy situation in Papua New Guinea as a basis for examining development ownership and aid effectiveness in the country. This is crucial in providing the context in order to localise global aid principles regarding aid effectiveness.

The study will begin by presenting the political and social context of PNG, then move to seeing how development frameworks and aid policies are designed and implemented. The chapter will then outline the institutions of the government. This will be followed by discussing Papua New Guinea's aid and development issues and challenges. The later parts of this chapter will look at the recent policy and legislative reforms as part of the country's commitment to aid effectiveness. This will be followed by examination of the paradigm shift in the aid industry, and finally the chapter will close by analyzing the need to bridge the gaps in development ownership, contextualizing the need for this study.

The following map shows the provincial geography of PNG and the main towns associated with the governmental and administrative structure of the country.

Figure 4.1. The Provinces of Papua New Guinea 


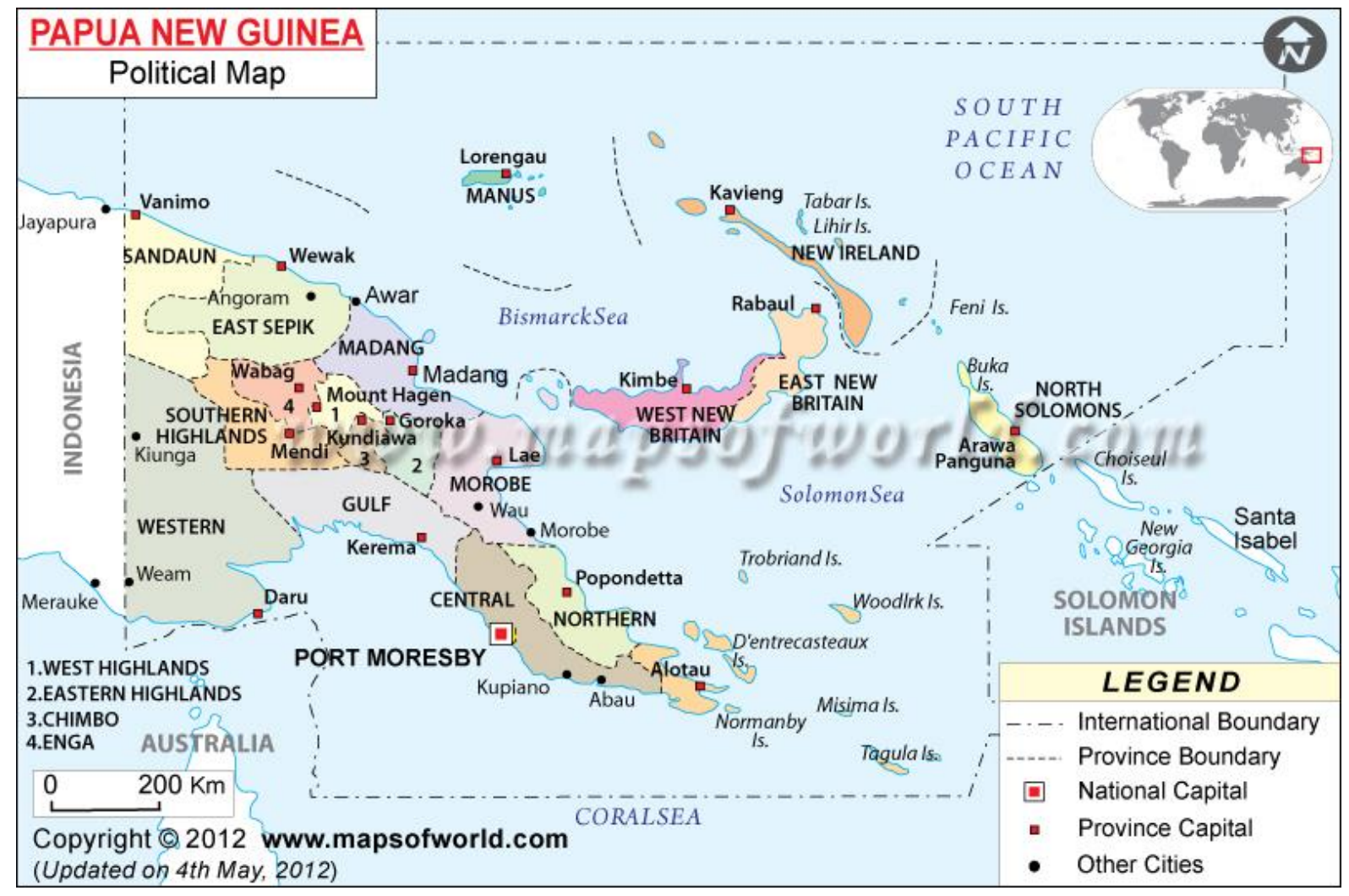

\subsection{Papua New Guinea's Political and Social Context}

Before proceeding to examine aid and its implementation, it is important to examine Papua New Guinea in which the aid discussion will be contextualised in this study. Papua New Guinea is a developing country in the Melanesian archipelago. The colonial history of the country established much of its political and administrative structure. The country was divided into two by rival colonial powers: The Territory of Papua (annexed by British in 1888 and administered by Australia after 1906) and New Guinea (annexed by Germany in 1884). After the Germans left due to their defeat in World War I, the Commonwealth of Australia assumed a mandate, through a League of Nations trusteeship, to rule the former German territory of New Guinea. Administration was eventually combined in practice and Papua and New Guinea remained British possessions until independence in 1975.

Independence was officially granted by the Australian Administration on the $16^{\text {th }}$ of September 1975 declaring the two separate territories into one as Papua New Guinea. The founding father of the nation, Grand Chief Sir Michael Thomas Somare became the first Prime Minister. Ever since then, Australia has become the closest and biggest major donor and development partner for the country. It has helped PNG in undertaking institutional, legislative and policy reforms, improving governance in 
resources and service delivery, and financing projects and programs through its development cooperation.

Since independence, the country adopted a decentralised system of government, practicing a Westminster parliamentary constitutional democracy. It has three levels of government: the central/national Government and agencies; the provincial governments (22 provinces); and the districts and local level governments (89 districts, 326 LLGs and 6122 wards). The National Parliament is a 111 -member unicameral legislature elected for five-year terms by universal suffrage, and PNG is a Commonwealth country in which Her Majesty Queen Elizabeth II is currently the Head of State represented by the Governor General. The country accommodates more than 8 million people and has a current economic growth rate of $3.1 \%$ (The Treasury, 2019).

Culturally, the country is highly diverse. It has a unique cultural diversity with more than 830 different languages and over 1,000 distinct ethnic groupings which makes it one of the most complicated anthropological jig saws on earth. Most people live in rural communities which are geographically scattered and are faced with significant challenges in health, education and economic opportunities. Such cultural, geographical and political extremities have made the development efforts more challenging since independence. Despite these mounting challenges, development partners (bilateral partners and multilateral financial institutions), through aid resources, have assisted the Government of Papua New Guinea to achieve their development aspirations enshrined in their various national, sectorial and provincial development plans and policies through grant and loan resources.

\subsection{Development and Legislative Framework}

The national constitution of Papua New Guinea continues to remain a guide for the planning of the country. Post-independence development priorities in Papua New Guinea have been about the challenges and quest for translating the vast potential of the country into improved standards of living for all Papua New Guineans (Kaiku, 2020). Such has been demonstrated in the work of the Constitutional Planning Committee (CPC) preceding independence in 1975 in crafting the constitution. It is notable that the CPC's recommendations fed into the National Goals and Directive 
Principles (NGDPs) in the preamble to the constitution and have remained prominent for the country ever since. The NGDPs are essentially aspirational. The five NGDPs are: integral human development; equality and participation; national sovereignty and self-reliance; natural resources and environment; and Papua New Guinean ways. A notable paper presented by Patrick Kaiku, from Australia's Department of Public Affairs (Kaiku, 2020), questioned whether the NGDPs will have practical relevance to the citizenry if they are used to guide policy planning and applied in decision-making processes.

The development strategy, plans and vision of PNG have been high prioritized to achieve the above-mentioned development objectives of the national constitution. Therefore, in order to achieve these objectives, the country came up with the following plans in the post-independence period (MTDP 2018-2022).

1. National Development Strategy, $1976-1985$

2. National Development Plan, $1986-1990$

3. Development Plan, $1989-1997$

4. Medium Term Development Strategy, 1997-2002

5. Medium Term Development Strategy, 2003-2007

6. Medium Term Development Strategy, 2005-2010

7. PNG Development Strategic Plan 2010-2030

8. PNG National Strategy for Responsible Sustainable Development (an addendum to PNGDSP 2010-2030)

9. Medium Term Development Plan 2011-2015

10. Medium Term Development Plan 2 2018-2022

11. Vision 2050

The Planning and Monitoring Act $2020^{5}$ gives certain levels of powers to the DNPM to regulate the formulation of medium to long-term national development plans. This legislation also empowers the DNPM to implement and monitor the national planning frameworks as well as take responsibility for reporting of the annual capital investment budget. The law also enhances and strengthens the custodian role of all the development cooperation with the bilateral partners, multilateral financial institutions and other philanthropic agencies. There is some level of comfort in the much

\footnotetext{
${ }^{5}$ The Act was under review at the time of this study.
} 
anticipated review of the act on the part of development cooperation policy concerning loans and grants, to reaffirm that all state bodies should not mobilise grant funding directly from development partners except DNPM. With the NGDPs and the above plans in mind, Figure 4.2 illustrates the development planning framework of the country. 


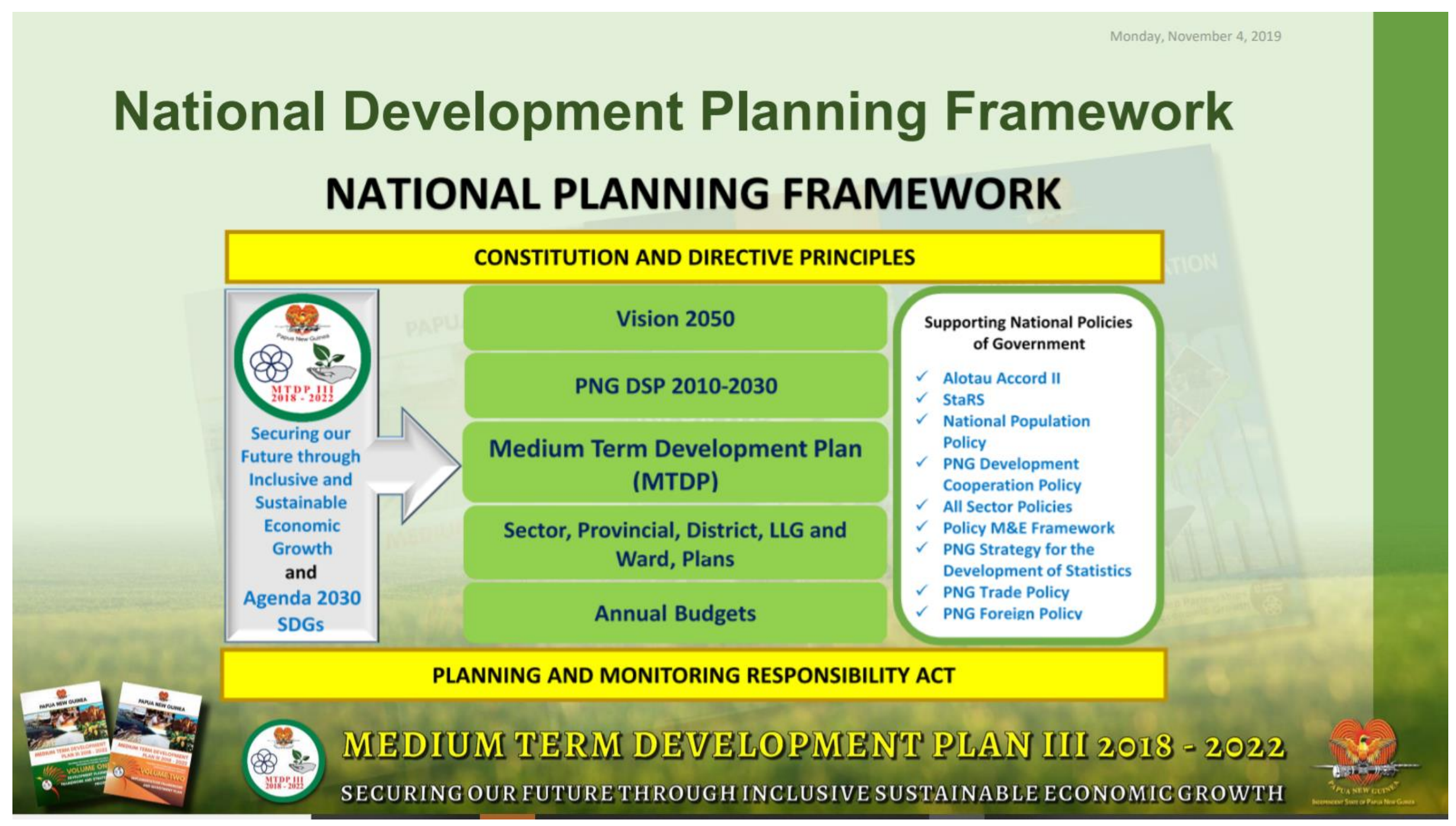

Source: Development Cooperation Policy 2018-2022, DNPM 
The Government has taken critical stock of the country's level of progress and has set a new path for the future to ensure that positive development is not left to chance. In December 2007, the National Executive Council (NEC) of Papua New Guinea, on advice from the National Planning Committee (NPC), made a decision to develop a framework for a long-term strategy - "The Papua New Guinea Vision 2050" - that should map out the future direction for the country and reflect the aspirations of the people of Papua New Guinea (Vision 2050, 2008). The Vision 2050 document was framed by capitalizing on the great potential through PNGs natural resources - land, cash crops, forests and fisheries - to improve the country's socioeconomic development status. It captures the visionary statements of PNG to build a "smart, fair, wise, healthy and happy nation" (GoPNG, 2010: xv cited in Kaiku, 2020), in 50 years' time.

The PNG development Strategic Plan and the addendum (Strategy for Responsible Sustainable Development) or the StaRS in short adopt a thirty years timeframe. This PNG DSP document, for the first time, attempts to translate the dreams of the country's founders as enshrined in the directive principles of the National Constitution into workable plans. Concurrently, it maps out 'how to get PNG to where country's Vision 2050 wants them to be'. It therefore sets out the broad framework, targets, and strategies to achieve the vision of the Government (PNGDSP, 2010). The country has determined to frame and set long term goals and targets that will guide development planning and, importantly, setting the priorities for development expenditure (PNGDSP, 2010). The objective of the PNG DSP is basically to translate the focus areas of the Papua New Guinea Vision 2050 into concise directions for economic policies, public policies and sector interventions with clear objectives, quantitative targets, and baseline indicators. The focus areas are: Integral Human Development; Equality and Participation; National Sovereignty and self-reliance; Natural resources and Environment; and PNG Ways. In so doing, it dismantles the dominance of short term, annual budgets over the allocation of resources.

The Medium Term Development Plans (MTDPs) are the operational plans which detail the country's five-year development plan. The MTDP sets out development objectives, strategies and financing plans to fund the key development priorities in line with the plan. The country's annual budget is tied to the MTDP deliverables. It follows the five- 
year political cycle. The country would be implementing ten MTDPs to achieve its Vision 2050.

Finally, we have sectoral plans and subnational government development plans (provincial and district development plans). The other cascading plans are aligned to the MTDP targets and deliverables.

The country's system of government is founded in the National Constitution, upholding parliamentary democracy. The three tiers of government are provided for and established by the Organic Law on Provincial and Local Level Government. This promotes and enhances the decentralised system of government giving more administrative and financial powers to the subnational level. Lately, the District Development Authorities have been created through the District Development Authority Act 2014. This law gives more functional and financial powers to the district authorities. However, the success of such elements have yet to be tested.

One of the key factors that detracts from effective planning and financing is the legislative tool for planning. As such, the need to have a planning and monitoring Act was sought by the government and it eventually drafted the Planning and Monitoring Act 2015. This acts sits at the bottom of the planning framework to give legal effect to the planning framework. However, this law does not criminalize or prosecute those who mistreat the planning processes. The recurrent and development financing including procurement and expenditures of the public funds are guided, endorsed, enforced and instructed by the Public Finance Management Act 1995.

\subsection{Institutions of the Government}

PNG's public sector encompasses three tiers of government: National Government, Provincial Government, and Local Level Government (LLG). Since 2014, the provinces and districts have been given more direct funding through the Provincial Service Improvement Program and the District Service Improvement Program. As such, provinces and districts now play a greater role in government and are afforded greater flexibility in utilizing public funds for addressing local development needs. In 2016, the Government budget allocated K500, 000 to the Local Level Government Service Improvement Program. However, due to a lack of utilization, most of these resources were unused and reverted to the Government's consolidated revenue account. 
The 2014 District Development Act seeks to further enhance the role of District and Lower Level Governments in managing budget allocation priorities and responsibility for service delivery. While many of the DDA's implementation and operation processes are yet to be established, the aim of the DDA is to play a significant role in: a) allocating DSIP funding in accordance with the development priority needs express by LLGs; and $b$ ) harmonizing the use of DSIP funds and the district's service delivery plans with the provincial development plans. A successful government partnership will necessitate a strong relationship with the relevant DDA bodies.

In terms of sector agencies, there are more than 25 government sector agencies and authorities (National Budget $\mathrm{Vol} 2 \mathrm{a}, 2020$ ). Among these there are six central government agencies as shown below in Table 4.1. The term "Central Government Agencies" refers to those authorities in any country's system of government responsible for setting the policy agenda and for providing the necessary human and material resources to oversee that agenda's implementation and evaluation. These departments must not only meet their respective responsibilities, but also establish effective coordination processes covering the numerous line departments and other agencies at the national and subnational levels.

Table 4.1. Agencies of the Government of PNG

\begin{tabular}{|c|c|}
\hline GOVERNMENT & LINE/SECTOR AGENCIES \\
\hline AGENCIES & \\
\hline $\begin{array}{l}\text { Department of Prime Minister \& NEC } \\
\text { Department of Treasury } \\
\text { Department of National Planning \& } \\
\text { Monitoring } \\
\text { Department of Finance } \\
\text { Department of Personal Management } \\
\text { Department of Justice \& Attorney } \\
\text { General }\end{array}$ & $\begin{array}{l}\text { Department of Works \& Implementation } \\
\text { National Department of Health } \\
\text { Department of Education } \\
\text { Department of Law \& Justice } \\
\text { Department of Commerce \&Industry } \\
\text { Department of Foreign Affairs \& Trade } \\
\text { Department of Environment \& } \\
\text { Conservation } \\
\text { Department of Community Development, } \\
\text { Youth \& Religious Affairs } \\
\text { Department of Lands \& Physical } \\
\text { Planning }\end{array}$ \\
\hline
\end{tabular}




\section{Department of Higher Education, \\ Research, Science \& Technology \\ Department of Information \& \\ Communication \\ Department of Mineral Policy \& \\ Geohazard Management \\ Department of Transport \\ Department of Labour and Industrial \\ Relations \\ Department of Defence \\ Department of Immigration \\ Internal Revenue Commission \\ PNG Royal Constabulary \\ PNG Customs}

The Department of National Planning and Monitoring remains the key central agency responsible for coordination, mobilization, management and implementation of Official Development Assistance (ODA), while their primary role is to formulate and coordinate national development plans and polices, monitoring and evaluations of the plans and strategies, and custodian of the national development budget. The Development Cooperation Management Division within the policy wing of the Department plays the custodian role of ODA and aid effectiveness. The division also formulates relevant policies and acts as a focal point for the country's commitment to aid effectiveness and other high level discussions in the sector of aid and development. Importantly, the department is party to the Central Agency Coordinating Committee, a high level committee that reports to the National Executive Council, which is responsible for setting the policy agenda and providing necessary human and material resources to oversee that agenda's implementation and evaluation.

Other central agencies that play a direct role in aid management and implementation are the Department of Treasury (Treasury), Department of Finance, Department of Justice and Attorney General (DJAG), and Department of Prime Minister and National Executive Council. The Treasury is one of the key agencies responsible for promoting economic prosperity and ensuring the fiscal security of the country by handling the 
nation's revenues, financial assets and debts. Their role in aid and development is to act for and on behalf of the state to sign and approve financial instruments for loans and grants. The Department of Finance manages the clash flow of the country, and ensures there are enough funds available to meet the day-to-day payments of public goods, while also supporting the Government's decentralised structure implementing the integrated financial management system. One of their tasks on aid and development is to manage and coordinate the procurement process of the aid funded projects and release counterpart funding according to the Treasury's warrants. Legal opinions on loans and grants are provide by the DJAG. The DPM \& NEC provide overall policy guidance to all the line and central agencies through the Chief Secretary. However, the chief secretary position has been recently abolished in line with the Government's public service reform.

The Department of Foreign Affairs and Trade also plays an important role in aid and development. In some ways this department may not fall under the category of central agencies, as they coordinate and implement the country's foreign policy and protocol roles of the state while ensuring diplomacy is achieved internally (maintaining communication with donor communities and diplomatic corps) and externally (regional and international trade relations)

\subsection{Papua New Guinea's Aid and Development}

The foreign aid or ODA through various aid modalities have assisted many developing countries to achieve their development aspirations and paved their way for modernization. However, it also comes with challenges in terms of aid coordination, management, monitoring and reporting due to the proximities of aid architectures, many players in the industry, donor interest and so forth. However, discussions have been undergoing to improve the aid industry to achieve aid and development effectiveness through such commitments agreed to in Busan, Accra Agenda for Action and lately the Paris Declaration of Aid Effectiveness.

The 2008 Kavieng Declaration on aid effectiveness gives meaning to the country's commitment to aid effectiveness. The Kavieng Declaration on Aid Effectiveness was a joint commitment between the Government of Papua New Guinea and the Development Partnership. The purpose of this joint commitment was to localise and 
give meaning to the Paris Declaration on Aid Effectiveness. This was the continuation from the 2007 Madang Action Plan, a first joint commitment consistent with the Pacific Principles on aid effectiveness, after the Paris principles were borne in 2005. These series of collaborative efforts were constituted of certain underlying principles extracted from the global aid effectiveness continuums. PNG's commitment to aid effectiveness on shared principles are enshrined in the Kavieng Declaration and are summarised in the following table 4.2. 


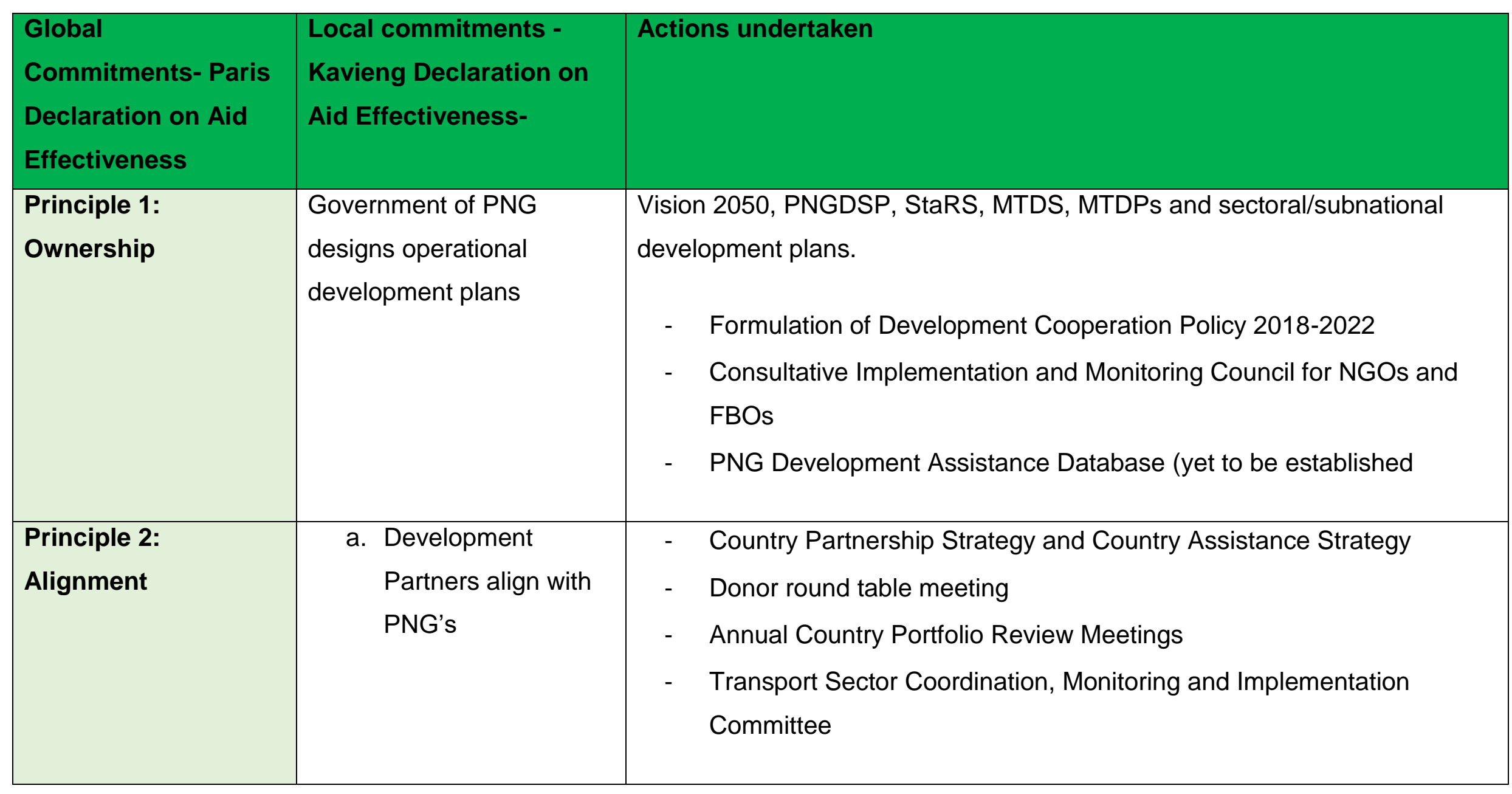




\begin{tabular}{|c|c|c|}
\hline & $\begin{array}{l}\text { b. GoPNG and DPs } \\
\text { work to implement } \\
\text { and strengthen } \\
\text { Program Based } \\
\text { Approach }\end{array}$ & $\begin{array}{ll}- & \text { RMRP, CADIP, HRRIP, TEIP, etc... } \\
\text { - } & 80 / 20,100 \% \text { financing, DP co-financing, counterpart funding }\end{array}$ \\
\hline & $\begin{array}{l}\text { C. GoPNG to } \\
\text { strengthen } \\
\text { institutional capacity } \\
\text { with the support of } \\
\text { DPs }\end{array}$ & $\begin{array}{ll}\text { - } & \text { Project Steering Committee meeting, Technical Evaluation } \\
& \text { Committees, etc... } \\
\text { - } & \text { CSTB (now National Procurement System) } \\
\text { - } & \text { introduction of Public Expenditure \& Financial Accountability }\end{array}$ \\
\hline & $\begin{array}{l}\text { d. Use of government } \\
\text { system }\end{array}$ & $\begin{array}{ll}\text { - } & \text { setting up of Project Management unit } \\
\text { - } & \text { using National Procurement System } \\
\text { - } & \text { Relying on IFMS }\end{array}$ \\
\hline $\begin{array}{l}\text { Principle 3: } \\
\text { Harmonization and } \\
\text { simplification }\end{array}$ & $\begin{array}{l}\text { Development } \\
\text { Partners implement } \\
\text { common } \\
\text { arrangements and } \\
\text { simplify procedures }\end{array}$ & $\begin{array}{ll}\text { - } & \text { Analytical studies by DPs } \\
\text { - } & \text { Portfolio reviews } \\
\text { - } & \text { Use diagnostic reviews such as Public Expenditure \& Financial } \\
& \text { Accountability and Country Procurement Assessment Report } \\
\text { - } & \text { Using whole of Government Approach development framework }\end{array}$ \\
\hline
\end{tabular}




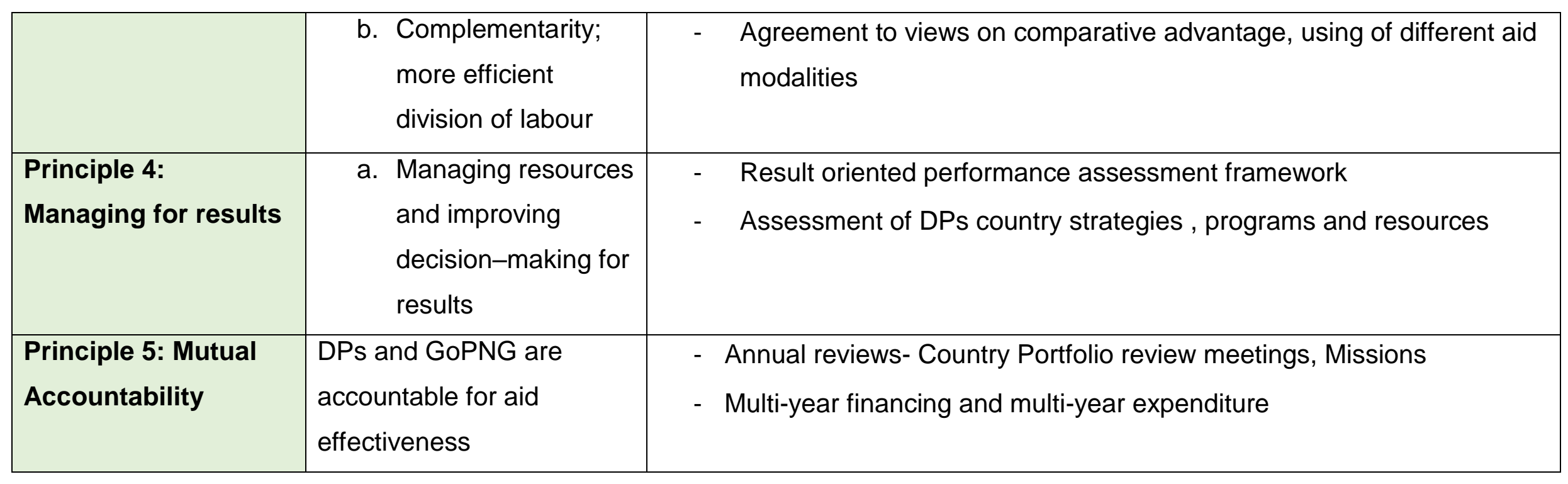


PNG's main development partners and the budget allocation using Government and ODA resources are only demonstrated in the following table extracted from the 2017 National Budget. Most of its aid are in the following form with their own terms and conditions: (i) Direct Budgetary Support Grants; (ii) Program or Project Grants; (iii) Micro-project Grants; (iv) Concessional Loans; (v) Technical Assistance; and (vi) adhoc Aid.

Table 4.3. Sample of Donors in PNG

\begin{tabular}{|l|r|r|r|r|}
\hline Development Partner & Grants & Loans & $\begin{array}{r}\text { GoPNG } \\
\text { Counterpart } \\
\text { Funding }\end{array}$ & Total \\
\hline DFAT & 711.4 & 0.0 & 8.0 & 719.4 \\
\hline European Union & 78.9 & 0.0 & 2.0 & 80.9 \\
\hline United Nations & 74.7 & 0.0 & 0.0 & 74.7 \\
\hline New Zealand & 25.0 & 0.0 & 0.0 & 25.0 \\
\hline China & 0.5 & 298.0 & 57.0 & 355.5 \\
\hline Asian Development Bank & 14.0 & 277.0 & 59.5 & 350.5 \\
\hline World Bank & 0.0 & 90.4 & 21.0 & 111.4 \\
\hline JICA & 38.7 & 114.0 & 25.0 & 177.7 \\
\hline Ceska/Erste & 0.0 & 23.0 & 0.0 & 23.0 \\
\hline ElB & 0.0 & 0.0 & 5.0 & 5.0 \\
\hline Indian EXIM & 0.0 & 0.0 & 10.0 & 10.0 \\
\hline IFAD & 0.0 & 14.5 & 1.0 & 15.5 \\
\hline Totals & $\mathbf{9 4 3 . 1}$ & $\mathbf{8 1 6 . 9}$ & $\mathbf{1 8 8 . 5}$ & $\mathbf{1 , 9 4 8 . 5}$ \\
\hline
\end{tabular}

Source: Department of National Planning and Monitoring (2018)

PNG's commitment to aid and development effectiveness have been encouraging through their policy reforms and leadership. For instance, the Government formulated its first development cooperation policy in $\mathbf{2 0 1 5}$ for its commitment in the Paris Principles for country ownership of their own development. The continued effort of aligning development priorities through various country assistance strategies and country assistance partnership are ongoing and are effective. The donor contributions towards the country's annual budget have gradually drooped while the Government's own contributions rose significantly since 2000 . This does not necessarily mean the donors have reduced ODA, rather the Government of PNG's contribution is more than the donor support. However, the purposes and worth of spending remain issues of debate by observers (Hnanguie 2003). 
The table 4.4 below gives a glimpse of the Overseas Development Assistance (ODA) given to Oceania, including PNG since 1970-2017. The actuals presented in US dollars from 2016 represented by the shared percentage shows that PNG receives the highest share of ODA within Oceania. About 28.5 per cent of ODA donated from 20102017 went to PNG. While that amount has been gradually decreasing since PNG gained independence, it still remains the recipient receiving the largest amount of aid in the region. Despite these glory days of aid assistance, the question remains of whether the aid has really impacted the development or if it was merely used for other foreign and commercial interests. The following paper may partly answer some of these questions while promoting the concept of private sector led development.

Table 4.4. Sample of ODA to Oceania by recipient country (1970-2017)

\begin{tabular}{|c|c|c|c|c|c|c|c|c|c|}
\hline \multicolumn{10}{|c|}{$\begin{array}{l}\text { 6.2.7. ODA to Oceania by recipient country } \\
\text { USD million, } 2016 \text { prices and exchange rates, net ODA receipts }\end{array}$} \\
\hline & $2010-17$ & $1970-79$ & $1980-89$ & $\overline{1990-99}$ & $2000-09$ & $2010-17$ & 2015 & 2016 & 2017 \\
\hline & Share(\%) & \multicolumn{5}{|c|}{ Annual averages } & \multicolumn{3}{|c|}{ Annual amounts } \\
\hline Cook Islands & 1.1 & 23 & 32 & 19 & 11 & 19 & 26 & 17 & 18 \\
\hline Fiji & 5.1 & 74 & 82 & 66 & 56 & 91 & 103 & 117 & 141 \\
\hline French Polynesia & - & 195 & 423 & 439 & - & - & - & - & - \\
\hline Kiribati & 3.1 & 24 & 32 & 24 & 26 & 56 & 65 & 61 & 75 \\
\hline Marshall islands & 3.4 & - & - & 51 & 70 & 62 & 58 & 13 & 71 \\
\hline Micronesia & 5.8 & - & - & 89 & 133 & 105 & 83 & 51 & 96 \\
\hline Nauru & 1.4 & 0 & 0 & 4 & 20 & 25 & 32 & 23 & 24 \\
\hline New Caledonia & - & 234 & 389 & 448 & - & - & - & - & - \\
\hline Niue & 0.9 & 11 & 12 & 11 & 14 & 16 & 20 & 14 & 14 \\
\hline Northern Mariana Islands & - & 280 & 322 & 28 & - & - & - & - & - \\
\hline Palau & 1.3 & - & - & 80 & 35 & 22 & 14 & 18 & 22 \\
\hline Papua New Guinea & 28.5 & 943 & 718 & 562 & 375 & 511 & 592 & 532 & 504 \\
\hline Samoa & 5.6 & 38 & 55 & 57 & 50 & 100 & 95 & 89 & 127 \\
\hline Solomon Islands & 12.2 & 69 & 74 & 59 & 174 & 219 & 192 & 176 & 178 \\
\hline Tokelau & 0.8 & 3 & 6 & 7 & 13 & 15 & 9 & 14 & 7 \\
\hline Tonga & 4.0 & 19 & 39 & 40 & 32 & 72 & 70 & 83 & 79 \\
\hline Tuvalu & 1.5 & 4 & 17 & 10 & 13 & 27 & 51 & 24 & 26 \\
\hline Vanuatu & 6.0 & 56 & 67 & 56 & 63 & 107 & 189 & 129 & 129 \\
\hline Wallis and Futuna & 5.4 & 8 & 6 & 13 & 85 & 97 & 106 & 85 & 87 \\
\hline Oceania, regional & 13.8 & 31 & 73 & 117 & 159 & 248 & 229 & 239 & 315 \\
\hline Oceania total & 100.0 & 2010 & 2348 & 2183 & 1332 & 1793 & 1937 & 1683 & 1912 \\
\hline
\end{tabular}

Source: OECD (2019)6:

Having discussed PNG and its aid management and development, the second section of this paper deliberates on the aid principles and its discourses. It also compares and contrasts the different aid instruments, while drawing attentions to the challenges the

\footnotetext{
${ }^{6}$ Development Aid at a Glance Statistics by Region. https://www.oecd.org/dac/financing-sustainabledevelopment/
} 
country faces and what has been done. Importantly, the paradigm shifts in aid really provide gaps that could be filled by private sector led development.

Over the last 20 years, the development cooperation has been rapidly changing. Contemporary research suggests that on average, economic growth has been stimulated through foreign aid (Feeny 2007). This escalated from different actors not in the aid industry such as private companies and philanthropic, increased domestic resource capacities, trade and geopolitical interests. As such, it has lessened the importance of the development assistance contributed by Development Assistance Committee of the Organisation for Economic Co-operation and Development (OECD$D A C)$. Despite the critiques of modernization on the aid assistance and the developments that are driven from external such as Millennium Development Goals (MDGs) and Sustainable Development Goals (SDGs) of the United Nations (UN), the Structural Adjustment Programs (SAPs) of the World Bank (WB) and International Monetary Fund (IMF) during the great depression, the foreign aid resources have lifted many countries from extreme poverty, economic recovery and social inequalities.

\subsection{Challenges and Issues in the Aid and Development Industry in PNG}

While the Government of PNG (GoPNG) acknowledges the continued support from donors and has tried to maintain good working relationships with them, implementation challenges are still being faced by the country and require improvement. Some issues are ongoing fiduciary issues and some are operational issues. For instance, low or even nil counterpart funding issues have been ongoing in all loan and grant funded projects and have been raised in all the Country Portfolio Reviews and Project Steering Committee Meetings (for example World Bank Country Portfolio Review Meetings). The provisions of Government counterpart funds seem to be low and untimely. Another issue is the procurement process which takes up a lot of time for contract/contracts to be approved by Central Supply \& Tenders Board (CSTB). Also the banks' (ADB, WB, etc.) cumbersome process is relatively new to most implementing agencies, thus resulting in long delays which often incur additional costs. The Legal Opinion on Effectiveness Conditions for the project which is sought from the State Solicitors for the clearance is very lengthy and causes a lot of delays. There are outstanding and a backlog of audits with the Auditor General's Office, some dating 
back years. There are high sustainability issues with some of the WB projects because they were designed and agreed upon outside of the government's normal process. These initiatives usually do not sustain themselves, and because they were agreed on without the support of the government, they are not allocated sufficient counterpart funding. Capacity and Commitment of PMUs/Implementing Agencies becomes a compounding issue. And social safeguard issues are also imminent especially in the road projects. DPs' direct connection with line agencies bypassing central agencies results in providing unrealistic financial projections for their projects, which are yet to fully comply with Government Finance Statistics (GFS) 2014 reporting standard. As such, it leads to unnecessary delays and project extensions.

One of the policy challenges is the disparity of resource allocation due to complex geographical settings using the conventional aid modality of project aid that is outside of government policies or structures. It involves donors' direct participation in their design and implementation, or the donors will provide support to the recipient government's budget while imposing conditionalities on how to allocate the available resources, known as conditional budget support (Cordella \& Dell'Ariccia, 2007). PNG has received project aid since independence in 1975. The strong role of donors in aid has helped the PNG government reallocate their own resources to other programs and projects. However, it can have the effect of delegitimizing the state's ability to drive their own development as well as sparsely allocating of resources which have less development impact. It makes the state a complementary actor in the development. The other issue with this modality is the aid fungibility (McGillivray \& Morrissey, 2000). The argument is not about fungibility itself, rather it is what the donors want to support serving their interests. Two things are required for this; first, the rate of return should be assessed properly prior to interventions, and secondly, one must examine how the fiscal management can be improved. The move away from project financing to budget support is a way forward to address such distrust of government as well as allowing the government to take ownership of their own development. Despite this, governance issues are still evident in budgetary allocation and priority setting.

Moreover, the issue of donor driven aid practice is still visible in the country despite the paradigm shift in aid modalities promoted in the Paris Declaration on aid effectiveness. The continuous consorted efforts to achieving aid effectiveness and efficiency require reorienting of aid instruments. The neo-structural aid modality of 
normal budget support encompassing general budget support and sector wide approach which have been narrowly used in the aid industry in PNG. The advantage of Budget Support modality is that it ties in with recipient government structures, promotes platform for policy dialogue with partner countries and contributes to strengthening country systems and budget processes (EU, 2018). For instance, the EU budget support contributes towards all 17 sustainable development goals (SDGs)" (EU 2018, p. 7).

The most complete critique of neostructuralism comes from Murray and Overton (Murray and Overton 2011). They provided a number of common threads that can be identified in terms of the post-Paris regime and the general tenets of the neostructural paradigm. Three threads that this study would like to pay attention to are: the handing back of control to the state, wrapped in the notions of ownership and sovereignty; the concept of inclusiveness, harmony and participation; and the attempt to include voices from across society in order to determine policy priorities. Such are reflected in the budget support modality.

However, the disadvantage of this modality is that donors distrust the country's systems and processes, primarily in the areas of procurement and financial management. Such trust issues lead to having mismatch of development objectives. PNG has been facing mounting challenges especially when the objectives of donors and recipients are not perfectly aligned (Cordella \& Dell'Ariccia, 2007). In other words, aid was not effective when the principal objectives of the donor were not Papua New Guinea's economic development (Hnanguie, 2003). The recent reforms, including the establishment of the National Procurement Commission, and Development Cooperation Policy 2018-2022, would give the donors some level of confidence. However, politicking the procurement system must be addressed properly as it is a common practice in the country.

It is also striking to see that aid dependency is still present in PNG with minimal ownership of economic assets, despite the call for economic independent according to PM Marape's manifesto, Take Back PNG (2019). As per the Addis Abba Agenda for Action (2015), the call for action for all countries, public policies and the mobilization and effective use of domestic resources, underscored by the principle of national ownership, are central to the common pursuit of sustainable development, including 
achieving the MDGs and SDGs. That action was promoted due to recognizing the importance and potential of revenue generation from domestic resources by economic growth, supported by an enabling environment at all levels. The saddest thing in PNG is that the state's own enterprises that generate domestic revenues have been mortgaged by the state to obtain foreign loans, which becomes a controversial issue in the politics of the country. For instance, the former PM of PNG, Hon. Peter O'Neil announced in the Parliament on the $27^{\text {th }}$ of May 2019 (Online EMTV News, 2019) that all the state-owned entities were mortgaged for the IPIC and UBS loan to buy shares for the Oil Search (Braunstein, 2017), and are now owned by United Arab Emirates. Perhaps the most conspicuous issue here is that PNG does not own the economy as far as the Addis Action and Paris Principle of aid effectives is concerned. The true sense of economic independence in Papua New Guinea is at a watershed. Fisheries, forestry, mining, corporate businesses are owned by foreign investors, exploiting resources and sending profits offshore. Hence, the country's internal economic assets and enterprises that will trigger economic independence departing from foreign aid is volatile.

Adding to the dependency issue, PNG has the potential to become less aid dependent if private sectors are involved appropriately in development, as the Addis Ababa Agenda for Action (Montes 2016) suggests. It has become one of the common arguments posed by Papua New Guinea's development partners that foreign aid to the country is no longer necessary because of the dramatic increase in private capital flows from the developed countries to the developing world (Hnanguie, 2003, p.163). Such has been seen in the increase in Foreign Direct Investments (FDIs) in forestry, fisheries, mining, and SMEs. The concepts of inclusiveness, harmony and participation from all stakeholders including business communities is essential to neostructuralism. The donors assert that there is no need to provide aid because private flows have exceeded and have overtaken the public aid flows of about US $\$ 120$ billion. PNG does have the resource capacities, including, minerals (gold, oil, gas, and copper), forestry, fisheries (tuna stock) and tourism. Such abundance of resources attracts private flows for investments and can sustain the economic without foreign aid. However, the Government of Papua New Guinea did not have prudent economic policies and legislations to control and regulate FDIs to serve the country's economic interests. For instance, Rimbunan Hijau (RH), a Malaysian logging company, controls 
80-86 percent of PNG's log export market while enjoying tax holidays (Larmour, 2007; Filer, 2011; Group, 2012). This means on top of the export revenue, the company enjoys significant tax exemptions. This also led to the concern relating to the international commitment of domestic resource mobilization as discussed above. PNG needs to tighten its laws, regulations and policies regarding tax holidays/exemptions, downstream processing, employment (including contracts) and equity for the resources in order to generate adequate revenues to finance its development priorities rather than depending on too much concessional loans and foreign aid.

\subsection{Recent Policy and Legislative Reforms}

Despite these implementation challenges, the Government of PNG is serious and committed to provide the leadership required to effectively delivering development interventions with the support of its DPs. PNG's commitment to aid and development effectiveness has been encouraging through their policy reforms and leadership dating back to 2005 and the Paris Declaration. For instance, the first ever Madang Plan was formulated to improve aid effectiveness. After the global principles were agreed through the Paris Declaration of Aid Effectiveness, the Government localised those principles through the Kavieng Declaration in 2008. This provides clear and customised principles and tailored actions suiting the country's needs based on comparative advantage. Later, the Government formulated its first development cooperation policy in $\mathbf{2 0 1 5}$ for its commitment to the Paris Principles for country ownership of their own development and reviewed in 2018. There have been other recent reforms, such as creating National Procurement Commission (NPC) while doing away with Central Supplies and Tenders Board, outsourcing the auditing for all donor fund projects to private firms, introduction of Public Expenditure \& Financial Accountability (PEFA) assessment, the formulation of the PEFA Roadmap and the subsequent PEFA Assessment Report which have progressed the process of having a strengthened Government system supported by the strategic Medium Term Development Plan 3 (MTDP III) and PNG Development Cooperation Policy (DCP) 2018-2022. Such finally gives the confidence to its Development Partners (DPs) that the Government is increasing its efforts to achieve aid and development effectiveness.

Furthermore, during my tenure as a senior aid coordinator, the 100 percent financing for all loan funded projects has been agreed to while doing away with the traditional 
20/80 financing modality, which gave financial comforts to the Government and development partners under new aid modality. The Government is also embarking on budget support modality for development financing. The present reforms and continued effort of aligning development priorities through various country assistance strategies and country assistance partnership has the ambition to contribute towards aid effectiveness.

\subsection{Paradigm shift to Retro-literalism: Private sector a key player}

This also draws attention to the issue of neglecting the contemporary retro-liberalism aid practice of private sectors as central players in development. The rules of the game have been shifted. According to McEwan et al. (2017) the private sector has always been an object, partner and agent of international development in both its 'intentional' (Development) and 'immanent' (development) forms.

In a comprehensive study of what Warwick and Overton (Murray and Overton 2016) coined as retroliberalism, the state positioned itself as a safety net for private corporations. Their argument is relevant to this study in that the retroliberalism rejuvenates elements of both classical liberalism and neoliberalism with the intention of bolstering private sector accumulation. What is worthy to note in their study for this context was a renewed guiding role for the state- though not in terms of poverty reduction targets but towards facilitation of the market and bolstering of the private sector. PNG needs to take such an approach if the intent of the latest manifesto, 'Take Back PNG' is to be realised, which can be done if the government creates a regulatory role for private sectors to thrive.

Beyond the shared goal of profit seeking, the private sector is, of course, highly diverse. It includes formal and informal organizations, ranges from financial services and the commerce of goods and services to mining and agriculture, and ranges in scale from one-person enterprises to vast transnational corporations. Coffey International and Cardno have been operating in PNG to deliver technical services and advisory roles. The former concentrates on more advisory roles on economic and social sectors, while the latter is more involved with architectures and road designs. Department of Works is a key beneficiary of Cardno's services. The ADB and World Bank has been relying on them as their employer's project manager on all the road projects in the country. Australia's Department of Foreign Affairs and Trade (DFAT 
2015) notes that private sectors do not operate alone but critically depend on the choices governments make either to encourage or discourage private investment in an economy. The PNG Government needs to provide a more enabling environment, such as economic conditions (minimum tax, infrastructure, law and order, markets), and proper policies and legislation for securing business and customers. It would be worthwhile to continue what the Mekere Morauta Government in conjunction with IMF and WB for the Structural Adjustment Programs (SAPs) (Feeny, 2005) did to tighten macroeconomic management, further public sector reform and strengthen financial institutions and privatization.

Not only do aid recipient countries face challenges in the aid industry, but the donors also face mounting challenges, most often these come at a high level of policy in relation to financing modalities and priorities. For instance, Mawdsley (2015) in her publication titled, DFID, the Private Sector and the Re-centring of an Economic Growth Agenda in International Development, highlighted three interconnected challenges which she referred to as 'crises'. They include: ontological (a challenge to their "traditional" monopoly of donor identity), ideational (the erosion of their normative/ agenda-setting dominance) and material (the relative and absolute rise of the South). Donors in PNG have tried their best in their geographical visibility and by-passed systems and processes which resulted in parallel projects and disparity of resource allocations. This makes coordinating challenges even worse. For instance, the bilateral donors such as Australia, New Zealand and the US, provide funds to ADB and World. However, the visibility is monopolized by ADB and WB and not the cofinanciers. Another example for the second crisis can be seen during the formulation of country assistance strategies (multilateral) and country partnership strategies (bilateral). Recently the bilateral donors have been subsumed into Ministry of Foreign Affairs and/or increased subordination to Trade Ministries (e.g. Australia, Canada, New Zealand, and the Netherlands). Such merging presents questions over the definition and future of foreign aid and sprouting of private sectors and international organizations such as OECD-DAC to have dominance over the architecture of international development (Mawdsley, 2015; Mawdsley et al., 2018).

To conclude, the concerted efforts and continued dialogue at the global level by both DAC of OECD and recipient countries have changed the rules of engagement in the aid industry, particularly, the aid instruments and how the private sector can contribute 
to the economic and social development. Despite having substantive criticism of the aid instruments, developing financing through aid resources has tied in to the global development agenda (MDG) and has contributed to the achievement of the targets. However, PNG still has the potential to have a private sector led development given the massive natural resource capacities, particularly in the extractive industry, fisheries and forestry; forging can be done away with if properly regulated. The government needs to tighten up its governance mechanisms-procurement, tax legislation and other policy framework-to have impact on the private flows of development assistance given to the country.

Compounding conventional issues in the aid industry such as choosing which aid modality to use, the relevance of development using aid resources, competing for donor visibility which comprises the development of the recipient country, the negligence of the private sector as the key players in development, disparity of resource allocation and aid dependency still affect development practices. Simultaneously, implementation issues affect the smooth delivery of the aid financed projects.

Importantly, if PNG is to have economic independence, it needs to put private sectors at the centre in the engineer room for development. A true assertion is that the private sector has particular strengths to bring to bear in delivering on the SDGs, including innovation, responsiveness, efficiency and provision of specific skills and resources. Interestingly, the business sector had a strong role in influencing development of the SDGs. This will enable private-public partnership modality to deliver service, while it also creates an enabling environment for private capital flows from external sources. As such, the domestic wealth creation will be boosted and this revenue used to finance the service sectors.

However, the current reforms, including establishment of NPC, introduction of PEFA assessment, the formulation of the PEFA Roadmap and the subsequent PEFA Assessment Report, supported by the strategic MTDP III and PNG DCP 2018-2022, need more leadership support in implementing and making it all work. Sometimes, the Government formulates quality policy reforms, however, there is no leadership to drive change, from neither policies nor administration. If these reforms had leadership 
support, then PNG would certainly improve aid governance while giving more investor and donor confidence in their strategic partnership for development.

\subsection{Bridging the Gap: Development Ownership}

What is missing from current knowledge is the contents of a gap between the policy and the practice around the issues of development ownership and improving aid delivery using the best practices of donors that are relevant to PNG's context. The National Government and its central agencies set the policy frameworks and the legal parameters while the subnational and the sector agencies implement the policies in which aid resources are being utilised for development financing.

Thus, there are certain hypothetical questions this study asks. For example, do the subnational levels participate meaningfully in the aid effectiveness dialogue? Do they take ownership of their own development? When the projects and programs are completed, did they learn some good things from the donor funded initiatives that they can use in their efforts to service delivery? And, how are the sectors and subnational actors adopting some of the best practices in their service delivery?

The study does not give sufficient consideration to what constitutes ownership but poses questions on how effective the domestic ownership of development has been contextualised to inform the national ownership as far as aid effectiveness is concerned. It is important to look at how effective the ideal of ownership trickles down to all levels of government through their budgeting, policy and programming, in a country that has three levels of government.

\subsection{Conclusion}

This section has discussed the political and social context of Papua New Guinea, as it remains a unique and a culturally and geographically complex country. The section then moved on to seeing how development frameworks and aid architectures have been designed and implemented, and it was worth noting that there is a sense of policy cohesion and coherence in their planning architecture. The chapter then examined the institutions of the Government, particularly, the central government agencies and their specific roles towards aid and development. This was followed by succinctly discussing Papua New Guinea's aid and development, with issues and challenges thereafter, in the aid and development industry as a supplement to this subsection. In 
the latter part of this chapter, it briefly discussed the recent policy and legislative reforms as part of country's commitment to aid effectiveness, followed by the paradigm shift in the aid industry. And finally the chapter was summed up by analyzing the need to bridge the gap in policy and practice of development ownership, contextualizing and positioning the need for this study.

The chapter that follows moves on to examine and analyse the research data and findings of the study. What is intriguing to learn is whether or not development ownership at the subnational level is feasible and achievable. Such will be carefully examined and analysed by revisiting the literature and analyzing the views and experiences of development agencies and officials in PNG. 


\section{FINDINGS}

\subsection{Introduction}

This chapter presents the results of the questionnaires and interviews that have been conducted in this study. Primarily more data were collected through interviews than through questionnaires. The findings section has been categorized into three major themes: general Official Development Assistance management in PNG, development ownership, and development financing. The first part of this chapter will outline the findings on how the participants have generally perceived aid management in PNG. The subsections will cover the performance of the Official Development Assistance along with governance and institutional coordination. The second part will present the findings on how development ownership is supposedly understood from all levels of government including donors. Findings on leadership and decision making (grassroots participation) and capacities at all levels will form part of this section. The findings derived from qualitative study on development financing at the subnational level forms the final section of this chapter. In this section, Capital Investments and Public Investment Programs (PIP) will be used interchangeably. This chapter will be summarised with key findings of the study.

There were two major donor agencies which were interviewed, four central government agencies including sector agencies, a provincial administrator, and two local level government councils. A total of 13 people participated in the data collection exercises. The following section presents their views on how aid and development effectiveness is perceived in PNG. However, Table 5.1 presents the summary of the findings. The following table 5.1 only constitute the general observations from the interviews and the questionnaires obtained. 
Table 5.1. Summary of the Findings

\begin{tabular}{|c|c|c|c|c|c|}
\hline \multirow[b]{2}{*}{ Description of the finding areas } & \multicolumn{4}{|c|}{ PARTICIPANTS } & \multirow[b]{2}{*}{ Themes } \\
\hline & Donors & National & Provinces & LLG & \\
\hline $\begin{array}{l}\text { Does the agency implement, coordinate or mobilise donor } \\
\text { resources and programs? }\end{array}$ & 4 & 4 & 2 & 1 & \multirow[t]{6}{*}{$\begin{array}{l}\text { Participation } \\
\text { and Ownership }\end{array}$} \\
\hline $\begin{array}{l}\text { Does the agency participate in high level aid effectiveness } \\
\text { dialogue? }\end{array}$ & 4 & 4 & 3 & 1 & \\
\hline $\begin{array}{l}\text { Are they aware of the (5) aid effectiveness principles } \\
\text { (Ownership, Alignment, Harmonization, Managing for Results } \\
\text { and Mutual Accountability)? }\end{array}$ & 4 & 3 & 2 & 1 & \\
\hline $\begin{array}{l}\text { Are their concerns on development effectiveness taken into } \\
\text { consideration by top management or higher authorities? }\end{array}$ & 4 & 3 & 2 & 1 & \\
\hline $\begin{array}{l}\text { Do they (donors and national gov't) invite grassroots and civil } \\
\text { society organizations to participate in the implementation and } \\
\text { decision-making processes in development activities? }\end{array}$ & 4 & 3 & 2 & 2 & \\
\hline $\begin{array}{l}\text { Are the lower levels of government willing to accept changes or } \\
\text { reforms? }\end{array}$ & 3 & 3 & 2 & 2 & \\
\hline $\begin{array}{l}\text { Are the current agreed systems, processes and procedures of } \\
\text { aid delivery, coordination and management working effectively? }\end{array}$ & 3 & 3 & 3 & 2 & Capacity \\
\hline
\end{tabular}




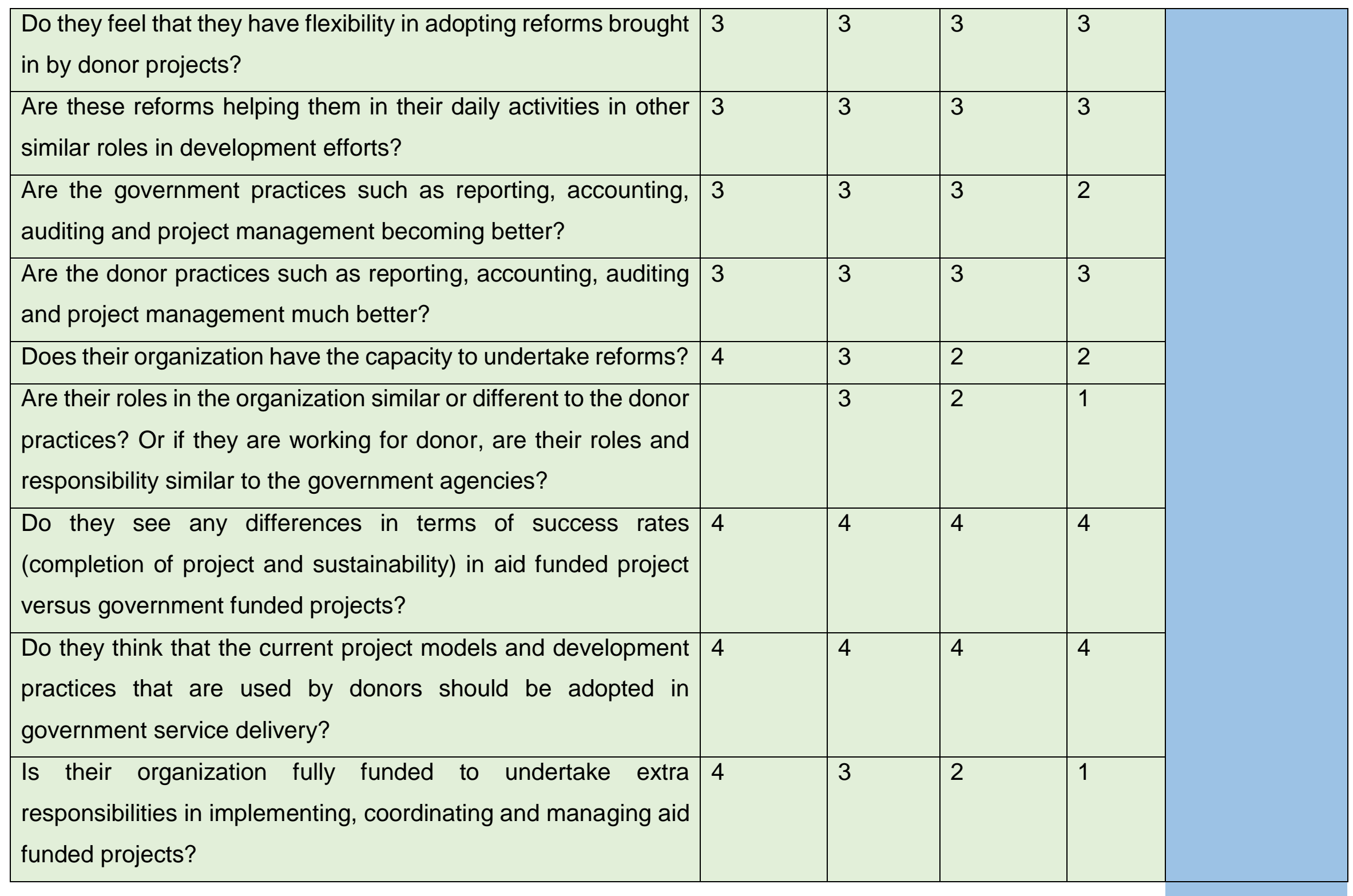




\begin{tabular}{|c|c|c|c|c|c|}
\hline $\begin{array}{l}\text { Do they think that certain functions of aid management, } \\
\text { coordination and implementation should be decentralised to the } \\
\text { subnational government, particularly the provinces and the } \\
\text { districts? }\end{array}$ & 3 & 3 & 3 & 3 & \\
\hline $\begin{array}{l}\text { How satisfied or dissatisfied are they with the National } \\
\text { Government's overall development ownership of Aid } \\
\text { effectiveness principles? }\end{array}$ & 4 & 3 & 2 & 1 & \\
\hline \multicolumn{6}{|c|}{$\begin{array}{l}1 \text { - NO. The response was not in favor of current aid effectiveness practice or not satisfactory, this means certain things } \\
\text { were not done or yet to be done. }\end{array}$} \\
\hline \multicolumn{6}{|c|}{ 2- $\quad$ YES. Few favorable responses with less satisfaction. Respondent is not too sure of the answer, or not aware of what is } \\
\hline \multicolumn{6}{|c|}{$\begin{array}{l}\text { 3- YES. Moderate with satisfaction. This shows there are signs of progress and needs more improvements. The } \\
\text { respondent is sure of the question and sees progress and improvement on the current interventions but also acknowledges } \\
\text { need to see change. }\end{array}$} \\
\hline \multicolumn{6}{|c|}{$\begin{array}{l}\text { 4- } \quad \text { YES. Very satisfactory results and would like to continue producing similar outcome. The respondent is very much } \\
\text { satisfied with the current progress and would like to see similar things happening going forward. }\end{array}$} \\
\hline
\end{tabular}




\subsection{General Aid Management and Performance in Papua New Guinea}

This section will be split into two subsections. The first part presents the findings on the performance of Official Development Assistance Management and Development Effectiveness. The latter part of this section will set out the findings on governance and institutional coordination.

5.2.1. Official Development Assistance (ODA) Management and Development Effectiveness

At the outset, a general definition of aid was distinguished to differentiate what is a debt to the government and a grant aid (a free will gift). The Department of Treasury spelled out an unequivocal definition of aid such that "any financing in the form of debt is not considered as aid." "We don't consider borrowings and loans as aid because we have an obligation to meet when it dues. We consider grants and technical assistance as aid. That is our categorization and our understanding of aid," commented a spokesperson for the Treasury (Treasury, phone interview, October 2, 2020). Therefore, this study has decided to deploy 'Official Development Assistance' (ODA) as an official term to include both loans and grants. The term 'official' connotes whatever resources that are recognised and captured in their annual budget for development financing. Both loans and grants make up the capital investment budget which will be discussed in the latter part of this section.

Generally, ODA management and coordination in PNG has never been effectively strengthened and improved, despite the fact that certain commitments to aid effectiveness were made, such as localization of Paris Declaration on Aid Effectiveness through the Kavieng Declaration and formulation of the Development Cooperation Policy 2018-2022. Such ODA management and coordination require strong control from the central government. Commenting on overall aid management, one of the interviewees from the Department of National Planning and Monitoring said, "We have to work within the national development framework, and strengthening the role of the National Planning Department to provide strategic policy directions in terms 
of the national planning act and other instruments" (DNPM, phone interview, November 4, 2020).

Another notable response from a senior government official from the same department presented eloquently when asked to provide his view on how the development planning and funding are coordinated. He explained that the overall objectives of the government, the department and the Ministry are to "develop medium term development plans, rolling out investment plans" and also "coordinate all the policies" and then "formulate development budget to fund those programs and projects" that are highlighted in those plans (DNPM, phone interview, September $1^{\text {st }}$, 2020). It is worthy to note that he said, "the resources from the development partners are to support government budget." In other words, the resources from the development partners are to "complement Government's effort" or to "support national Government's budget" to fund the government policy priorities or development aspirations of the government. So far, the National Planning Department has been sitting on top of all the aid effectiveness measures to ensure that donor resources are contributed strategically towards the development aspirations of the government.

There were some suggestions that there are some improvements needed in ODA management, coordination and implementation. This was echoed by one of the Government's key central agencies, the Department of Treasury. According to the Treasury perspective, the "management and coordination" of the aid program at the moment "cuts across three agencies"; (1) "Department of Foreign Affairs and Trade have some legislation that are empowering them to discuss aid". (2) "Department of National Planning and Monitoring for coordination and management of ODA" as well as the "agency responsible for development planning and budgeting (capital investments)" and, (3) "Treasury" to some extend where they are "discussing some trends through bilateral (grants) and multilateral partners (concessional loans)" (Treasury, phone interview, October 2, 2020). The aid coordination is spread among these three national levels.

The single most striking statement to emerge from the interview from the Treasury Department was that the "information on how aid is managed" and "coordinated" needs to be "captured in a centralised way" regardless of these three agencies working separately. It was further stated that it would be ideal to have a "centralised database" 
for all information to be accessed regardless of which agency is doing the discussion. "This is the missing part of it." In terms of borrowings, Treasury said they have a centralised database in place that "captures and disseminate information for any users." Moreover, comments were made that for the "grants and other technical assistance, they don't have a department centralised database" for anybody or users to obtain or have access to useful information at any time. "This is lacking in our government and records are not kept in one place plus the database. The databases have to be together with the records. The records we have accessed in the past days to date it's all fragmented. But the implementation and management of the program, many are still successful. However, only the data and records are fragmented", said a spokesperson for the Treasury (Treasury, phone interview, October 2, 2020).

Another interviewee from the donors commenting on overall development effectiveness said that ODA management in PNG has been improving over time, but it is about time the government should enact strong policies to take ownership of their own development. "We are here to support the government and its development aspirations. We are not here to change everything," said the spokesperson from ADB (ADB, phone interview, September 30, 2020).

It was quite surprising and ironic that when donor funded projects were compared to those of Government funded projects, there was a general observation that the former tend to perform better than the latter. An interviewee from the PNG Customs Office said;

"I think the government funded projects, what I normally see is that government delays, meaning long time consumption and ongoing, then I suspect this is a government project. When I see a project is implemented day night and night consistently I see that that is a donor project" (PNG Customs, phone interview, November 9, 2020).

What amazes me and prompted me to delve into this observation a little deeper is to ask: what are the different things the donor does to produce such a different prospect for the public? Further analysis of such a thought-provoking question will be discussed in the next chapter.

When subnational representatives were asked to provide their views on the general ODA management in the country, there was a mix of results presented. One senior 
official from the Eastern Highlands Provincial Administration said that in terms of aid management and coordination, "They have less say in the decision-making process," although they have donor funded projects in the province (E.H.P Provincial Administration, questionnaire, November 9, 2020). A long-serving and prominent village ward councillor from Hagen Central District in the Western Highlands Province, when asked about any information on the donor funded projects and programs further reaffirmed this with a similar response. He said, "We do not have many donor funded projects at our level often, but few from woman association and others like UNDP7 AusAid ${ }^{8}, \mathrm{EU}^{9}$, or $\mathrm{JICA}^{10}$. But we do not have a say on where it comes from and how it is implemented." He further stated, "Sometimes we only see there is an infrastructure being built and say this was built by a donor" (Tiling LLG ward 9 Councillor, phone interview, September 29, 2020). The participant was trying to allude to the fact that donors come for smaller projects to work with churches and women but not through the LLG level, which has no say in these projects' establishment.

On a comparative scale, an experienced informant who was a LLG council president and a tradesman for more than 20 years before that eloquently said that donor financed projects are implemented more successfully than others. The LLG president further said that they do not receive government services. "Maramuni has been living in isolation since independence, but we see Australian Government, China, and US comes and do projects in other parts of Wabag and PNG, and the do very well" (Maramuni LLG President, phone interview, November 5, 2020). This LLG president was very impressed at the way the classrooms and aid post are delivered at the rural areas where government cannot reach.

Similarly, one respondent who was also a LLG ward councillor (Tiling LLG ward 9 Councillor, phone interview, September 29, 2020) applauded donor interventions but the councillor does not actually participate in the whole project cycle. He commented that: "The difference we see is that when funding comes in, the money is given direct to service providers and projects are delivered on time and on budget. But when politicians pledge money for any development project, we hear the amount but actual

\footnotetext{
7 United Nations Development Programmes- PNG Resident Mission.

${ }^{8}$ Australian Aid Programs.

${ }^{9}$ European Union Programs.

${ }^{10}$ Japan International Cooperation Agency.
} 
money doesn't reach us, and sometimes no project on the ground," said the worried councillor.

\subsubsection{Governance and Institutional Coordination}

Governance issues around development financing and implementation were some of the biggest concerns raised across all interviewees in this study. These issues can stem from the lack of human resource and financial capacity, weak institutional leadership, cumbersome and stringent systems and processes including procurement, budgeting and planning.

Despite the existence of some loopholes and gaps in the overall aid management and coordination in PNG, there was a strong indication of improvement and effectiveness in development cooperation, particularly in delivering successful donor programs. When asked why donor projects are implemented more successfully than the government projects, most responses were in favour of the donor performance. This was demonstrated when interviewing one of the government's key sector agencies, the Department of Agriculture and Livestock. A chief policy officer of the department praised the good work of the World Bank and its Productive Partnership in Agriculture Project (PPAP), stating that "every agency should adopt some of the practices from this project" (DAL, phone interview, October 2, 2020). When further asked to justify his claim, he said, "Because it is the management aspect of it that makes it more successful." What was worth noting is that the "officers involved in the project implementation and management..., comply [with the] financial management guidelines, procurement guidelines, reporting and accounting" and all other aspect of project management.

One participant from the Department of Treasury also alluded to the notion of why donor funded projects are performing better than the government, explaining that the governance structures of the donors are more effective and credible. He said, "Donors seems to have very good governance structure. It is the governance structure that they have make their projects look different from the government funded projects. We totally lack this" (Treasury, phone interview, October 2, 2020). 
In line with the Treasury's comment on the governance aspect of development, a participant from the World Bank made a notable remark when asked why donor funded projects are more successful than the government own funded projects. The informant was a key sector specialist with vast experiences in the agriculture sector for almost 30 years, cross country experiences in the Solomon Islands, and at the time of interview he had been with the World Bank for 10 years. His experiences stem from the private sector in agriculture investment where he worked for 40 years as a regional economist. From his engagement with the private sector, he made a submission to the national Government to "adopt and institutionalize" the agriculture innovation grant scheme, a program funded by AusAid. He tried to find a way forward for best funding agriculture when K100 million through National Agriculture Development Plan (NADP) annually was lost every year. According to his testimony, he said;

"During the design and formulation of the program, two important things popped up and that is what PPAP model adopted: (1) Governance. You have to set up Governance structure of the funding, and (2), Established systems and processes. Once you have these set up no one or no politician would play with it" (World Bank, phone interview, September 29, 2020).

Another interviewee who was a sector specialist with ADB (ADB, phone interview, September 30, 2020), alluded to the notion of effective coordination, that the "ADB has a relationship with the Government at the national level" and that's where and how most of the ADB financed projects are developed, and thus these projects have support through the "established national government procedures and systems." And the ADB has been financing projects "through the national government's systems", meaning through the Department of Treasury. He continued that they have a "day to day coordination and relationship" with the Department of National Planning and Monitoring when projects are approved and being implemented.

Furthermore, the World Bank highlighted precisely this lack of governmental capacity as a serious problem in a very surprising tone when commenting on the performance of the sector institution, particularly the commodity industry, which are underperforming. He said, "One of the problems we faced while in the private sector was the non-performance of the research and extension institution in the country" (World Bank, phone interview, September 29, 2020). "NARI is now just going down", 
he added. Basically the need was "to build their capacity". Offices such as OPIC, Coffee Research Institute, FPDA, Cocoa and Coconut Research Institute, PNG Oil Palm research association need to have adequate capacity to run their programs. The interviewee was the national coordinator for the grant scheme and developed an agriculture innovation grant scheme, which he is encouraging the government to institutionalise at the subnational level. What was striking to note was this instance of a lack of institutional coordination and communication.

Talking about this issue, an interviewee commented: "In terms of ADB coordination or interaction with the subnational levels, the provincial, the districts and the Local Level Governments, it is quiet minimal" (ADB, phone interview, September 30, 2020).

This was demonstrated in one of the projects funded by World Bank, the Smallholder Agriculture Development Project (SADP). When asked to share the experiences of failures and challenges in working with the government and donor funded projects, the interviewee said that SADP was actually a very good project. Since the World Bank was introduced in 1976, their first project was funding the oil palm development project in PNG. This Oil Palm project was successful because "it was driven by the private sector" and with "very little government influence". And also at that time the World Bank had very "good extension services". However, what went wrong in SADP was the "lack of government support". There was "no coordination" between the five key departments that "need to be collaborating on oil palm- i.e, DAL, department of lands, CEPA, NFA, and DPLLGA" (World Bank, phone interview, September 29, 2020). What is worth noting in this testimony is the lack of coordination across government institutions.

This view was echoed by again another informant from the ADB. When asked about how they should improve on the service delivery and development effectiveness, he said "I think it is just effective coordination and communication" (ADB, phone interview, September 30, 2020). The Government has established overriding development goals and plans, and it's now up to the "us" (donors) and also up to the Government to open up "effective coordination and communication with different agencies", with whom the Government thinks they can work to implement and realise these plans and goals.

This notion was further supported and reaffirmed by participants at the subnational levels. One informant from the Project Management Unit of the PPAP reported, "What 
I see is corruption" (PPAP-PMU, phone interview, October 2, 2020). The government money that is given to the agencies are "used on administrative things" and "not on actual development projects." This comment was made regarding the Public Investment Program (PIP) funds. "Basically it is the governance issue in the organization and people working in there. They work or not, every after two weeks they turn up and collect their pay, but in the project management unit they are there to achieve development targets, delivered, achieved and go," he added. This view was further flagged by another interviewee who made specific reference to the people driving successful projects and programs. "To me there is no magic to the model, but the key thing is the people who are driving it," expressed the component coordinator from the Project Management Unit for PPAP (PPAP-PMU, phone interview, October 2, 2020).

Moreover, the LLGs have also experienced similar issues of governance and lack of proper institutional coordination. At one account, a three term ward councillor responded vividly about how they work in their LLGs saying that they act like an elephant with no head. "No one tells us, no idea, and no clue about development plans or whatsoever. Opposition and government at the Provincial level determines who gets the share down here," said the disappointed councillor (Tiling LLG ward 9 Councillor, phone interview, September 29, 2020).

If we now turn to the opposing view of how the ODA is managed, there was a particular comment that challenged some of the practices (social and safeguard) by the donors. A participant from the Project Management Unit of the PPAP adamantly said that donors should not come and "dictate us what to do. We cannot get some things that are working in Asia or Africa and think that it will work in PNG. No it won't," the PMU concluded (PPAP-PMU, phone interview, October 2, 2020). He was referring specifically to settling land disputes and compensation.

Turning now to the practical evidence on a way forward to improve the challenges faced by the government in service delivery, there were a few suggestions made by the interviewees. Propositions were made in relation to policy and planning.

It was suggested that all levels of government and sector agencies, including the donors, must have policy cohesion and coherence. An informant from the DAL proposed that "alignment" is the "very important" and "key thing" we should undertake. 
He also added that "funding support" and "man power" can be channelled accordingly based on needs (DAL, phone interview, October 2, 2020). The comment below illustrates one case where development planning and budgeting has been coordinated by the government agencies.

One informant, a senior public servant, reported that the effort to coordinate and formulate economic policies of the country must be "strengthened and effective" so that they are "aligned to the higher development polices" they have. They should also be "integrated with other existing economic policies" or new policies, not only economic but with other social and environment policies as well. And also, the "translation of those policies including medium term development plans into what they call Annual Budget Framework Paper must be realistic and achievable," which they produce on an annual basis, so that the budget is "policy driven". Policy objectives can be funded by the budget comprised of donor and the government's own resources (DNPM, phone interview, September 1 ${ }^{\text {st }}, 2020$ ). As such, donors coordinate the resources (both internal and external) and fund the policy priorities of the government. In this case the development partners have their Country Assistance Strategies and Country Partnership Strategies which are aligned to the Government's development plans.

Commenting on alignment, one of the most experienced interviewees from the donor sector said: "One of the things I have learned from this project is that we have understood the success and the impact of the PPAP. The current problem is the aligning of the priorities" (PPAP-PMU, phone interview, October 2, 2020). The ENB Province is one part of this successful partnership in which they see this model as a success for service delivery, and they want to align and adopt these processes of PPAP. He further suggested that "what they need to do at the district, once the completion of the project" you "sign an MOU with the district" to "ensure there is maintenance and sustainability of the project" (PPAP-PMU, phone interview, October 2, 2020).

In one case, the participant from the PPAP-PMU thought that what he learned from this project (PPAP) is that the government needs an institutional coordinator. Such a person can extract the lessons learned, consolidate best practices and start talking to all the stakeholders in the institution. 
Generally, a majority of participants agreed with the statement that the donor's development financing including coordination, management, implementation of projects and programs are more successful than the government's own initiatives. Alignment of policies and development priorities is key for development effectiveness, a proposition alluded to by almost all interviewees. Whilst a minority mentioned that the donors' governance structures were too stringent and cumbersome, almost all agreed that such leads to good governance and successful implementation of programs and projects. Such praise and applause causes one to raise an eyebrow and should send a shock wave across the government causing it to question its development financing.

\subsection{Development Ownership}

The third section of this chapter presents the findings of the research, focusing on the three key themes that underpin development ownership: (1) leadership, (2) decision making, and (3) capacities. A recurrent theme in the interview discussions was a sense amongst interviewees that development ownership has not trickled down very much to all levels of government. Despite the decentralization policy which will be discussed in the next chapter, providing for devolution and delegation and deconcentration of administrative and financial functions of the government, there were clear indications that policy and financial decisions were not affirmative, and capacity issues were affecting the effort to engineer and drive development at all levels of government. The findings set out in the following sections collectively demonstrate how decision making and capacity determines the development ownership of the country. Particularly what constitutes development ownership is when good decisions are made and adequate financial and human resources are provided to execute and implement the decision (political or technical/administrative). The findings of the leadership and decision making will be presented in the following passage.

\subsubsection{Leadership and Decision Making at the National Level}

At the outset, this section will cover the findings on leadership at levels of government. However, decision making is core to this section, as leaders makes decisions for the good of the country and social progress. According to Diesing (Diesing 1962), there are five types of rationality in decision making in social behaviour. They are: technical, 
legal, economic, social, and political. The application and limitations of the different types may differ depending on the context. This section will use political and technical rationality in decision making. The former denotes the policy and planning decisions. This includes decisions on who gets what and when they get them. The latter denotes the administrative aspects of decisions of how they get it. What most of the interviewees referenced in their experiences were in relation to political decision making.

The findings below illustrate the lack of will and power at the national, provincial and subnational levels of government in supporting development projects. For example, one interviewee from the Treasury said: "Funding issue is big in East New Britain sewerage project." Here there is a lack of financial resources where they can do their own work in doing the individual connections. They need or "lack the ability or willingness" to spend their own resources towards the project that will negatively impact the sustainability of the program. Further comments were made that if the subnational levels of government are not willing to commit their resources to it to continue and make money out of that infrastructure, which will cost the Treasury millions of Kina, then "sustainability becomes an issue" because "they have the money but are not willing to spend" (Treasury, phone interview, October 2, 2020).

One participant commented:

"When there is strong leadership and coordination at the national level aid effectiveness works, when there is a lack of strong leadership and coordination at the top level, we turn to compromise, and that is where donors come and do their own things. Sometimes they do things against the development aspirations pursued by the government. The classic examples of lack of leadership are the Rabaul Sewerage Project and Lae Tidal Basin Project, the Government do not need this projects, but then the burden is that the State are going to repay the loan" (DNPM, phone interview, November 4, 2020).

In one case, the participant thought that the government (including National, Provincial and Districts) should take the leadership role in driving the development agenda of the country, rather than letting the donors run the show. The comment below illustrates a 
failed donor funded project because of lack of leadership from the government stakeholders. An experienced agriculturalist said confidently:

"When I was with the Oil Palm industry we have a local planning committee, in Oro and in West New Britain. The committee is always chair by the Provincial Administrator. The Provincial Administration takes ownership of oil palm because it is the main income generating activity in their province, and in their annual work plan this should be picked up because that's where they make their money to run their services. However, this support was never there" (World Bank, phone interview, September 29, 2020).

So in the end, the Bank was blamed for this failure. In fact, it was the government stakeholders. It was claimed that the project had issues with NGOs complaining of contamination of river systems in Oro (pollution) and lack of consultations and consent. These are the processes in designing World Bank projects that should be "led by the Government." So because of these issues, the World Bank is reluctant to reengage in oil palm.

One informant (World Bank, phone interview, September 29, 2020) suggested when raising the issue of sustainability that the projects and programs funded by donors and development partners, "they come and die." "Why are we not buying them and institutionalizing them?" the World Bank asked.

Commenting on lack of leadership at central levels of government, one of the interviewees questioned the functions of the central agencies. Concerns were raised on appraising project proposals and providing implementation completion reports on donor funded projects to the stakeholders including the financiers (donors). These appraisals and reports are currently provided by the donors. This implies that there is no ownership and leadership from the government.

Also it was noted that in certain occasions, the local authorities where not informed of what is happening in the provinces and districts. Such information again questions the ownership of subnational levels and concern for sustainability is at stake. As one interviewee put it eloquently:

"What we need to learn is that the project has got some number of criticisms from politicians. They asked why you are in the provinces. That they were not 
informed. I think what the project has lacked was to inform at the high level, at the policy level is to make awareness and to inform the ministers and leaders because they are planners and policy makers and they can then buy into this project and they can also help counterpart the project. That is where we lack" (World Bank, phone interview, September 29, 2020).

While a minority mentioned lack of funding and human resource capacity, all agreed that the government at all levels is not taking ownership of its own development. As such, most donor funded projects end up with sustainability issues while most government funded projects are either incomplete or in defects due to lack of poor coordination and leadership at the agency level. Such induces us to delve deeper into the level of participation and decision making at the subnational level.

The next subsection of the interview was concerned with the subnational levels of government participation in decision making. The questions were not only in decision making but also in implementing programs and projects and seeking understanding on whether or not their participation has been valued. It also sought to find if there was an inverse relationship with the higher levels of government.

\subsubsection{Subnational Participation in Decision making}

The questionnaire and interview guide asked participants to answer and complete three open-ended questions to examine development ownership, grassroots participation and institutionalization of best practices by the government, particularly at the subnational levels. Subnational levels of government are comprised of provinces, districts and LLGs. There are 22 provinces, 89 districts and LLGs in the country. Findings are representative of these levels of government. However, there are other views and comments made by participants from donors and central agencies also reflecting on how they engage civil society participation in their operations at the subnational levels.

When asked about the decision-making process and how reforms are to be undertaken if needed, the participants were unanimous in the view that sometimes decision are not taken into consideration from the top. For example, one interviewee from the provincial government said, "We do not have much say in decision making 
particularly in setting development priorities, planning and budgeting. Everything is dictated from the top."

Participation at lower levels of government and their relationship with other government agencies seemed to be weak or non-existent. Talking about these issues, an interviewee said: "We do not participate in decision making, in both donor and government projects" (Maramuni LLG president, phone interview, September 29, 2020).

Similar sentiments were echoed by another interviewee:

"We do not have development plans. Every year we have funds coming in from provincial government, but the funds are withheld by the president, we do not have a say in that. It applies to all LLG president around the country. Funds withheld by the president who is the chairman. We council work voluntarily. We only get our K400 monthly salary. We do not have development plans and budget" (Tiling LLG ward 9 Councillor, phone interview, September 29, 2020).

In his additional comments, he mentioned that sometimes the project funds are given to the contractors and delivered with financial acquittals provided by the contractors. Apparently, LLGs do not know anything about how the project is managed, funds are acquitted, and what reports are submitted.

In one case, a participant from a donor (World Bank, phone interview, September 29, 2020) thought that the technical committee at the subnational level should be the representative of people who are actually in the business of coffee and cocoa or whatever the project it is. They should have a mouth piece on this board. The board should not be filled by those appointed by politicians. As such, the participant has been very adamant in asking the subnational levels to adopt the systems and processes, but they are very slow.

One individual stated affirmatively:

"The people who involve in the project does not inform the communities about the benefits of the projects and what will be other indirect benefits this project may bring into the community. Less awareness and less engagement with community leaders resulted in wider resistance to development projects at the subnational levels" (PNG Customs, phone interview, November 9, 2020). 
Another commented when asked about their experiences in working with the subnational levels: "It differs." Despite other provinces learning from the project, when those government officers who have no interest in the project, including $\mathrm{CIC}$, then you have disconnection regardless of what you are doing on the ground (PPAP-PMU, phone interview 2, October 2, 2020).

Turning now to experiential evidence from those who have hands-on experience with projects, they also provided their views on whether or not the good practices will be institutionalised.

For example, one interviewee said: "Yes the province and the districts are appreciative of what the PPAP is doing. Whether they will use it and integrate the model into their own system is beyond my control" (PPAP-PMU, phone interview 1, October 2, 2020). Such comments show that the technocrats at the subnational have no inverse relationship and interest in adopting the models and practices once the project reaches its completion date.

This view was echoed by another participant who had vast experiences at the LLG level. This person worked together with the donors in terms of project identification. "The donors reach out through association, women groups, and communities and community leaders, elders and LLG administration give their views, while the donors give their views, and we work together" (Tiling LLG ward 9 Councillor, phone interview, September 29, 2020)

One participant (PPAP-PMU) commented;

"Before I came into this project, I saw two parallel projects running side by side. But now it is one. For them $(\mathrm{CIC})$ to operate as an industry, they must change the way of doing business and apply using PPAP model".

Another interviewee from the same unit, when asked about the working relationship with the provinces and district, said: "There is always an overall project steering committee which is established and that is where the participation of the provinces or the subnational level governments come in" (PPAP-PMU, phone interview 1, October 2, 2020). 


\subsubsection{Capacity}

The findings on capacity outlined in this subsection are twofold. Firstly, capacity may be in the form of human resources. And secondly, capacity may come in the form of financial resources. There is no order of preference as they are being presented. The findings set out in this subsection demonstrate that the lack of sufficient financial capacity at the subnational levels distorts and affects their willingness and efforts to drive development. It is not only the financial shortcomings, but the lack of technical skills and expertise such as project management, accounting and reporting also affects their performance as well as hindrance to development

An interviewee was asked about one of the cases of a livestock project in East Sepik Province. The interviewee presented some important key points on the capacity issues of the subnational levels. Among those, the first example that he presented was on their capacity. The comment below illustrates this when further asked to distinguish between human resource capacity and financial resource capacity or both. He said,

"In this case, facilities, and livestock were there, everything were there and ready. It just needed good management practice so that they could manage the expenditures and revenues, and make good money out of it. However, they left that program after it was completed, because it was much bigger than their knowledge" (World Bank, phone interview, September 29, 2020).

Other responses to this case included:

"The project was good and has the potential to supply the whole country and also for exporting. After the program was completed and delivered, the provincial government has no capacity to manage, and after a while the livestock had gone wild, complaints received from community etc., and the project came to a halt due to improper and poor management of the program (Treasury, phone interview, October 2, 2020).

As one interviewee from the LLG level put it: "We councillor are hanging there without anything. On the ground we have nothing. I am a third term councillor but no training, no funding and nothing from the government accept few donors" (Tiling LLG ward 9 Councillor, phone interview, September 29, 2020). 
One individual stated that "with the knowledge" and "without the funding" you cannot do anything. This was in reference to empowering farmers to transform the way they do the farming (World Bank, phone interview, September 29, 2020).

There were other examples of cases where there were adequate trainings provided to the officials who have retired to come back to work in the agriculture sector. However, after training them, their skills became a waste as there was lack of funding to utilise their skills.

One interviewee from the World Bank expounded on his work with the Farmer Training Centre where he led the development of farmer training modules. These are key tools for extension services. He engaged DPI officers from the districts from the provinces and called them public trainers. Private trainers, then, were the retired public servants with expertise in coffee, cocoa and livestock. He reengaged them to be trainers. He said, "Once I started doing the training, I realised that after skilling the farmers with knowledge and skills, they couldn't utilise those skills because they didn't have the funding. That is why I joined AusAid to develop the grant scheme" (World Bank, phone interview, September 29, 2020). Findings have demonstrated repeatedly that lack of capacity at the subnational level has weakened the effort to deliver services.

The next section of the interview was concerned with financial capacity. There is a separate section at the latter part of this chapter succinctly presenting development financing. This section only captions the narratives of the interviewees. Most of the interviewees raised a concern of development ownership as the reason projects are incomplete even though the national government is channelling adequate funds to the provinces and districts. It was acknowledged that the lack of access to finance had a mounting pressure on the sub nationals' service delivery efforts.

One participant commented:

"As you know, most of the projects in the sector are not implemented successfully because of so many issues and resourcing is a major concern. Most projects are not implemented successfully and completed because of the shortfall or no GoPNG funds" (DAL, phone interview, October 2, 2020).

There were other cases in which provincial governments entirely depended on national government funding. Such demonstrates that they have not taken ownership of the 
infrastructure project. Although they are the owners of that project, after the completion of the project, they do not have any sustainability plan that includes maintenance.

For example, one interviewee said:

"Kokopo Sewerage Project has been funded by the national government through the funding from China. After the infrastructure has been developed, the next thing is that the provincial government is still sitting there and requesting the national government to give them some funding to them so that they can connect all the houses to the main sewerage fly" (Treasury, phone interview, October 2, 2020).

He further commented that the subnational government was not making any effort to sustain or keep what had been given to them like sustaining it by investing money into the project rather than expecting the national government to do everything for them.

Taken together, the results in this subsection suggest that there are three issues identified if development ownership is to be assessed critically. First, lack of leadership (coordination) at all levels of government. Secondly, decision making (participatory and inclusive development) has never been democratic and transparent particularly at the subnational levels (LLGs). And thirdly, financial and human resources capacity issues were experienced at all levels of government. Despite these negative results, there were some positive comments about donors' efforts to improve coordination with the government agencies and building capacities at the subnational level. The donor practice of having effective consultative dialogue with the lower levels of government received positive feedback, including notes that this led to delivery of successful projects. Such results lead to the next question of this study: what does development financing looks like in the country? Are there adequate funds going down to the subnational levels? The following section will examine this question.

\subsection{Development Financing}

To answer this question, a qualitative study was undertaken on the amount of development funds that have been going down from the national government to the subnational government levels. This has been shown on table 5.2 below. The recurrent budget is done by the Department of Treasury while the Department of 
National Planning and Monitoring is the custodian of the capital investment budget or Public Investment Programs (PIP). The figures presented in both table 5.2 and table 5.3 were all extracted from the annual budget documents from fiscal years 2008-2018 (The Treasury, 2021). The period selected does not represent any preference but only an indication of the trend in which budget growth has been demonstrated. While the figures in table 5.3 are based on revised budget (supplementary budget) captured in the annual Final Budget Reports, the figures in table 5.2 are all actuals extracted from the Public Investment Budget records. 
Table 5.2. Public Investment Program Appropriation from 2008-2018

\begin{tabular}{|c|c|c|c|c|c|c|c|c|c|c|c|c|}
\hline \multicolumn{12}{|c|}{ PUBPLIC INVESTMENT PROGRAM PPROPRIATION FROM 2008-2018 } & \multirow{3}{*}{\begin{tabular}{|l} 
TOTAL \\
11 \\
YEARS
\end{tabular}} \\
\hline & \multicolumn{11}{|c|}{ Yearly allocation based on the actuals. } & \\
\hline COMPONENT & 2008 & 2009 & 2010 & 2011 & 2012 & 2013 & 2014 & 2015 & 2016 & 2017 & 2018 & \\
\hline $\begin{array}{c}\text { TOTAL } \\
\text { BUDGET }\end{array}$ & $6,999.2$ & & $7,489.7$ & $9,328.1$ & $10,560.3$ & $13,030.0$ & $\begin{array}{r}15,000 \\
0\end{array}$ & $16,200.0$ & $14,762.6$ & $13,349.5$ & $14,718.0$ & \multirow{3}{*}{$\begin{array}{r}121,437.4 \\
48335.9 \\
\\
11439.8\end{array}$} \\
\hline $\begin{array}{c}\text { DEVELOPMEN } \\
\text { T PIP }\end{array}$ & $1,887.1$ & $2,595.2$ & $3,394.8$ & $4,041.0$ & $4,279.8$ & $5,795.8$ & $7,470.6$ & $7,005.5$ & $5,095.9$ & $4,013.3$ & $4,643.9$ & \\
\hline $\begin{array}{c}\text { PIP } \\
\text { PROVINCES }\end{array}$ & 162 & 568.8 & 199.3 & 177.3 & 349 & $1,955.9$ & $2,021.6$ & $1,702.6$ & $1,547.4$ & $1,402.2$ & $1,353.7$ & \\
\hline & & & $\begin{array}{l}\text { PROVIN } \\
\text { Special S } \\
\text { Provincia } \\
\text { District S } \\
\text { Support t } \\
\text { Provincia }\end{array}$ & $\begin{array}{l}\text { AL GOVE } \\
\text { oport Grar } \\
\text { and Distric } \\
\text { port Impr } \\
\text { LLG } \\
\text { Support Im }\end{array}$ & $\begin{array}{l}\text { NMENT } \\
\text { Support Gr } \\
\text { /ement Pro } \\
\text { rovement }\end{array}$ & & & & & & & \\
\hline
\end{tabular}


Table 5.2 is quite revealing in several ways. First, what stands out in the table is that since 2008, the budget has been progressively increasing at a rate from 10 per cent to 12 per cent per year. In 2008 the total budget was K6, 999.20 million, and it was doubled in 2018 with an intriguing budget figure of K14, 718.00 million.

Secondly, the funds allocated for capital investments or public investment programs have been proportionately increasing since 2008. The capital investment constitutes the sector allocation to sector agencies and the provinces from the capital expenditure and net lending. It has exponentially increased from k1, 887.10 million in 2008 to K4, 643.90 in 2018 with an increase margin of K2, 756.8 million. However, it was striking to note that capital investment budget in the year 2014 and 2014 has remarkable increased with $K 7,470.60$ and $K 7,005.50$, and then it declined by $K 2,000.00$ million in the subsequent year (2016) and then picked up again in 2017. Apparently, this exponential increased may have been caused by the government's fiscal reform to allocate K500, 000.00 for Local Level Government Service Improvement Programs (LLGSIP). The pros and cons of this funding at the lower levels of government will be discussed in the next chapter.

Thirdly, the budgetary allocation to the provinces for development financing every fiscal year has also increased significantly. From K162.00 million in 2008 to K1.35 billion is a massive budget support to the provinces and the LLGs. The Provincial PIP constitutes the Special Support Grant, Provincial and District Support Grant, Provincial Support Improvement Program (PSIP), District Support Improvement Program (DSIP), and Support to LLG (i.e., LLGSIP). With successive increases in intensity of the capital investments, the Provincial PIP allocation increased proportionately. Additionally, closer inspection of the table shows that between years 2013 and 2017, the provincial baskets was larger than in 2018 and the previous years of 2008 to 2012. Perhaps, such a large share of the budgetary allocation to the subnational levels may have been caused by the O'Neil Government's most passionate policy for subsidizing service sectors such as free health and education policy from 2012-2017.

What is interesting to note is that the annual budget has been guided, formulated and operationalised through effective fiscal policies and legislations including budget strategy papers, medium term fiscal strategy, medium term development plans and other cascading high level plans, such as the Fiscal Responsibility Act 2006 and Public 
Finance Management Act 1995 (amended in 2006). The Budget Strategy Papers are a key budgeting instrument developed simultaneously with the annual budgets to be guided by the doctrines of development espoused by the Five National Goals and Directive Principles, the National Strategy of Responsible Sustainable Development (StaRS), and Papua New Guinea's commitment to the 17 United Nations Sustainable Development Goals (SDGs), that have been captured in the development principles defined by Vision 2050, and Development Strategic Plan 2030, and woven into the prescriptions of Medium Term Development Plans (MTDPs) II and III. In every fiveyear political cycle, when new a government comes into power, they have their joined commitment to development and policy priorities. In 2012 after the National General Election was conducted and members were sworn in for the $8^{\text {th }}$ parliament, the leaders of the PNG coalition Government outlined their priorities in what is called the Alotau Accord. Then after the $2017 \mathrm{NGE}$, the incumbent prime minister and leader of the People's National Congress Party, Peter O'Neil, signed the second accord (the Alotau Accord II). In 2020, the new government formed through Vote of No confidence had put forward the 'Loloata Commitment' as a rescue and reconstruction strategy that began with a fiscal re-adjustment and a revised Medium Term Fiscal Strategy (MTFS) 2020-2024.

The single most striking observation to emerge from the comparisons of political and development priorities set out in various political commitments is that the 'government of the day' determines what priorities the annual budget funds. In other words, the annual budget was surprisingly dictated and revolved around the political ambitions and priorities of the ruling government.

The significant expansion of expenditure in the years between 2013 and 2018 could be a reflection of the government's commitment under the Alotau Accord to invest in the enablers of broad-based growth, including infrastructure, health, education and law and justice.

From 2014-2018, the budget breakup has changed, unlike the previous year's budget books, development financing allocations were specifically mentioned as either capital investment or development budget (see the sample displayed in Table 5.2a \& Table 5.2b). Under expenditure and net lending, the capital expenditure comprised of government direct financing on capital investment projects, project support grants from 
donor agencies, spending on projects facilitated by the Tax Credit Scheme (ITC) offset by reductions in Mining and Petroleum Taxes, as well as drawdowns on Concessional Loans (Department of Treasury, 2014).

\begin{tabular}{|c|c|c|c|c|}
\hline \multicolumn{5}{|c|}{$\begin{array}{l}\text { TABLE 5.2A. EXPENDITURE BY FUNDING SOURCE } \\
\text { Expenditure by Funding Source 2014-15 (Kina Millions) }\end{array}$} \\
\hline Source of Funding & $\begin{array}{r}2014 \\
\text { Actuals }\end{array}$ & $\begin{array}{r}2015 \\
\text { Original }\end{array}$ & $\begin{array}{r}2015 \\
\text { Revised }\end{array}$ & $\begin{array}{r}2015 \\
\text { Outcome }\end{array}$ \\
\hline Domestic Funding & $13,158.0$ & $13,708.8$ & $12,332.4$ & $11,749.8$ \\
\hline $\begin{array}{l}\text { Project Support } \\
\text { Grants }\end{array}$ & 867.5 & $1,396.1$ & $1,396.1$ & 819.5 \\
\hline $\begin{array}{l}\text { Infrastructure Tax } \\
\text { Credit Scheme }\end{array}$ & 133.2 & 207.8 & 207.8 & 219.5 \\
\hline Concessional loans & 610.1 & 886.3 & 886.3 & 707.3 \\
\hline Savings & -279.0 & & & \\
\hline Total & $14,489.8$ & $16,199.1$ & $14,822.6$ & $13,496.1$ \\
\hline
\end{tabular}

Source: Department of Treasury

*Savings in the 2014 Outcome refer to savings from the Trust Accounts

Table 5.2b. Sample of the Budget 2011-2012

\begin{tabular}{|l|r|r|r|r|}
\hline \multicolumn{4}{|c|}{ Total Expenditure and Net Lending 2011-2012 (Kina Millions) } \\
\hline & $\begin{array}{r}2011 \\
\text { Outcome }\end{array}$ & $\begin{array}{r}\mathbf{2 0 1 2} \\
\text { Original }\end{array}$ & $\begin{array}{r}2012 \\
\text { Revised }\end{array}$ & $\begin{array}{r}2012 \\
\text { Outcome }\end{array}$ \\
\hline $\begin{array}{l}\text { Service Delivery } \\
\text { Expenditure }\end{array}$ & $5,339.6$ & $6,123.2$ & $6,123.1$ & $\mathbf{6 , 1 9 7 . 2}$ \\
\hline $\begin{array}{l}\text { Development and } \\
\text { Capital } \\
\text { Investments }\end{array}$ & $3,249.2$ & $4,437.1$ & $4,437.1$ & $\mathbf{3 , 8 4 6 . 8}$ \\
\hline $\begin{array}{l}\text { Expenditure } \\
\text { Supplementary Budget }\end{array}$ & 781.8 & & & \\
\hline
\end{tabular}




\begin{tabular}{|l|c|c|c|c|}
\hline $\begin{array}{l}\text { Total Expend and Net } \\
\text { Lending }\end{array}$ & $9,370.6$ & $10,560.3$ & $10,560.1$ & $\mathbf{1 0 , 0 4 4 . 0}$ \\
\hline $\begin{array}{l}\text { \% of GDP } \\
\text { SOURCE: DEPARTMENT OF TREASURY }\end{array}$ & $31.2 \%$ & $32.3 \%$ & $32.3 \%$ & $\mathbf{3 0 . 7 \%}$ \\
\hline
\end{tabular}

The following table (Table 5.3) presents the summary of the Final Budget Outcome Report from financial years 2008 to 2018 . This table has been formulated to present the findings of how much money has been spend on development financing across all levels of government including the agencies of the government. The Government Budget is comprised of capital investments and recurrent budget. The figures in the table below only represent the aggregate amount of capital budget per year with the actual amount being expended as shown in the outcome column. This includes the PSIP, DSIP, and recently cancelled LLGSIP.

Since independence, PNG MPs have received funding to spend in their electorate, initially through the Electoral Development Fund and, more recently, through the District Services Improvement Program.

Table 5.3 Final Budget Outcome Summary from 2008-2018

\begin{tabular}{|c|c|c|c|c|}
\hline \multicolumn{5}{|c|}{ FINAL NATIONAL BUDGET OUTCOME } \\
\hline \multicolumn{5}{|c|}{ Total Expenditure and Net Lending 2007 - 2018 (Kina Millions) } \\
\hline $\begin{array}{l}\text { Expenditure } \\
\text { /Financial year }\end{array}$ & Budget & Revised & Outcome & low-high \\
\hline 2008 & $1,887.10$ & $1,874.60$ & $1,630.10$ & -244.50 \\
\hline 2009 & $2,595.20$ & $2,595.70$ & $2,348.70$ & -247.00 \\
\hline 2010 & 3393.8 & $3,430.30$ & $3,278.90$ & -151.40 \\
\hline 2011 & 4041.1 & 3924.5 & 3194.2 & -730.3 \\
\hline 2012 & $4,437.10$ & $4,437.10$ & $3,846.80$ & -590.30 \\
\hline 2013 & $5,795.80$ & $5,879.30$ & $5,119.60$ & -759.70 \\
\hline 2014 & $4,889.60$ & $4,889.60$ & $4,506.20$ & -393.4 \\
\hline 2015 & $5,838.00$ & $5,090.10$ & NA & NA \\
\hline 2016 & $5,095.90$ & $4,410.20$ & $4,473.40$ & 63.2 \\
\hline 2017 & $4,013.30$ & $4,012.50$ & $3,167.40$ & -845.1 \\
\hline
\end{tabular}




\begin{tabular}{|rrrrrr|}
\hline & $\mathbf{2 0 1 8}$ & $4,643.90$ & $2,620.90$ & $2,040.70$ & -580.20 \\
\hline TOTAL & & $\mathbf{4 6 , 6 3 0 . 8 0}$ & $\mathbf{4 3 , 1 6 4 . 8 0}$ & $\mathbf{3 3 , 6 0 6 . 0 0}$ & $\mathbf{- 4 , 4 7 8 . 7 0}$ \\
\hline
\end{tabular}

Source: Department of Treasury

Final Budget Outcome Report 2008-2018

Note: NA- The reduction in actual expenditure relative to the Revised Budget stems from a significant float of 2015 expenditure into 2016 that was not captured at the time of writing the report (Final Budget Outcome Report 2015)

(-) negative figure represents the savings.

From the table above, it can be seen that by far the greatest allocation of development financing has been from 2011 and onwards. This saw a record increase of K4, 437.10 which is a K647.3 million increase from 2010. And the budget allocated for development financing has increased substantially. Additionally, as it is being vividly observed that there has been a supplementary budget every year and each revised budget experienced a budget cut. This may have been caused by any number of factors. First, this could be caused by a fall and reduction in the country's revenue. Secondly, it may have been triggered by slow disbursement or drawdowns on concessional loans and grants. And finally, it could be caused by slower implementation of projects and programs due to lack of counterpart funding for mobilization and stringent procurement systems and processes.

Furthermore, from this data, we can see that since 2008 to 2018, just within the period of ten years, the government has allocated K46,630.80 million of which only $\mathrm{K} 33,606.00$ has been actually spent on development financing. That is a substantial amount of money a national government can allocate to its subnational levels. And assumingly, the figures will have been increased in subsequent fiscal years due to many reforms the government is undertaking to expand its revenue generation options.

Indeed, PNG seems to rely more heavily on constituency funding to disburse its budget than any other government in the world. This hypothesis has been tested and provided by a notable research by the colleague from the Australian National 
University. In this report it stated that, since the 1980s, PNG MPs have received funding to spend in their electorate, initially through the Electoral Development Fund and, more recently, through the DSIP. Figure 5.1 (Howes, Mako et al. 2014) shows the huge increases in these programs over the last decade and in the 2013 budget. In the 2013 budget (and again in the 2014 budget) PNG's 89 open electorates (normally made up of one or two districts) were allocated K10 million each, more than double the previous average annual allocations from 2007-2012. This claim is illustrated in the following figure.

Figure 5.1: The upsurge of subnational budgetary allocation in PNG (Kina million)

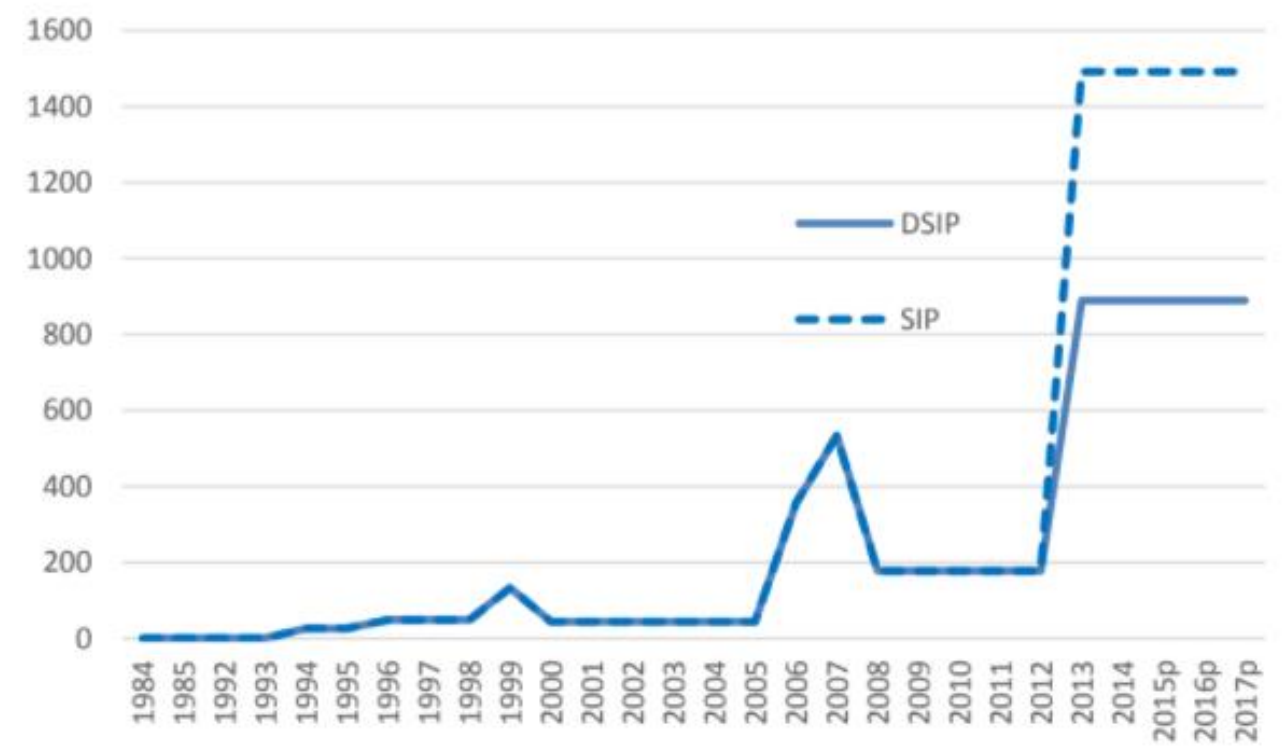

Note: DSIP: Electoral Development Fund from 1984-2005 and DSIP thereafter. SIP includes PSIP and LLGSIP funds as well. 2013 and 2014 are budget figures. 2015 onwards are projected figures. Sources: Ketan (2007), IMF (2013) and budget documents.

Source: DevPolicy website (Howes, Mako et al. 2014)

Data from this figure can be compared with the data in Table 5.2 which shows that there have been a significantly increased amount of funds that have been channelled down to the subnational levels through PSIP, DSIP and LLGSIP. The single most striking observation to emerge from the data comparison was that from 2012 and onwards, there has been a substantial increase in the subnational budgetary allocations compared to previous years in both data sources (Table 5.1 and Figure 5.1). This is seen immediately in a record increase of over K1300.00 million in 2013 
from just K200 million in 2012. This could have been caused by the increased funding of K10 million, an increase of K5 million and additional K500 thousand for the LLGSIP. This significant increase has been commented on by the Development Policy (PEPE, 2015), who said that the LLG Services Improvement Program is supposed to be implemented through the JDPBPC ${ }^{11}$ rather than the LLG Assembly, since there are no clearly established mechanisms for development spending at the LLG level.

Overall, all the tables and figures demonstrates that there is an increased amount of funding down to the subnational levels. It is apparent that the funds are no longer held at the central government agencies such as DNPM or DOT. Also, the budget envelope of the country has been expanding every fiscal year. Whilst the recurrent budget increased, the capital investment concurrently increased. Therefore, discussions in the next chapter is centred on whether or not development financing at the subnational level is effective.

\subsection{Conclusion}

In summary, the results in this chapter set out and highlight three key issues while also presenting optimistic perceptions on the development and aid effectiveness in the country.

In general, over half of those interviewed agree with the statement that the donor's development financing-including coordination, management, implementation of projects and programs-are more successful than the government's own initiatives. This is demonstrated in the PPAP, a flagship project funded by the World Bank.

The most striking result to emerge from the qualitative study is that there is an increased amount of fund going down to the subnational levels. It is apparent that the funds are no longer held at the central government agencies such as DNPM or DOT. Also, the budget envelope of the country has been expanding every fiscal year. Whilst the recurrent budget increased, the capital investment concurrently increased.

Despite the financial and budgeting reforms being in favour of the subnational governments, there seems to be certain institutional issues ever present. When

\footnotetext{
11 JDPBPC- the Joint District Planning Budget Priorities Committee (JDPBPC) is the decision-making body for the DSIP. It is chaired by the MP of the district (or electorate) and also includes LLG presidents and community members. The District Administrator is the CEO of the JDPBPC. District officials are responsible for informing schools and health facilities about allocations made, as well as implementation plans.
} 
assessing development ownership and aid effectiveness critically at the subnational level, these issues or challenges can be categorically presented in threefold terms.

Firstly, there is lack of leadership and coordination at all levels of government. Poor leadership denotes lack of effective institutional coordination at the central government level as well as at the subnational level. This includes donor coordination and improving working relationships with the subnational governments.

Secondly, decision making, necessary for participatory and inclusive development, is not democratic and transparent, particularly at the subnational levels (LLGs). Results have shown that the donor to government or government to government agencies working relationships, particularly in making policy decisions, were moderately satisfactory. However, provinces and particularly the LLGs have less or sometimes no say in designing budgeting and planning priorities. To some extent, LLGs have less awareness of what is happening at the national level.

And thirdly, capacity issues are experienced at all levels of government. Capacity issues were twofold stemming from a lack of both (1) human resources and (2) financial resources. Experiences have differed from province to province, though sometimes both issues are being faced concurrently. Although there has been adequate funding trickling down to the provinces and districts through PSIP, DSIP, LLGSIP and development support grants, the subnational governments are continuing to punch below their weights due to a lack of skilled people. In other experiences, there were some trainings given by donors, but the issue of lack of access to finance to utilise the skills being taught was shown to be a struggle for people at the subnational levels. Such shows that that is no empowerment at the subnational level.

Despite these negative results, there were some positive comments about donors' efforts to improve coordination with the government agencies and build capacities at the subnational level. Particularly, the donor practice of having effectively engineered consultative dialogues and other governance mechanisms with both the national and lower levels of government received positive feedback, including notes that this led to delivery of successful projects.

Furthermore, alignment of policies and development priorities is key for development effectiveness, a proposition alluded to by almost all interviewees. Whilst a minority mentioned that the donors' governance structures were too stringent and 
cumbersome, almost all agreed that such leads to good governance and successful implementation of programs and projects. Such praises and applause signal important lessons to be learned by the government in its employment of development financing modality.

And finally, almost all participants from donor groups remarked how the government could be institutionalizing some of the best practices used by the donors. At some instances, few comments were made by government agencies on using some of the models used by donor funded projects to be adopted to implement PIP or capital investment programs. And of course, there were positive response to this proposition.

The next chapter of this study will discuss the key findings in a more analytical approach to assess whether or not subnational governments have a fair deal in aid and development effectiveness efforts. It will be interesting to see if there are distinctive correlations between the findings and the literatures that this study has examined for the purpose of assessing and analyzing development ownership in a decentralised system of government, such as in the case of PNG. 


\section{DISCUSSION: OWNERSHIP IN PRACTICE IN PNG}

\subsection{Introduction}

This chapter gives a detailed discussion of the findings of the study. The study was designed to determine the effect of development ownership at the lower levels of government. The chapter is divided into two parts. The first part is concerned with data interpretation and identifies correlations, patterns and relationships among the data collected in regards to PNG's commitment to aid effectiveness. The discussions will be centred on PNG's commitment to aid effectiveness, making reference to aid effectiveness principles, and localization of aid effectiveness efforts (Madang Plan, Kavieng Declaration and the Development Cooperation Policy 20182022). Specifically, this section will discuss the five principles of the Paris Declaration on aid effectiveness - ownership, alignment, harmonization, managing for result and mutual accountability.

The second section of the chapter is concerned with leadership and development coordination. This section is further divided into four themes, which focus on institutional coordination, leadership in aid politics and aid coordination, coordination of policies versus procedures and practices, and donor strategy coordination and national development programs. The third section of this chapter discusses the decentralization and development of PNG. Decentralization remains key theme for this study. However, discussions will not focus on the overall architecture of the decentralization policy. Rather, it looks at the impacts decentralization has on the decision space relating to aid effectiveness at the lower levels of government. This section is divided into three subsections. Firstly, it discusses the decentralization and aid effectiveness; secondly, it discusses grassroots participation and decision making in development; and thirdly, some discussion will be made on decision making at the lower levels of government.

A brief summary of the discussions will be presented towards the end of the chapter. 


\subsection{Interpretation of Results}

The primary objective of this section is to identify patterns and relationships among the data regarding aid ownership. The discussion in this section derives from interpretation of both qualitative and quantitative data.

\subsubsection{PNG's Commitment to Aid Effectiveness}

At the outset, the issues and politics of aid at the national and regional level are linked to the issue of sovereignty. PNG has been an aid-dependent country since independence and there are many views questioning the sovereignty of the state. This is not only the test of the economic and political strength of PNG, but other smaller neighbouring countries in the Pacific who recognise the value of aid for incomes and welfare but also the link between aid and dependency. This approach was argued by Overton et al. (2018), that the issue of aid is inextricably linked to the question of sovereignty. Greater levels of aid are often associated with greater limits on the ability of countries to determine and manage their own development. Despite many countries receiving negative and challenging criticism from donors, multilateral financial instututions and aid specialists, PNG seems to have made some progress in asserting control over its aid and development but still has more room for improvement.

An initial objective of this project was to identify whether or not development ownership is effective at the subnational levels of the government of Papua New Guinea. Findings have indicated that there has been progress made since the joint commitment to localise the Paris principles on aid effectiveness through the adoption of Kavieng Declaration. Generally, in spite of the fact that certain commitments to aid effectiveness were made, such as localization through the Kavieng Declaration and formulation of the Development Cooperation Policy 2018-2022, ODA management and coordination in PNG has never been effectively strengthened and improved at the subnational level. Although they do not actively participate in the aid negotiations, undoubtedly, subnational institutions are a branch of government and are direct beneficiaries of aid and development.

This study set out with the aim of assessing the importance of development ownership, and it found that the efforts to set development priorities and take leadership in driving 
the development agenda by the national government has been impressive in several respects. Starting from the underlying principles enshrined in the preamble of the national Constitution (the eight goals and directive principles), the government has worked through successive medium term development strategies until Vision 2050 was published in 2009, and this set the higher visionary statements of the country. The country has a broad development framework, from the Vision 2050 to the Strategic Development Plan 2030 and its addendum (Strategy for Responsible Sustainable Development) to Medium Term Development Plans (five year operational plans, in which the national budget is tied to the MTDP deliverables), and other sectoral plans and policies. These indications of country ownership in setting development priorities are encouraging. Mostly in unison, the development partners have aligned their country assistance strategies and country partnership strategies to these wider frameworks. This study notes strong indications from the donors that their aim is to support the government's vision and realization of development.

Another important finding was that the resources from the development partners are to support the government's annual budget and the activities identified in those plans and policies. In other words, the resources from the development partners are to complement the government's effort and to support the national government's budget to fund the country's development priorities and aspirations. Such leadership from the government has been demonstrated in the increased annual budget allocation to development sectors over the last two decades. Nonetheless, development partners have also not reduced their assistance packages. While concerted efforts were made to strengthen and deepen their development assistance, the aid contribution from donors increased and moved to support a variety of aid delivery models. For example, SWAP and budget support were two major funding modalities agreed to be used by almost all donors.

The question of who actually takes charge of the role of aid coordination and management role was raised during the interviews. It was a question that reverberated both from donors and participants from the lower levels of government. This lack of clarity could be attributed to two things. Firstly, the function of aid coordination and management is fragmented. Secondly, the agency(s) that is (are) responsible for this 
function is (are) not doing enough. Among the possible reasons for the latter could be a lack of institutional capacity and leadership.

With respect to the question of who deals with and coordinates foreign aid, the function of aid management, coordination and strengthening of development cooperation between development partners, has been to some extent fragmented, despite the primary responsibility falling under the DNPM. This study has been informed that there are other central agencies who also in some ways deal with foreign aid. For example, DFAT through certain levels plays a part in aid coordination, and DOT also plays certain roles in concessional loans and debt financing. Although the DNPM is the mandatory agency responsible for development cooperation, in practice, grant negotiation and arrangements are done collectively with other agencies. This indicates that there is no central agency in practice who has absolute power and authority to sanction aid negotiation. This can inhibit the ability of the central government to exert effective ownership of its aid and development resources.

However, the most obvious finding to emerge from the analysis pertaining to the function of aid management and coordination is that the country does not have a centralised development assistance database system covering all activities covered by aid assistance. The DOT has their own selective database, whereas DNPM, as well as DFAT, has no data base. Data management plays a significant role in making informed decisions and also assessing various development partners of their activities and performance. A comprehensive and accurate central database would provide quality and timely information for such assessment and other diagnostic studies. This study has seen the need to have a centralised database system located in the DNPM but also accessible to DFAT and DOT.

Institutional capacity for aid coordination and management was found to be a need in the departments where aid coordination and management roles are instituted. In accordance with the present results, previous studies have demonstrated that recipient countries in the Pacific Islands have small over-stretched bureaucracies and the principle to be able to interact on an equal basis with donor countries is an illusion (Overton et al., 2018). This is particularly the case for small island nations and territories, and we might expect that, due to PNG's large size and natural resources, that it would have better bureaucratic systems and capacity to deal with donors. 
However, this study found that PNG also faces significant capacity constraints. Given the large country portfolios of, for example ABD and World Bank, mission coordination, reporting, and monitoring and evaluations of programs and projects become increasingly challenging for PNG institutions to engage with effectively. Intrinsically this is a primary role of the government agencies. For example, DNPM, is to formulate and coordinate development plans, be the custodian of the development budget and coordinate development cooperation. What is striking to note is that the government's Public Investment Programmes (PPI) require the same amount of capacity as donor funded projects and programs.

However, it was a striking observation in this study of such discrepancies that the monitoring and evaluation done on donor funded projects are more effective than the government's PIP M\&Es undertaken by DNPM. A possible explanation for this result may be the lack of adequate institutional capacity. It is obvious that there is still more room for improvement in M\&E as it is the primary function of the DNPM. Such actions would settle several doubts indicated in this study by the participants such as comparison between government and donor-financed projects and the need for information management on how aid is managed and coordinated. It is therefore a further indication of the need to have a separate government authority to take full charge of development cooperation to address such capacity issues.

The following section discusses and contextualize the findings within previous research and theories. This includes PNG's commitment to aid effectiveness. There have been a series of policy dialogues on aid effectiveness to localise, modernise and deepen the development cooperation with the development partners in the country.

\subsubsection{Aid Effectiveness Principles}

The Paris Declaration principles of aid effectiveness continue to remain as key principles in the aid industry worldwide. Country development ownership, alignment of development assistance and priorities with the recipient country takes a central part in country democratization. Harmonization of donor practices, using country systems and processes, and making sure that every penny spent produces results continues to improve the best aid practices. Importantly, the concern for mutual accountability from both donor and recipient country are key for aid effectiveness as far as aid 
governance is concerned. These are collectively the key principles of aid effectiveness. The principles were essentially concerned with improving the effectiveness of aid delivery. In retrospect, the core principles presented a remarkable degree of consensus about what made aid work (Overton et al., 2018). The realization of aid effectiveness at the country level through concerted efforts have been praiseworthy. This study has observed that development ownership by the PNG government through policy reforms, fiscal reforms and leadership particularly at the central government were fairly impressive. The 2008 Kavieng Declaration on Aid Effectiveness presents the fundamentals of PNG's commitment to aid effectiveness. Overall, the country has progressed moderately satisfactorily in all the five key principles, and these are now addressed in turn.

\section{i. Ownership}

An initial objective of the project was to identify development ownership, and that was clearly indicated in PNG. For instance, PNG has made an effort to localise the Paris Declaration principles in its own Kavieng Declaration of 2008 (Government of PNG, 2008). Prior to that was the Madang Plan. The Kavieng document, agreed to by the major donors to PNG, sought to define the principles that were appropriate to the country and spell out how donors and the government of PNG would work together to achieve them.

The government's steps in taking ownership of development were vividly demonstrated when they first localised the Paris principles through the Kavieng Declaration in 2008. The Kavieng Declaration was a succinct communique with development partners and government that basically reaffirmed the Paris Declaration but added localised targets contextualizing the principles of aid effectiveness based on local advantages and needs. Another aspect of leadership on development ownership was shown when the government formulated its first development cooperation policy in 2015 for its commitment to the Paris principles for country ownership of their own development.

However, the results of this study indicate that the ownership at the subnational levels continues to be missing, and this is expressed both in capacity and decision space. PNG DCP needs to be clear and succinct so that the targets and indicators are feasible 
and create room for where the subnational agencies should contribute to the aid effectiveness dialogue. This was further supported by participants who suggested that some improvements need to be made in ODA management, coordination and implementation from the national down to the provinces and districts because this is where much of the actual international assistance is directed. A possible explanation for this might be that the aid coordination and management is fragmented and the capacity to carry out these functions are limited. According to the findings, the management of the aid program at the moment cuts across three agencies (DFAT, DOT and DNPM) and aid coordination is spread among these three central agencies of the government. One of the objectives of the PNG DCP 2018-2022 is to build and strengthen national capacity for the effective delivery and sustainability of development initiatives. This is yet to be seen both at national and subnational levels.

The most obvious finding to emerge from the analysis is that despite the government taking ownership by injecting more money into its annual development budget over the last decade and a half, the effort to unleash the potential of development ownership at the subnational levels is disappointing. Lower levels of government are still disconnected from the top, despite the decentralization policy providing for devolution and de-concentration of powers and functions with clear administrative processes and procedures. However, the increased funding for development does not translate into development at the subnational level. For example, the resource envelope for government has increased significantly and at a higher rate than the donor contribution. Thus, government has put in more money into its development budget, while donor support has increased concurrently but at a relatively lower rate. The total expenditure and net lending from 2008 to 2018 as outlined in the findings chapter above demonstrate this increased spending on development financing. The line graph below (Figure 6.1) illustrates the trend in which the government's development expenditure increased from 2008 to 2013.

Figure 6.1: Donors and GoPNG Contribution towards Development Budget (20072013) 


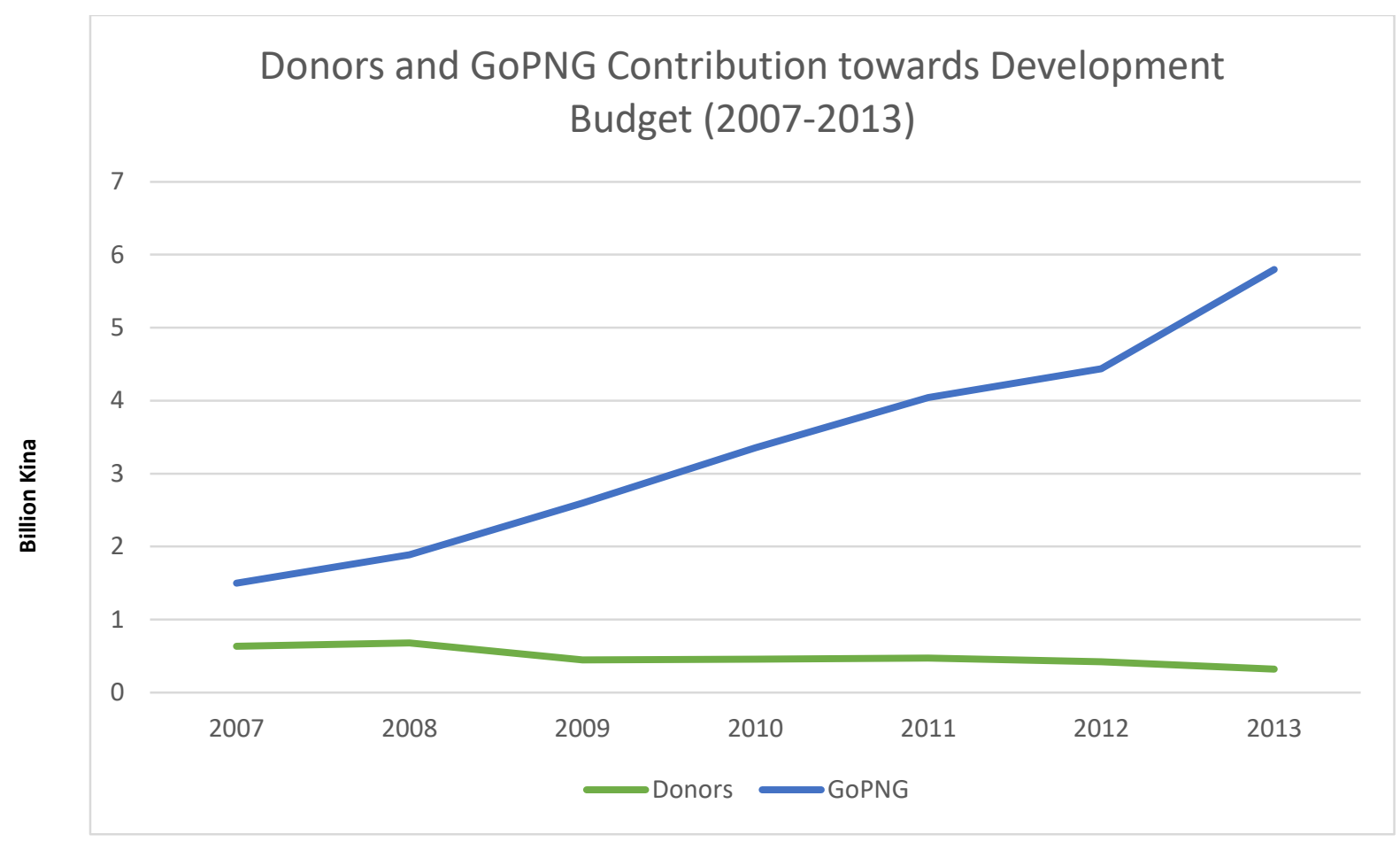

Source: Department of Treasury

Despite the country's effort to increase its development budget, questions remain about how much of this funding reaches the lower levels of government and whether or not the funding spent has translated into tangible development at the local level. Perhaps the national government dictates to the provinces and districts what to fund and how to fund. As such, development ownership at the subnational levels is still a huge task the government needs to improve on.

\section{ii. Alignment}

Alignment of development plans and country assistance strategies from the donors seem to work well. This principle involves donors coming into line with PNG's overall development strategies and systems. The government has taken stock of the country's level of development and put forward a framework for a long-term development strategy- "The Papua New Guinea Vision 2050"-that should map out the future direction for the country and reflect the aspirations of the people of Papua New Guinea. It captures the visionary statements of PNG to build a "smart, fair, wise, healthy and happy nation" (GoPNG, 2010: xv cited in Kaiku, 2020), in 50 years' time. The country's development documents, such as PNG's Development Strategic Plan and the addendum (Strategy for Responsible Sustainable Development or StaRS) have a thirty-year span (PNGDSP, 2010) and are complemented by the Medium Term 
Development Plans (MTDPs), which are the operational plans which detail the country's five-year development plan. The other cascading plans are aligned to the MTDP targets and deliverables. In so doing, together these plans counter the dominance of short term, annual budgets over the allocation of resources. There are sectoral plans and subnational government's development plans (provincial and district development plans) guided by the National Service Delivery Framework, ensuring that it identifies services delivery centres, and categories responsibilities of minimum standards of services from the national level linking down to the provinces, districts and wards. This broad planning framework has provided the basis for donors to align their country partnership strategies to the government's development aspirations.

The donor's country alignment exercises have been effective. A series of country assistance strategies and country partnership strategies from ADB, WB, and other bilateral partners have been developed to assist the government to achieve its development aspirations. Australia, as the largest donor, has also recognised the importance of these development planning frameworks. All these assistance strategies have aligned well with the higher development priorities enshrined in various cascading development policies, plans, and strategies of the government. Such have ensured the development to transpire and to see people actually thriving.

However, it is an undeniable reality that donors are still the gatekeepers of their resources even if they align with the broad strategic framework. This can impose unnecessary delays particularly on loan financed projects and programs, incurring an increasing amount of commitment charge on the part of the borrower. This study supports evidence from previous observations (Murray \& Overton, 2011; Overton et al., 2018) on the 'process conditionality' where donors continue to demand close attention to external reporting and compliance processes that impose burdens and delays on local government agencies. So high level alignment of donors with local strategic directions may be matched by the reality of local alignment with donor systems. This issue is of particular concern in small Pacific Island states where the small size of government is coupled with increasing demands from donors for consultation, accountability and engagement to create what Overton et al. (2018) argue is an 'inverse sovereignty' effect: despite the rhetoric of ownership and 
independence, recipient states are actually losing control over their development strategies, policies and programs. Again, although PNG is larger than all other Pacific states, this study has observed similar levels of reverse alignment in practice as donors impose high levels of compliance.

\section{iii. Harmonization}

Harmonization refers to the goal of having donors working together more efficiently by using common systems and joint activities to avoid duplication, complexity and competition. In the Kavieng Declaration, both government and development partners agreed to implement common arrangements and simplify their processes and procedures. There are other recent reforms that contribute to the ease of doing business in the aid industry in a harmonizing way. Some of these successful reforms include analytical studies by donors, portfolio reviews, the use of diagnostic reviews (such as Public Expenditure \& Financial Accountability and Country Procurement Assessment Reports), and using a whole of government approach in the development framework. Several milestones have been achieved, for instance, cutting down cumbersome and lengthy procurement processes by the creation of a more robust system, the National Procurement Commission (NPC), while doing away with the Central Supplies and Tenders Board.

In addition, as mentioned in the literature review, the government has outsourced the auditing for all donor fund projects to private firms, and introduced the Public Expenditure \& Financial Accountability (PEFA) assessments. The formulation of the PEFA Roadmap and the subsequent PEFA Assessment Report have progressed the process of having a strengthened government system supported by the strategic Medium Term Development Plan 3 (MTDP III) and the PNG Development Cooperation Policy (DCP) 2018-2022. These are intended to give confidence to donors that the government is increasing its efforts to achieve aid and development effectiveness.

However, the current study found that there are certain donors that have a dominant voice in the aid industry in PNG. For instance, Australia continues to dominate in almost every sector and lead in bilateral donor contributions towards the government's national budget (see Figure 6.2). The graph shows the trends in donor assistance by donor, aggregating the support from donors who provide both grants and loans 
support to GoPNG. Overall, significant increases have occurred across ADB, World Bank, Japan and the UN from 2007 to 2013, with the largest increase from the ADB from K123 million in 2007 to K423 million in 2013, signifying an increase in support (particularly in concessional loans) of $244 \%$. AusAID's grant support has remained fairly stable from 2007 to 2013 , but with NZAID, grant assistance was fairly stable and increased slightly between 2007 to 2010 until 2011 when assistance decreased from K65 million to K38 million in 2013. The EU has experienced the largest decrease since 2008 by K179 million, predominantly as a result of the Global Financial Crisis. Grant and loan support have experienced a decrease from 2011, partly as a result of the Global Financial Crisis, but also due to the changing nature of development support from the PRC via the Exim Bank loan signed in 2013, which has not been captured in the graph.

Figure 6.2. Trend in Donor Funding to GoPNG 2007-2013

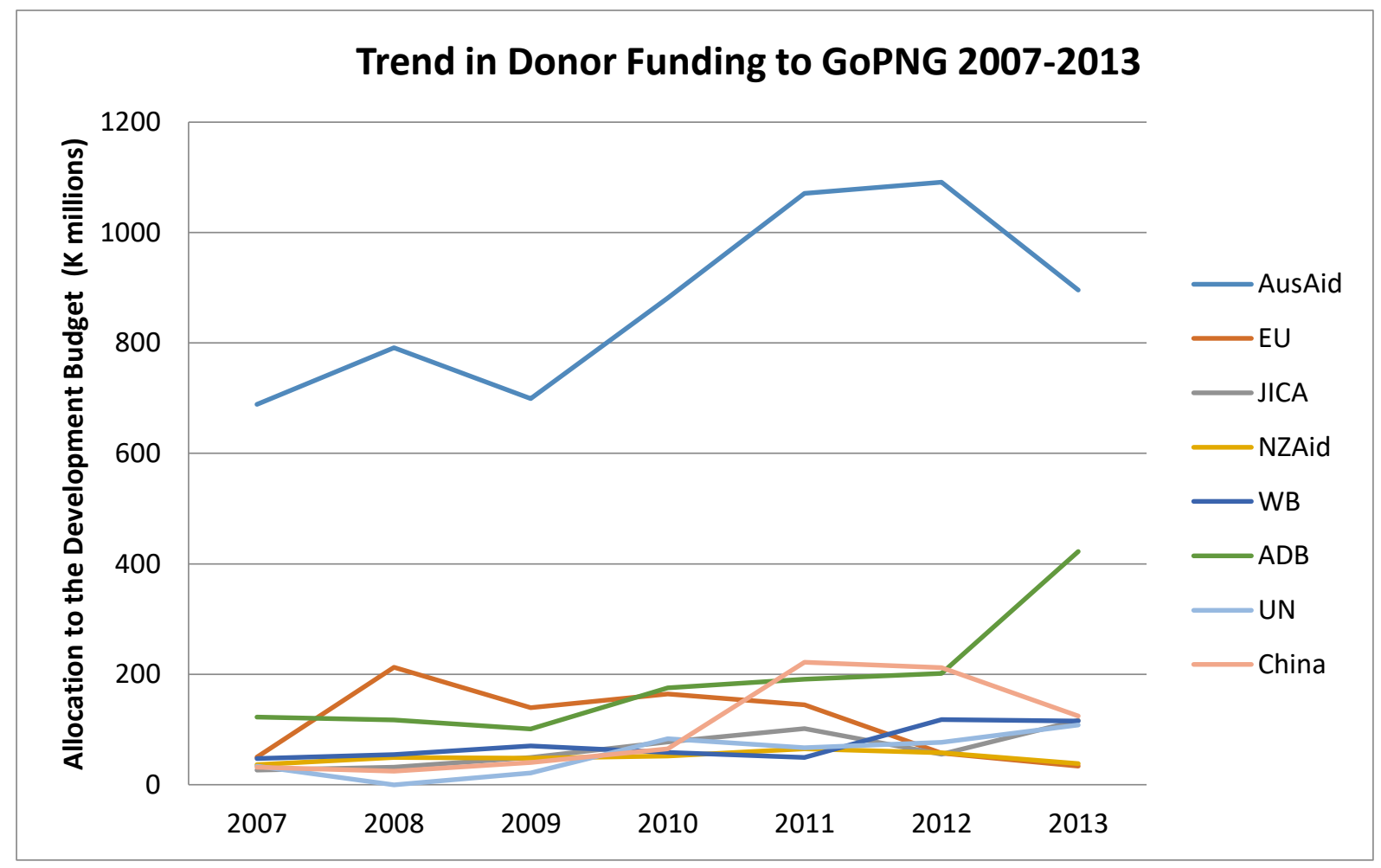

Source: Department of National Planning and Monitoring

It is evident that Australia is certainly the dominant party in the donor community, and this makes donor harmony across diverse systems more problematic. There are arguments from the government that there are still more efforts to be made on 
agreement on different aid modalities. PNG would like greater use of higher-order modalities such as SWaPs and general budget support but this seems to be slowed in practice by reluctance on the part of some donors. It seems that donors are comfortable operating in certain areas where there is ease of doing business for them but less so when they lose some control over aid disbursement. Enhanced donor harmonization requires a more united voice and coordination of operations both vertically (with PNG government institutions) and horizontally (across all donors).

\section{iv. Managing for results}

When the Paris principles of aid effectiveness were localised through the joint Kavieng Declaration in 2008, managing resources and improving decision making for results required certain key activities. This included developing a results-oriented performance assessment framework and assessment of donor country strategies, programs and resources. This is to ensure that every dollar spent on development initiatives must produce results - results that are measurable and visible.

The present reforms and continued efforts of aligning development priorities through various country assistance strategies and country assistance partnership has the ambition to contribute towards aid effectiveness. The reforms also demonstrated in having effective governance mechanisms for aid funded projects such as establishing project management units, aid coordination units, and having effective reporting and accounting formats ensuring every dollar spent is not wasted or misappropriated.

However, certain results have not yet been fully achieved. For example, there are still more efforts needed to institute a results-oriented performance assessment framework, and importantly, assessment of donors' country strategies, programs and resources. The latter has been one of the recurring concerns raised by participants from the donor's circle, who indicated that they too need to be assessed and presented an independent performance report from the government on their effectiveness. It seems possible that these results are due to lack of certain aspects. For example, lack of government leadership at the central level is a pressing concern. Inefficient human and financial capacity from the key government agencies who liaise directly with the donors, for tasks such as having independent project appraisals, and conducting independent monitoring and evaluation forms part of the issues contributing to aid 
ineffectiveness. This lack of keeping and owning of a development assistance data base and, importantly, sluggish implementation of the DCP are additional issues that need to be rectified.

One unanticipated finding was that there were suggestions to adopt the donor's PMU model in government's PIP programs. This project delivery mechanism has never been practised elsewhere in the country. Perhaps there are specific project management approaches for every project. However, the governance structure, implementation mechanisms, reporting and accounting systems are quite different from the donors. That is why donor projects seem to be managed and delivered well despite sustainability issues due to lack of government ownership. A good number of participants in this study have raised concerns regarding governance issues in all government-financed projects. And that remains undisputed, unless and until the government has good delivery models and governance structures to rely on.

\section{v. Mutual Accountability}

The objective of donors, Government of PNG and other stakeholders being jointly accountable for aid effectiveness was echoed in the Kavieng Declaration. The need to have annual reviews (Country Portfolio review meetings), and fielding implementation support missions were agreed for mutual accountability. Agreement on having multi-year financing and multi-year expenditure marked an improvement on both sides. Such has been demonstrated in the ADB's Multi-Tranche Financing Facility for Civil Aviation Development Project (tranche one to three), and the Highlands Regional Road Improvement Program.

This study has been unable to demonstrate clearly whether mutual accountability on the part of government is weak or strong. However, certain efforts have been undertaken to strengthen their part in ensuring accountability. Such has been indicated in the government outsourcing the audits for all the donor funded projects to private firms and introducing the Public Expenditure \& Financial Accountability (PEFA) assessment. The formulation of the PEFA Roadmap and the subsequent PEFA Assessment Report have progressed the process of having a strengthened government system supported by the strategic Medium Term Development Plan 3 (MTDP III) and the PNG Development Cooperation Policy (DCP) 2018-2022. These 
are intended to give confidence to donors that the government is increasing its efforts to achieve aid and development effectiveness.

In summary, the aid effectiveness principles of the Paris Declaration of 2005, reworked and localised through the Kavieng Declaration of 2008, has had a major impact on the management of aid in PNG. We have seen some notable signs of progress guided by these principles. There are stronger signs of ownership by the PNG government, particularly at the wider strategic level, and there are promising indications that forms of alignment and harmonization are being improved. However, on the other hand, there are also indications that these principles are being held back in other areas. Decentralization of aid management and ownership has been limited and donor alignment and harmonization has not been strong at the local and operational levels. Overall though, improvement has been achieved and will continue if effective local leadership is strengthened.

\subsection{Development Leadership and Coordination}

\subsubsection{Institutional Aid Coordination}

The need to improve and enhance aid coordination has become a recurrent theme in the discussions and strategic thinking of national and international aid agencies. The Paris Declaration (2005) and the Accra Agenda for Action (2008) thus mentioned aid coordination as one of the key mechanisms to be mobilised with a view of enhancing aid effectiveness. The signatories, indeed, made a commitment to eliminate duplication of efforts and rationalise donor activities so that they become as costeffective as possible. Furthermore, aid coordination has subsequently become a key dimension in the operationalization of the partnership concept. In a similar fashion, there was an equal call for institutional aid coordination within the government and the recipient country to take ownership of their development to further aid effectiveness and development ownership.

Very little was found in the literature on the question of whether or not the aid coordination within the government was effective, although one study in the Pacific (Overton et al., 2018) has pointed to the success of Samoa in this regard. Samoa has been able not only to put in place clear institutions and policies but also exert a strong 
set of day-to-day practices and attitudes that have allowed the country to keep firm control over development and aid planning and implementation. Elsewhere, there has been little in the literature analyzing partnerships in aid coordination. However, it is worth sharing the experiences of Norway as a donor prior to the call for aid effectiveness in Paris. Instead of partnership, Norway has used a recipient responsibility concept to underline the need for donors to retreat and have donor coordination subordinated to recipient priorities (Disch, 1999). This came about when the donors previously had developed a mentality of letting donors make the real decisions when it came to the utilization of external financing. There were three things that are worth taking note of from the Norway case: (i) aid must be structured so that it acts as a supplement to local efforts; (ii) the division of labour of roles and responsibilities must be clear; and (iii) skills and institutional capacity are fundamental prerequisites for developing countries taking responsibility of their own development. Such actions demonstrated a robust approach to development ownership by aligning their efforts for aid coordination.

The Kavieng Declaration reaffirmed this approach per the Paris Declaration's second principle of aid effectiveness by the call for alignment with PNG's efforts to aid effectiveness. Such has been clearly demonstrated in the establishment of PNG's Transport Sector Coordination, Monitoring and Implementation Committee, the donor round table meeting, and Annual Country Portfolio Review Meetings.

PNG's aid coordination, both across government agencies and donor coordination, needs more strengthening and deepening. The lack of effective aid coordination could be related to providing solid leadership at both national and subnational levels. The leadership provided in donor coordination has been improved to some extent due to the fact the donors know their roles in adhering to country systems and processes. This improvement could be related to the fact that the donors are also the custodians of the high level aid effectiveness principles and others including Agenda 2030. These principles declare that it is the donor's equal duty to ensure that they coordinate and liaise well with the government, the executing agencies and other stakeholders. However, the weakness that needs to be addressed is coordination among the government agencies. The executing agencies and other agencies that are party to any donor project must act in accord and be aware of what is happening in their sector 
and what is required from them. The government's call for a Whole of Government Approach in development must encompasses this in the field of aid and development. Deepening coordination across government agencies and donors entail using improved templates for information collection, data management, and building capacity for aid coordination and management in all levels of government (National, Provincial, Districts and LLGs).

Prior studies have noted the importance of assessing whether the country's donors have increasingly specialised and better coordinated their aid activities at the district and sector level. This included a study on aid fragmentation and donor coordination in Uganda (Nunnenkamp et al., 2016). This study revealed that over the period 2006-2013, aid from most major donors in Uganda became more fragmented and the duplication of aid efforts increased. There is tentative evidence that donors were more active in poorer parts of the country, which would provide some justification for clustered aid activities. PNG had a similar experience in the same period until localization of the Paris Declaration through the Kavieng Declaration and Development Cooperation Policy 2018-2022. As seen from participant interviews, coordination at the subnational level has been weak.

In most instances, the donor programs are dictated from the central government and the provinces and districts have little or sometimes no say. Such practices have given birth to serval recurring issues. Firstly, the programs and projects are not in line with the policy and development priorities of the subnational governments. Secondly, there is no ownership in terms of country funding either in cash or in-kind contribution from the host provinces and districts. And finally, where there is lack of ownership, the sustainability of projects and programs is compromised.

\subsubsection{Leadership: Aid Politics and Aid Coordination}

The politics around aid coordination and management in PNG is nothing new to that of other countries' experiences. Successful aid coordination demands structural changes to resource flows - in particular that central agencies take on a robust coordinating role. It is important to address issues such as disparity of resource allocation. There is a wider perception that certain donors are concentrating on a particular region while others are missing out on donor programs. Such denotes 
inequalities of donor resource allocations. This discrepancy could be attributed to lack of effective aid coordination both from the political level and bureaucratic level. Understanding the politics of aid coordination is therefore as important as understanding the economics of it (Disch, 1999). Where there is stronger political will the efficacy of coordination is evident. Effective and independent aid coordination is lacking at the central government level in PNG. The reason for this is not clear but it may have something to do with leadership at the central government level. The government must improve its governance and address scarce human capital if aid and development effectiveness is to be achieved.

Moreover, the findings in this study demonstrated that leadership at the central government level is key. The subnational agencies have less say in development planning, policy priorities and even national budget appropriation. In particular, the LLG councils and wards seem to drift away from what is happening at the national level. They do not know what the development priorities are in their district, province and country as a whole. The LLGs seem to be a completely isolated branch of the government. Clearly, the channel of communication between the national and the lower levels of government needs to be more effective.

Given evidence of poor leadership at the subnational level, national government leadership for development ownership is paramount. For example, the subnational levels should be able to look for leadership from the central government for policy guidance, monitoring and evaluation of aid and development financing including PIPs. This is to ensure that the donors are not duplicating roles and investments, rather allocating donors based on their comparative advantages. Also, strong leadership would minimise disparity of resource allocation on smaller projects, while appraising and evaluating donor performance are fundamental for development ownership. Donors seem to provide project performance appraisals on a project basis, but there is no performance appraisal from the government of the donors. It is difficult to explain this result, but again, it might be related to lack of leadership in coordination. There must be some level of leadership from the government in assessing each donor based on their current portfolios and their investments.

When there is weak central government leadership in terms of coordination, management and administration of public policy, development financing and human 
resources, the negative effects trickle down to the subnational levels. That is where subnational agencies have little or no room to participate in decision making but only act as an end receiver of the programs and projects. There are two likely issues to stem from this: lack of sustainability of the projects and programs and no ownership of the development initiatives from the local government and the project beneficiaries.

\subsubsection{Coordination of Policies versus Procedures and Practices}

Some of the issues emerging from this finding relate specifically to competition between coordination of policies versus procedures and practices. PNG has experienced a number of cases where the country tends to have good development policies, but the models and practices of implementing projects and programs have failed. Such has been demonstrated in the National Agriculture Development Plan and its implementation, and the World Bank's Small Holder Agriculture Development Project. The former was a government-led policy initiative and the latter was a donordriven project. The latter lacked institutional coordination from the government, while the former lacked best practices and implementation models to achieve policy objectives. As a result, there was another project funded by the World Bank which became a flagship project for the country: The Productive Partnership in Agricultural Project. The practices and model of this project became a blueprint for the agriculture sector. However, the challenging task is for the government to adopt and institutionalise the best practices into the mainstream service delivery architecture. That is something not within the jurisdiction of the projects, rather with the government and its sector institutions.

Moreover, the real disagreements tend to appear with regard to procedures and practices. According to Disch (1999), coordination of policies may not be so important, however, since it is relatively easy to reach agreement on policies and priorities. It is at this level, therefore, that coordination gains are potentially the greatest, since differences in how activities are to be implemented generate enormous administrative and transactional costs to both donors and recipients. Establishing a program for identifying "best practices" at this level would seem to be important.

As mentioned in the literature review, partnering with donors to adopt best practice to achieve aid and development effectiveness is crucial. Such has been demonstrated in 
Uganda's leading example of the successes of new approaches to partnership in one of the projects in the education sector (Higgins \& Rwanyange, 2005). What is interesting in this case was the local experiences of planning for education change which both government and donor funds support in the Poverty Eradication Action Plan (PEAP) through a sector wide approach (SWAP) of financing aid modality. Uganda's successful exemplification of adopting a SWAP in the local government and political structure is worth noting in the efforts of aid effectiveness. It is also widely acknowledged that ownership of developments or reforms entails robust engagement and participation by those involved in implementation.

However, the reality of aid turns out to be somewhat different in PNG. The study found that donors are reluctant to pass on their resources to the recipient, despite relaxation of policy conditionality by donors which shaped the neoliberal era of the 1980s and 1990s. What transpired after the adoption and localization of alignment and harmonization principles of Paris Declaration, is what Overton et al. (2018) have coined "process conditionality". The donors ensure that the plans, systems, and audits conform to international standards and templates to make the global aid system consistent, workable and understandable. This result may be explained by the fact that the country governance systems and processes are not fully trusted.

\subsubsection{Donor Strategy Coordination and National Development Programs}

The Kavieng Declaration calls for very clear donor alignment processes. Practically, the development of country assistance strategies and country partnership strategies are aligned to the government's development aspirations enshrined in the national development plans and strategies and other cascading sectoral plans and policies. Experiences have suggested repeatedly that if there is no coherent government development program and strategy in place, then the donors dictates. Donors cannot substitute for this by coordinating their own strategy processes, but should rather support the government's efforts at developing a credible program. This position was arrived at, for example, in the context of a Mozambique survey (Manning \& Malbrough, 2010). This position is not accepted by all donors, who believe that many recipient governments are not serious about addressing key structural issues and that donor conditionality is still required. Recent studies (Singh, 2004; Montinola, 2010; Molenaers et al., 2015) note the failure of conditionality as a means for attaining policy 
changes, however, and this points to the need for more imaginative and constructive support for recipient-managed strategies.

Several thematic studies (Sobhan, 2009; Booth, 2012; Sjöstedt, 2013) have shown that a core of tension of making country ownership a priority for both donors and recipient countries development ownership, as a fundamental principle for development co-operation. Although all donors are supposed to promote partner country ownership, harmonise their efforts with other donors, and align themselves with partner country priorities, results-based management simultaneously implies a focus on continuously measuring and reporting results. Ownership is therefore complex in practice. PNG has donor consultations on a regular basis to ensure country partnership strategies and country assistance strategies contribute effectively to the development of the country. Donor prioritization of aligning their country assistance with the government has been progressing well. Such has been demonstrated through donor round table meetings, annual country portfolio review meetings, sector consultation meetings and many other diagnostic studies undertaken by the World Bank and ADB to identify policy and development gaps in which information could be made available for policy and financing undertakings by development partners.

Figure 6.3: Standard PSIP and DSIP allocation

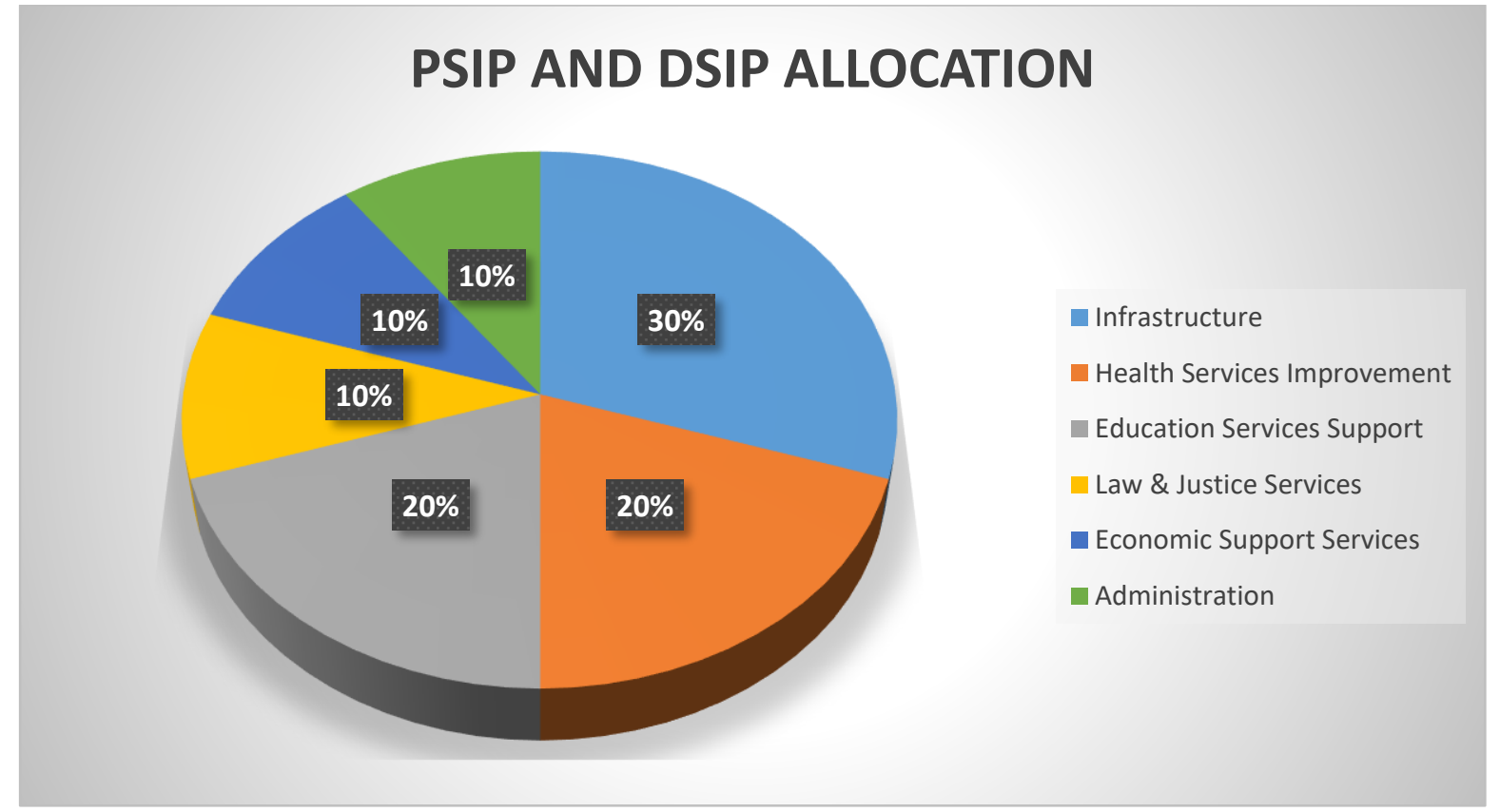


The above pie chart demonstrates the sector allocation of the funding given to the subnational levels. Allocation per province is $\mathrm{K} 5$ million multiplied by the number of districts in the province (Example: Enga Province $-\mathrm{K} 5$ million $\times 5$ districts $=\mathrm{K} 25$ million), and the districts are given K10.0 million per year. Of this $\mathrm{K} 10.0$ million, 30 percent of the funds are allocated to infrastructure, 20 percent to health service improvement, another 20 percent allocated to education services improvement, and the rest, 30 percent, are equally shared among law and justices, economic and administrative services.

This study received critical questions from the participants asking whether the national government is really ensuring the DSIPs and PSIPs are actually implemented according to their guidelines, and importantly whether they are monitored and evaluated. Experiences have shown that the PSIPs and DSIP funds tend to be more political and those district MPs and provincial governors have more control over these funds deciding where, how and what to spend them on. The question that any ordinary citizen would ask is whether or not the actual percentage for health sector is given when the health services are deteriorating in the district. The same applies to other sectors when the districts and provinces are not operating effectively.

Furthermore, the study received concerning suggestions of whether or not the government should adopt donor best practices for implementing PSIPs and DSIPS, and most importantly the PIP. The PIP funds also have similar governance issues with the central government. Certain donors and even the DNPM suggested that it is possible to adopt certain governance mechanisms and practices of the donors into the PIP Programs. The PIPs are the deliverables of the Medium Term Development Plans and sector plans of the national government. These are high impact projects and programs that contribute towards achieving higher policy and development goals. These findings suggest that there is energy and determination to adopt certain donor practices, but they must emanate officially from the top management.

\footnotetext{
${ }^{12}$ DSIP and PSIP handbook has clear guidelines on the sector allocations of the funds. The Department of Rural and Implementation take charge of the reporting and ensuring that the DSIPs and PSIPs are put to good use according to the guidelines.
} 
The most important relevant finding which was echoed by both donors and government agencies is the difference between donors' governance mechanisms and delivery models with those that govern the government's PIP. It was intriguing to note that there were genuine concerns and concerted suggestions made that PIPs to certain extent should adopt some of the donor's governance mechanisms and delivery models. It was certain from the interviewees that if such approaches were undertaken, we would see some tangible development outcomes and better development effectiveness would be achieved. This result might be related to a call for institutionalizing Project Management Unit and Project Steering Committee which form part of the governance structure on all PIPs. Appealing evidences suggest that those countries who consolidate lessons and institutionalise best practices tend to improve on aid and development effectiveness. Despite this, there were concerns from the participants that the government should not adopt and accept every practice and model from the donors.

\subsection{Decentralization and Development Ownership}

\subsubsection{Decentralization and Aid Effectiveness.}

Decentralization has been a key policy priority in PNG in the last two decades. As governance is a matter of concern, decentralization takes a central place in development effectiveness discussions. As a matter of definition, decentralised systems are those in which central entities play a lesser role in favour of local and regional ones (Schneider, 2003). Decentralization is often advocated as a method of increasing the efficiency and responsiveness of government programs and enhancing citizen participation (Kewa et al., 1995), and it is viewed as a way to make government more responsive and efficient (Bardhan, 2002).

PNG has 22 provinces ranging in population from 30,000 to 370,000 , each with an elected legislative assembly and a public service administration. Elected government below the provincial level consists of local government councils which have limited powers over municipal activities. The process of transition from a centralised to a decentralised authority has resulted in a combination of provincial, and national government powers. 
Prior studies that have noted the importance of aid ownership and how aid resources have been effective in a decentralised political structure as is the case of Ethiopia. Furtado and Smith (2007) did an analysis of aid, ownership and sovereignty in Ethiopia, in which several attributes of Ethiopian systems were identified that make it different from other donor recipients and also influence the flow of donor-government and government-donor relationships. One of the interesting attributes in this literature which makes the country different from others is the federal system, under which seven regional states have a greater deal of autonomy for delivering services such as health, education, water supply, and transport services. These are the sectors where more activities are financed through aid resources; primarily, the budget is transferred in the form of block grants (Furtado \& Smith 2007). The administration and governance become highly decentralised while the policy and decision making were centralised.

What is worth noting in this literature is that the central function of aid management and coordination has been transferred to the municipal states, in which aid resources are directly managed by the autonomous government structure, while in many other cases including PNG, the function is still with the central government. An interesting part of donor coordination was that the government did not want anyone to dictate their development planning and financing efforts, rather it drives its own development agenda with limited donor influence over development prioritization which makes Ethiopia realise their development aspirations. This means there is a more domestically-owned agenda or a state-centred view of development.

PNG, therefore, could learn from these examples in its decentralization strategies, but, as we have seen, effective decentralization of aid management has not occurred.

\subsubsection{Grassroots participation and decision making in development}

This study has been interested in grassroots participation which refers to local level governments, civil society, women's groups and churches who are very close to the people. In other words, these are local authorities and interest groups that are dealing directly with projects, or they are the direct beneficiaries. Participants have raised sentiments that sometimes they are not invited to participate in ward development planning and other aspects of a project management cycle, in particular those LLGs which lack access to information and awareness of what is expected of them. In spite 
of the fact that they are the focus for development, grassroots participation in development planning and financing is minimal. The possible reasons for this could be lack of empowerment to participate, lack of capacity to participate, and obviously political differences affecting the community.

A notable study has confirmed that international development (ID) projects carried out by Non-Governmental Organizations (NGOs) and donors are considered one of the pillars for providing assistance to developing countries, but these projects are reported to have high failure rates and their performance is often considered not satisfactory (Golini et al., 2015). However, some researchers have started to consider project management $(\mathrm{PM})$ practices as a possible remedy for the poor performance of development projects. This is achieved by donor proliferation of certain project delivery mechanisms that are relevant and effective in operation (Golini et al., 2015; Gulrajani \& Swiss, 2019).

One of the important questions in the field of development is "whose development' are we pursuing (Chambers, 1997)? Who is really going to benefit from the programs and projects? In most cases it is the grassroots level that are at the centre of any discussions for development. However, the rural areas of Papua New Guinea continue to struggle on a daily basis to have access to better health care, basic education and engage in business opportunities to sustain them economically. Such aspirations are suppressed and high hopes for development are not realised. The intent of the decentralization policy was to bring the government closer to the people, but in reality, their voices are not heard.

Previous studies evaluating 'whose development' have highlighted some of the intellectual constructs (Crewe \& Harrison, 1998) that have gained prominence in the diverse institutions of development. These studies provided insights on a participatory approach to development (Cornwall, 2003), local resistance (Coumans, 2011) to development, questioning development ownership and other ethnographical experiences (Mohanty, 2017). Cornwall's study on a participatory development approach provides an in-depth look at efforts to promote participation in projects, programs and policy consultation. These efforts appear to offer everyone who has a stake a voice and a choice, as development matters to them. But this communitydriven development, participatory planning and other fine-sounding initiatives that 
make claims of "full participation" and "empowerment" can turn out to be driven by particular interests, leaving the least powerful without voice or much in the way of choice. Such needs to be seen at the lower levels of government in PNG. One of the many criticisms of decentralization in PNG is that despite having a system of decentralised government, those at the grassroots levels do not see and feel what the government looks like. Everything is happening at the corridors of Waigani and there is lack of community empowerment and actualization of having a decentralised system of government at the lower levels.

If PNG wants to see more than 85 percent of its rural population realise the promise of development, it is about time they listened to their voice through adopting a participatory development approach. When talking about a participatory approach to development in PNG, community empowerment and inclusiveness are key for inclusive growth. PNG's cultural setting provides the basis for having effective clustered groups in which communities can be easily engaged for development processes. When we undermine the potential of how communities are culturally structured, the approach to development remains challenging to this date.

The primary argument in regard to participatory development in PNG is that community/grassroots and lower level government participation in development is still disappointing due to political factions. The traditional and customary leaders who are aligned to the ruling government of the day to some extent have considerable influence in decision making, but political affiliations determine who gets what, when and how. Those who are not politically affiliated are being marginalised in development. Their voices are less likely to be heard. This was a reflection of what is happening everywhere in the country. As stated by Cornwal (2003), participation has become development orthodoxy. 'Holding out the promise of inclusion', of creating spaces for the 'less vocal and powerful to exercise their voices' and begin to gain more 'choices', 'participatory approaches' would appear to offer a lot to those struggling to bring about more 'equitable development'. Experience of this in PNG is quite disappointing. Leadership at the lower levels of government is weak and fragmented, and importantly decentralization is dysfunctional. This echoes the findings from studies elsewhere. For example, a failure to promote community participation in development was observed in Zimbabwe (Sibanda, 2011). In the Danga Ecological Sanitation Project, the 
community was not fully involved and, as a result, the project had poor performance. In the course of this study, political interference in community projects was seen in Zimbabwean rural communities, resulting in the failure to reach the intended beneficiaries. Other experiences in Bolivia, Honduras and Nicaragua revealed problems in implementing the principles. Problems included a lack of participation from civil societies, lack of prioritization between development and economic growth, and limited domestic ownership (Dijkstra, 2011). What is interesting about these studies was that the people-centred approach was chosen as a theoretical background. Again, decentralization without competent state administration and strong leadership is likely to aggravate social fracturing and to foster inequalities while, at the same time, failing to ameliorate public service and economic development (Ozcan, 2006).

Consistent with the literature, communities are treated only as beneficiaries and not as active participants in the whole development project cycle. These issues can be explained in part by the proximity of political differences and capacities. Those who have direct political affiliation with the ruling government have much say in any development happenings in the community, while the opposing political factions have less or even no say in any development planning, funding, and implementation. Nonetheless, capacity issues place mounting burden on non-participation from the communities and lower levels of government. There is lack of information, literacy, and access to government and officers. These shortcomings continue to detract from the effectiveness of decentralization policy at the lower levels of government. Perhaps, full community participation in community projects could ensure that empowerment and ownership take place. Institutional arrangements, which in most cases impede development, need to be readdressed with clear demarcation of decision-making processes.

\subsubsection{Decision making}

On the question of whether or not there is effectiveness of local level government and grassroots participation in decision making, this study found that it was marginal. Participation at lower levels of government and their relationship with other government agencies seemed to be weak. It was also found that less awareness and less engagement with community leaders resulted in wider resistance to development projects at the subnational levels. This study supports similar evidence from previous 
observations (e.g. Dijkstra, 2011) on the experiences of Bolivia, Honduras and Nicaragua, that lack of civil society participation and ownership from lower levels of government amounts to aid and development ineffectiveness. A possible explanation for this might be that due to physical disconnectedness between the government and the public it is complicated to gather stakeholders to participate in decision. This could be fuelled by lack of resources (i.e., information), and human capital to organise and design decision-making models to accommodate public and the hierarchies of government levels to have their say on the issues affecting them.

Accommodating decisions from the public as well as the lower levels of government has been a test of government effectiveness in PNG. Although there may be avenues such as CIMC and other consultative forums convened on policy basis, the voices from the grassroots and lower levels of government are not effectively heard.

\subsection{Conclusion}

PNG's commitment to aid and development effectiveness has been improving since the Kavieng Declaration in 2008. The localization of the Paris Principles of aid effectiveness continues to remain key principles in the aid industry. Country democratization for aid and development ownership, alignment of development assistance and priorities with the recipient country, harmonization of practices and use of country systems and processes, making sure that every dollar spent produces tangible results, and importantly mutual accountability from both donor and recipient country are key for aid effectiveness. The principles were essentially concerned with improving the effectiveness of aid delivery. In retrospect, the core principles presented a remarkable degree of consensus about what made aid work. The 2008 Kavieng Declaration on Aid Effectiveness presents the fundamentals of PNG's commitment to aid effectiveness. The country progressed moderately satisfactory in all of the five key principles. However, there is sufficient room to improve on process conditionality and the selection of aid modality that best fits the needs and advantages of the country.

This project is the first investigation of subnational agencies' participation in aid and development effectiveness in PNG. The study has revealed that aid coordination and management has been progressing well. However, in spite of the fact that certain commitments to aid effectiveness were made, such as localization of the Paris 
Declaration on Aid Effectiveness through the Kavieng Declaration and formulation of Development Cooperation Policy 2018-2022, there is still room for improvement at the subnational levels for effective and efficient ODA management and coordination for aid effectiveness.

There was some evidence of strong leadership shown at the national level. This was indicated in the country having a broader planning framework and having strategic directions for their development. Country democratization on aid and development remains central to this study as issue of politics of aid at the national and regional levels is inextricably linked to sovereignty. In particular, central agencies such as the Department of National Planning and Monitoring has to take on robust leadership in a coordination role across central agencies as well as across donors. Nonetheless, the same is not seen at the subnational levels. Therefore, there is more to be done at the central level to empower and support the central agencies as well as provinces and districts to provide strategic directions and leadership for their own development. When there is weak central government leadership in terms of coordination, management and administration of public policy, development financing and human resources, the negative effects trickle down to the subnational levels.

There is little evidence to show that aid coordination within the government is effective, though the focus of this study is not on aid coordination. This includes agency coordination at the central levels as well as the provinces and districts. The need to improve and enhance aid coordination, which become a recurrent theme in the discussions and strategic thinking of national and international aid agencies, was the main argument throughout the discussion. The donor programs are dictated from the central government, and the provinces and district have less say. Such denotes lack of ownership from the subnational levels, as sustainability issues are evident.

The disappointing experiences of lacking development ownership at the subnational levels continue to undermine the intent of the decentralization policy. Decentralization remains a key theme for this study. However, discussions were not surrounded on the architecture of the policy. Rather the study focused on the impact decentralization makes on the decision space relating to development ownership at the lower levels of government. Grassroots and lower level government participation in development and decision making continues to remain weak and administratively dysfunctional. This 
has resulted in poor leadership and no sense of strategic directions from the relevant subordinates of the government. Of significance to this study is that in all discussions, participants pointed out that participation was not easily seen at the lower levels of government and grassroots level. Politics of the day determines who should have a say in the development business. Those who are on the opposing side have either less or no say at all. 


\section{CONCLUSIONS}

\subsection{Introduction}

This thesis has examined the effectiveness of development assistance in Papua New Guinea, and the findings are in some ways surprising. The Paris Declaration Principles of Aid Effectiveness are still at the centre of aid effectiveness understandings since their launch in 2005. Of these principles, country ownership has come to be regarded as paramount. There are some, however, who see donors continuing to dominate the field of development in recipient countries. To date, research (Higgins and Rwanyange 2005) has been focussed on perceptions of how country ownership is exerted in their approaches, but little research has been done into how ownership is perceived by the lower levels of government. This thesis has examined the subnational levels of government participation in aid effectiveness in Papua New Guinea and how they influence decision making in development at the local level.

The following sections will summarise the main findings of this study. This includes setting out the summary of the country's commitment to aid effectiveness; leadership and development ownership; decentralization and some ethical considerations this study has experienced. There will be a few key recommendations towards the end of this chapter.

\subsection{Summary of main findings}

\subsubsection{PNG's Commitment to Aid Effectiveness}

Generally, aid management and coordination in the country is progressing well. Despite there being some burning concerns regarding the lack of capacity, the lack of an effective database system for accounting and reporting of ODA, and lack of information flow from the central government to the subnational levels, the efforts to assert country ownership of development have been demonstrated vividly through the setting of development plans, localization and adoption of the Paris principles of aid 
effectiveness through the Kavieng Declaration, and the formulation of DCP 20182022.

Each of the Paris principles can be summarized as follows in terms of their adoption in PNG:

Ownership - Country leadership efforts are progressing well in terms of putting in place a broad development framework. Government agencies at the central level and PNG funding for development activities have improved. But leadership and strategic direction at the subnational levels seem to be weak. Funding and information have not flowed well from the center, and there is a lack of coordination. If local ownership is to be improved, there needs to leadership from the top ensuring availability of adequate resources and support to build capacity at the subnational level to better make and implement decisions.

Alignment- Country partnership strategies are aligning well with the government's development priorities enshrined in the Vision 2050, PNGDSP, StaRS, MTDP and other cascading development plans and policies. But the process conditionality of the donors seems to undermine the principles of aid effectiveness. So some donors are still not falling in behind the directions and systems of the government of PNG. This needs to be rectified by building mutual understanding and trust between donors and government.

Harmonization - The harmonization principle has not been strongly followed despite some evidence of improvement in the form of mission coordination and the use of the comparative advantages of respective development partners. Australia continues to have a dominant voice and presence in the country's aid establishment. The harmonization principle calls for a more united voice across all donors.

Principally, there is a need to harmonise donors' operational procedures at the highest level so as to reduce transaction costs and make ODA disbursement and delivery more flexible, taking into account national development needs and objectives of PNG.

Managing for results - There is some evidence suggesting that certain reforms have been undertaken to ensure resources are not wasted. But there is more room for improvement in capacity building at the subnational and central levels of government to improve management and reporting systems. This again requires prudent and 
effective management of aid and development data which is lacking both at national and subnational level for effective and efficient planning, budgeting, accounting, reporting, monitoring and evaluation.

Mutual Accountability - In many respects, aid management has been performing well with donor partners, but the government's own systems and processes need to be improved and trusted. Concerted efforts have been undertaken by both government and development partners to ensure that there is transparency and accountability in aid and development coordination, management and implementation. However, this principle of mutual accountability is focused predominantly at the central level and between donors and the central government, but there is little buy-in from the subnational levels of the government.

Therefore, overall, we can suggest that the government of PNG has been strongly committed to the principles of aid effectiveness and some significant improvements have been made. However, there is still considerable room for improvement, particularly in the way these principles and their day-to-day implementation filter down to provincial, district and local community levels.

\subsubsection{Leadership and Development Ownership}

Leadership at the central level has been moderately satisfactory as indicated in the setting of broader development frameworks and consistent dialogue with the donors through aligning their country assistance strategies, and localization of global aid agenda such as the Kavieng Declaration. But, as with the aid effectiveness principles, little evidence was found at the subnational levels. There has to be more empowerment and capacity building for local leadership and ownership at the subnational levels as these are where actual developments are taking place.

Importantly, in addition to this need to build local level capacity, leadership in aid coordination seems to be fragmented and needs to be more integrated and this has to be reflected clearly on the DCP 2018-2022 when it is being reviewed. The lack of capacity at the central government affects the effectiveness of aid coordination with the donors, and vigorous government-to-government aid and development coordination has been lacking. 
Overwhelmingly, country leadership is demonstrated at the national level with broader development planning and priorities, localization of Paris Declaration on Aid Effectiveness through the Kavieng Declaration, formulation of the DCP 2018-2022. However, there is need for more coordination at the subnational levels, not to be dictated from the top, but through providing clearer strategic direction to the subsidiary levels and agencies to take ownership of their own development as is the intent of the decentralization policy.

\subsubsection{Decentralization and Development}

The issue of decentralization takes a fundamental place in development effectiveness dialogs. The principle of aid ownership and the question of whether aid resources have been used effectively are critical in the decentralised political structure in PNG due to the fact that the lower levels of government do not actively participate in aid effectiveness. While in many countries the central functions of aid management and coordination have been transferred to the regional agencies, in which aid resources are directly managed by the semi-autonomous local government structure, in PNG, these functions still lie with the central government. Although there are some issues regarding the influence of donors over central government, subnational levels of government have little or no influence on the decisions made at the central level. PNG therefore could learn from the example of Ethiopia and others for effective decentralization of aid management to occur for more local ownership of aid and development.

Significantly, lack of capacity at the subnational levels is a burning concern. Subsequent reflections on directive development financing and poor capacity building for effective delivery of aid and development at the subnational levels are some of the key concerning themes. Although some government sectors and agencies and NGOs receive training and human resource development skills for implementing donor initiatives, training and equipping public servants, members of civil societies, NGOs, and church groups at the lower levels remains critical for effective development locally.

Consequently, sustainability of development initiatives is a major concern for development practitioners, aid donors and government workers. The lack of development ownership at the subnational levels clearly indicates there are issues of 
sustainability. As such, some donor projects are seen to be departing with their best practices and experiences after completion without passing on lessons and capacity in the regions they operate. There is no consolidation and institutionalization of best practices by the subnational levels of government.

Moreover, even though decentralization has been occurring, it has been problematic in terms of capacity to exert ownership at the local level. The aim of the present research was to examine subnational participation aid and development effectiveness. On the question of whether or not there is effectiveness at the local level government and grassroots participation in decision making, this study found that it was marginal at best. Participation has become development orthodoxy, holding out the promise of inclusion, of creating spaces for the less vocal and powerful to exercise their voices and begin to gain more choices. Participatory approaches would appear to offer a lot to those struggling to bring about more equitable development, but unfortunately, active participation in development leadership and management at the subnational level has been largely absent.

\subsection{Recommendations}

The findings of this study suggest several courses of action for realizing the full potential of development and aid effectiveness. Although there are current efforts that recognize the importance of ownership, there is room for more improvement. This includes the following four key recommendations.

\subsubsection{Development Cooperation Authority}

A reasonable approach to tackle the leadership and capacity issues could be to set up a Development Cooperation Authority under the Ministry of National Planning. This would address capacity issues for monitoring and evaluation of ODA investments, ensure that the role of aid coordination is centralized and strengthened. Thus, provide strong leadership on aid and development planning, coordination, and management of aid information. This also could pave the way for accommodating other roles the government is playing. For instance, the government is on the path to becoming a strong, effective leader on many issues in the Pacific and has wider leadership aspirations in Asia. A Development Cooperation Authority could accommodate and 
facilitate such external relationships particularly for aid and development, perhaps even with the possibility of PNG itself becoming an aid donor in time.

\subsubsection{Establishment of a PNG Development Assistance Database}

Another important practical recommendation is that the government should establish a Development Assistance Database or to be specific, an Aid Information Management System (AIMS) within DNPM. The government must and should own a modernized AIMS to record all grant aid flows in a fiscal year for the purposes of accounting and reporting. As well as tracking grants, loan information should be included and be consistent with the data kept by the Department of Treasury. Perhaps the database could be synchronized with other key government agencies for policy, planning and budgeting. This is not only to capture inflows of aid resources, it would also be an important tool for assessing and evaluating development resources going down to the subnational levels of the government and quantify in monetary terms how much goes to each province and district. There is, therefore, a definite need for AIMS for effective aid coordination.

\subsubsection{Adoption of PMU and Donor Practices and Procedures on the PIP programs}

Continued efforts are needed to make PIPs more effective and efficient. The key aspect while promoting the adoption of PMU and donor practices and procedures on the PIP programs is governance. Governance issues surrounding the government interventions continue to fail many development projects and programs. The adoption of certain donor practices and process into PIP models would address such issues. This would include effective monitoring and evaluations, with robust project steering committees meeting regularly to ensure there is transparency and accountability, and finally, that projects are delivered as planned and budgeted.

\subsubsection{Independent Donor Assessments}

Greater efforts are needed to ensure independent donor assessment is conducted on their country assistance strategies as well as their performance. This is in consistent with what was agreed upon in the Kavieng Declaration. The management of different donor procedures incurs high costs for PNG. For example, meeting multiple donor requirements employs a significant proportion of PNG's administrative capacity, it 
impairs ownership over partners' own development plans and weakens capacity for effective public management. This is why the government has to undertake independent donor assessment. This could be to set up as a special task force to look at certain things including: assessing how aid can be delivered more effectively through simplifying and harmonizing donor procedures, performance of each donor and their development outcomes, or assessing their comparative advantages and aligning their country assistance strategies. There is, therefore, a definite need for having an independent assessment of all development partners for development and aid effectiveness.

\subsection{Conclusions}

PNG's commitment to aid and development effectiveness has been progressively improving. The Paris Principles of aid effectiveness continues to remain a key feature of the aid industry. The DCP 2018-2022 and the 2008 Kavieng Declaration on Aid Effectiveness present the fundamentals of PNG's commitment to aid effectiveness. The country progressed moderately satisfactorily in all the five key principles. Key to aid effectiveness are the following principles: country leadership for aid and development ownership, alignment of country assistance strategies and priorities with the recipient country, harmonisation of practices and using of country systems and processes, making sure that every dollar spent produces tangible results, and importantly the call for mutual accountability from both donor and recipient country. The principles were essentially concerned with improving the effectiveness of aid delivery and, in retrospect, the core principles present a remarkable degree of consensus about what makes aid work. However, there is little evidence of significant subnational participation in the whole aid effectiveness arena, and they remain passive subsidiaries of the national government.

Robust and prudent leadership at the central level is required for the peripheries to thrive in economic and social development as it is absent at present. When there is a weak central government, the propensity for subnational levels to feel disconnected is evident. Effective coordination both vertically and horizontally needs to be tightened as it is still fragmented.

The primary aim of this study to examine and assess the participation of subnational levels of government in aid effectiveness in a decentralised system of government in 
PNG revealed some important gaps and shortfalls. Evidently, lack of capacity (human resources, finance, and aid and development information) and poor leadership at the subnational levels of government continue to hinder the realisation of the intent of decentralisation policy. Having a modernised database for aid information and management system, setting up a development cooperation authority, adopting donor best practices to implement PIPs and conducting independent assessment on donor performance and their respective country assistance strategies, as recommended by this study, are some ways these issues may be addressed. 
Appendix 1: Consent form

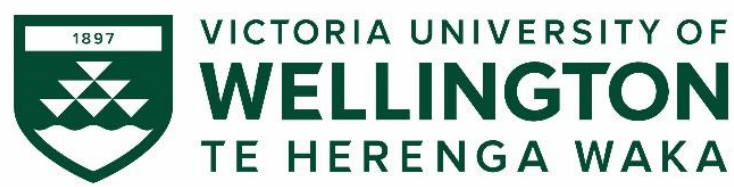

Ownership, Decentralization and Development in Papua New Guinea: Sub National Participation in Aid Effectiveness

\section{CONSENT TO INTERVIEW}

\section{INTERVIEWEE}

This consent form will be held for two (2) years.

Researcher: Edward Kapi, School of Geography, Environment and Earth Sciences, Victoria University of Wellington.

- I have read the Information Sheet and the project has been explained to me. My questions have been answered to my satisfaction. I understand that I can ask further questions at any time.

- $\quad$ I agree to take part in an audio (phone call) recorded interview.

I understand that:

- I may withdraw from this study at any point before $1^{\text {st }}$ of September, 2020 and any information that I have provided will be returned to me or destroyed.

- $\quad$ The identifiable information I have provided will be destroyed by April 2021.

- Any information I provide will be kept confidential to the researcher and the supervisor.

- I understand that the findings may be used for a Master's thesis.

- I understand that the recordings will be kept confidential to the researcher and the supervisor.

- I consent to information or opinions which I have given being attributed to me in any reports on this research:

Yes No

I would like to receive a copy of the final report and have added my Yes No email address below.

Signature of participant:

Name of participant:

Date:

Contact details: 


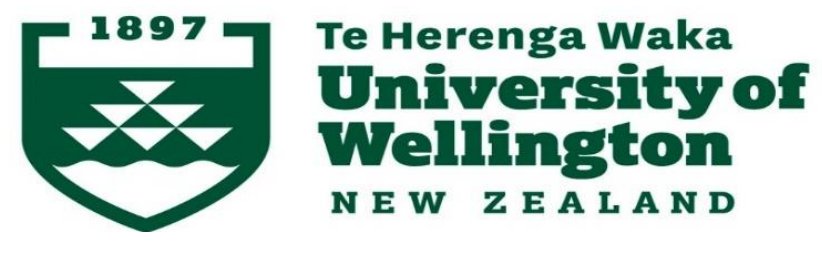

Interview Guide

Title of the Project: Ownership, Decentralization and Development in Papua New Guinea: Sub National Participation in Aid Effectiveness.

SECTION A: GENERAL QUESTIONS ON AID AND DEVELOPMENT EFFECTIVENESS

What roles have you undertaken in the aid sector particularly in relation to your agency?

What is your view on overall aid management and coordination in PNG?

Are there any examples you can point to of successful projects/programs implemented through aid funding in PNG?

\section{SECTION B: DEVELOPMENT OWNERSHIP - SUBNATIONAL LEVEL}

Have you had much experience of working with aid projects/programs at the subnational (provincial and district) level?

If so, what are your best and worst experiences of working at these levels?

How effective is working with/at the subnational level in terms of counterpart funding from the local government (national, provincial and local level governments)?

What are some of the issues and challenges faced at the subnational levels in aid delivery?

In your experience, have the implementing agencies at subnational level made any attempts to consolidate and institutionalize some of the lessons learned and best practices from the donor initiatives?

In your opinion, do you think officials (public servants) and leaders at the subnational levels are willing to accept reforms in terms of their financial and human resource capacity?

\section{SECTION C: GRASSROOTS PARTICIPATION}

In your opinion, are donor projects implemented more successfully than the government's own funded projects?

Is there strong citizen participation in development projects implemented at the subnational level?

\section{SECTION D: WAYS FORWARD}

How can service delivery at the subnational level become more efficient and effective? (Your own opinions) 
Appendix 3: Research Questionnaire

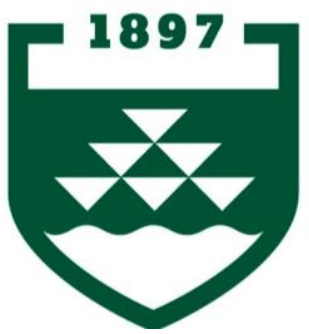

Te Herenga Waka University of Wellington

N E W Z E A L A N D

\section{RESEARCH QUESTIONNAIRE}

Title of the Project: Ownership, Decentralization and Development in Papua New Guinea: Sub National Participation in Aid Effectiveness.

\section{How to answer the questions (optional):}

1. You may print this questionnaire form and write your answers with biros. After answering them, you may scan and email back to me on edwardkapi2@gmail.com/kapiedwa@myvuw@ac.nz.You may skip some questions if you are unable to provide answers.

2. You may use the Microsoft Office Word version to type in your answers and send to me on my email address.

3. We can have an audio call so that you may provide your answers. Partial or attempted answers are acceptable.

4. For the boxes, if you are using the MS word, you may highlight the preferred answer. If you are using the PDF version, then you may tick on each boxes.

\section{PART ONE: Participation and Ownership}

Does your agency implement, coordinate or mobilize donor resources and programs?

$\square$ Coordinate and mobilize donor resources only

$\square$ Manage and implement donor funded projects and programs

$\square$ All of the above

$\square$ None of the above

Comments:

Does your agency participate in high level aid effectiveness dialogue?

$\square$ Yes

No

Sometimes 
Are you aware of the (5) aid effectiveness principles (Ownership, Alignment, Harmonisation, Managing for Results and Mutual Accountability)?

Yes, well aware

Yes, I am aware but know very little about them.

No, I am not aware of them

Comments:

Are your concerns on development effectiveness taken into consideration by top management or higher authorities?

$\square$ Yes

$\square$ No

$\square$ Sometimes

Comments:

Do you see grassroots and civil society organizations participate in the implementation and decision making processes in development activities?

$\square$ Yes, they participate often

$\square$ They participate but only sometimes

$\square$ No, they do not participate

Comments:

Do you invite grassroots and civil society organizations to participate in the implementation and decision making processes in development activities?

$\square$ Always

$\square$ Sometimes 
No

Comments:

Are the lower levels of Government willing to accept changes or reforms?

Always

Sometimes

No

Comments:

\section{PART TWO: Practices (capacity)}

Are the current agreed systems, processes and procedures of aid delivery, coordination and management working effectively?

$\square$ Yes - working effectively

$\square$ Some are working and some are not

$\square$ No - not working effectively

Comments:

Do you feel that you have flexibility in adopting reforms brought in by donor projects?

$\square$ Yes

$\square$ Sometimes

$\square$ No

Comments: 
Are these reforms helping you in your daily activities in other similar roles in development efforts?

$\square$ Yes

$\square$ Sometimes

$\square$ No

Comments:

Are the Government practices such as reporting, accounting, auditing and project management becoming better?

Much better

$\square$ A little better but they still need improvement

$\square$ Not better and need more improvement

$\square$ Not better and would not adopt them.

Comments:

Are the donor practices such as reporting, accounting, auditing and project management much better?

$\square$ Much better and need to adopt them

$\square$ A little better but they still need improvement

$\square$ Not better and needs more improvement

$\square$ Not better and would not adopt them.

Comments:

Does your organization have the capacity to undertake reforms?

$\square$ Yes

$\square$ In limited ways only

$\square$ NO 
Are your roles in the organization similar or different to the donor practices? Or if you are working for donor, are your roles and responsibility similar to the Government agencies?

$\square$ Very similar

$\square$ Slightly similar

$\square$ Not similar

Comments:

Do you see any differences in terms of success rates (completion of project and sustainability) in aid funded project and government funded projects?

$\square$ Yes

$\square$ No

Comments:

Do you think that the current project models and development practices that are used by donors should be adopted in government service delivery?

$\square$ Yes

$\square$ In some aspects only

$\square$ No

Comments: 
Is your organization fully funded to undertake extra responsibilities in implementing, coordinating and managing aid funded projects?

Well-funded

Not funded

Yes, but less funding

Comments:

Do you think that certain functions of aid management, coordination and implementation should be decentralized to the subnational government particularly the provinces and the districts?

$\square$ Yes - this is highly recommended

$\square$ Yes - but only limited functions

$\square$ No - not recommended

Comments:

How satisfied or dissatisfied are you with the National Government's overall development ownership of Aid effectiveness principles?

Very dissatisfied

$\square$ Dissatisfied

$\square$ Satisfied

$\square$ Very satisfied

Comments: 


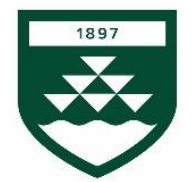

Ownership, Decentralization and Development in Papua New Guinea: Sub National

Participation in Aid Effectiveness

INFORMATION SHEET

\section{AGENCY \\ PARTICIPANT: \\ POSITION}

You are invited to take part in this research. Please read this information before deciding whether or not to take part. If you decide to participate, thank you. If you decide not to participate, thank you for considering this request.

\section{Who am I?}

My name is Edward Kapi and I am a Masters student in Development Studies at the Victoria University of Wellington. This research project is work towards my thesis. I am a New Zealand Aid scholarship student and this research is funded by the NZAid as part of my scholarship support towards my program.

\section{What is the aim of the project?}

This research focuses on "donors' best practices" in the ways in which official aid is given and the extent the subnational level agencies have adopted some of these practices.

The research aims to address the issue of development and aid effectiveness in the context of Papua New Guinea by examining those best practices that are relevant and institutionalising them into our mainstream service delivery efforts. This requires ownership from the recipient government including the sub national levels (Provinces and Districts). Specifically, it aims to assess and analyse the level of development ownership.

The objectives of this study are to: 1) seek to understand and identify how and what kind of decisions are made and what level of influences are made on the decisions to manage, coordinate, and implement aid resources particularly at the sub national levels of Government; 2) to understand and identify what are the capacities at the subnational to guarantee to adopt best practices that are relevant to country settings and requirements.

Your organisation's participation will support this research by contributing towards the country's effort and commitment to achieving aid and development effectiveness. This 
research has been approved by the Victoria University of Wellington Human Ethics Committee [Research Master Application number: 0000028445]

\section{How can you help?}

You have been invited to participate in this research project titled 'Ownership, Decentralization and Development in Papua New Guinea: Sub national Participation in Aid Effectiveness". You are invited to take part in this research project because you are an expert and a resourceful person at the donor agency who can be able to make and influence policy decisions on management, coordination and implementation of Official Development Assistances (ODA) in the country.

Your experience of development cooperation and aid effectiveness at the provincial and district levels is highly valued in this research.

This Participant Information Sheet and Consent Form tells you about the research project. Knowing what is involved will help you decide if you want to take part in the research. Please read this information carefully. Ask questions about anything that you don't understand or want to know more about.

Participation in this research is voluntary. If you don't wish to take part, you don't have to. If you decide you want to take part in the research project, you will be asked to sign the consent section. By signing it you are telling us that you:

- Understand what you have read.

- Consent to take part in the research project.

- Consent to the use of the personal information as provided by you.

You will be given a copy of this Participant Information and Consent Form to keep.

The results of this research will be used by myself to obtain a Masters qualification through Victoria University of Wellington. This research is not being externally funded.

If you agree to take part, I will interview you at your office through phone call and other mode of communication. I will ask you questions about; 1) seeking to understand and identify how and what kind of decisions are made and what level of influence are made on the decisions to manage, coordinate, and implement aid resources particularly at the sub national levels of Government; 2) to understand and identify what are the capacities at the subnational to guarantee to adopt best practices that are relevant to country settings and requirements.

The interview will take less than 30 minutes I will audio record the interview with your permission and write it up later. You can choose to not answer any question or stop the interview at any time, without giving a reason. You can withdraw from the study by contacting me at any time before $1^{\text {st }}$ of September, 2020. If you withdraw, the information you provided will be destroyed or returned to you.

\section{What will happen to the information you give?}


You will not be named in the final report but your organisation will be named (provided you have the authority to agree to this on behalf of the organisation).

Only my supervisors and I will read the notes or transcript of the interview. The interview transcripts, summaries and any recordings will be kept securely and destroyed by April 2021.

\section{What will the project produce?}

The information from my research will be used in Master's thesis. The thesis will be digitally available in the VUW library after completion.

\section{If you accept this invitation, what are your rights as a research participant?}

You do not have to accept this invitation if you don't want to. If you do decide to participate, you have the right to:

- $\quad$ choose not to answer any question;

- $\quad$ ask for the recorder to be turned off at any time during the interview;

- $\quad$ withdraw from the study before $1^{\text {st }}$ of September 2020;

- $\quad$ ask any questions about the study at any time;

- be able to read any reports of this research by emailing the researcher to request a copy.

\section{If you have any questions or problems, who can you contact?}

If you have any questions, either now or in the future, please feel free to contact [my supervisor/me]:

\section{Student:}

Name: Edward Kapi

University email address:

kapiedwa@myvuw.ac.nz
Supervisor:

Name: Prof. John Overton

Role: Principal Supervisor

School: School of Geography,

Environment and Earth Sciences

Phone: + 6444635281

John.overton@vuw.ac.nz

\section{Human Ethics Committee information}

If you have any concerns about the ethical conduct of the research you may contact the Victoria University of Wellington HEC Convenor: Associate Professor Judith Loveridge. Email hec@vuw.ac.nz or telephone +64-4-463 6028. 


\section{REFERENCES}

Aarons, G. A., Hurlburt, M., \& Horwitz, S. M. (2011). Advancing a conceptual model of evidence-based practice implementation in child welfare. Administration and Policy in Mental Health and Mental Health Services Research, 38, 4-23.

Anyan, F. (2013). The Influence of Power Shifts in Data Collection and Analysis Stages: A Focus on Qualitative Research Interview. Qualitative Report, 18(36).

Bardhan, P. (2002). Decentralization of governance and development. Journal of Economic perspectives, 16(4), 185-205.

Bissio, R. (2013). The Paris Declaration on Aid Effectiveness.

Booth, D. (2012). Aid effectiveness: bringing country ownership (and politics) back in. Conflict, Security \& Development, 12(5), 537-558.

Bourguignon, F. \& Sundberg, M. (2007). Aid effectiveness-opening the black box. American Economic Review 97(2), 316-321.

Braunstein, J. (2017). Understanding the politics of bailout policies in non-Western countries: The use of sovereign wealth funds. Journal of Economic Policy Reform 20(1), 46-63.

Castel-Branco, C. N. (2008). Aid dependency and development: a question of ownership? A critical view. Maputo: IESE (Working Paper 01/2008).

Chambers, R. (1997). Whose Reality Counts? London: Intermediate Technology Publications.

Cordella, T. \& Dell'Ariccia, G. (2007). Budget support versus project aid: a theoretical appraisal. The Economic Journal, 117(523), 1260-1279.

Cornwall, A. (2003). Whose voices? Whose choices? Reflections on gender and participatory development. World Development 31(8), 1325-1342.

Coumans, C. (2011). Whose Development? Mining, Local Resistance, and Development Agendas. In: Sagebien J., Lindsay N.M. (eds) Governance Ecosystems. International Political Economy Series (pp. 114-132). London: Palgrave Macmillan, London.

Crewe, E. \& Harrison, E. (1998). Whose development. An ethnography of aid: 23-65.

Dabelstein, N. (2012). Article 1: The Paris Declaration on Aid Effectiveness: History and Significance. Canadian Journal of Program Evaluation 27(pp.3).

Need reference for figure: Development Cooperation Policy. (2018-2022), National Development Planning Framework [Figure 3.1) 
Department of Foreign Affairs and Trade, 2015. Strategy for Australia's aid investments in private sector development. Australian Government

Department of Treasury PNG (2008-2021) Budget documents

Retrieved from: https://www.treasury.gov.pg/

The Treasury, (2021). Budget Strategy Paper (BSP). The Government of Papua New Guinea

The Treasury, (2021). Final Budget Outcome. The Government of Papua New Guinea

The Treasury, (2021). Volume 1-Economic and Development Policies. 2008-2021. The Government of Papua New Guinea

The Treasury, (2021). Volume 3A, Public Investment Programs. 20082021. The Government of Papua New Guinea

The Treasury, (2021). Volume 3B - Public Investment Program for Statutory Authorities and Provincial Governments. The Government of Papua New Guinea.

Diesing, P. (1962). Reason in society: Five types of decisions and their social conditions.

Dijkstra, G. (2011). The PRSP approach and the illusion of improved aid effectiveness: Lessons from Bolivia, Honduras and Nicaragua. Development Policy Review, 29, s110-s133.

Disch, A. (1999). Aid coordination and aid effectiveness, Royal Norwegian Ministry of Foreign Affairs.

Feeny, S. (2005). The impact of foreign aid on economic growth in Papua New Guinea.

Feeny, S. (2007). Foreign aid and fiscal governance in Melanesia. World Development 35(3), 439-453.

Filer, C. (2011). How can the mining industry contribute to sustainable development in the Pacific? Keynote speech, Conference "Mining and mining policy in the Pacific: History, issues, prospects", Nouméa.

Furtado, X. \& Smith, J. (2007). Ethiopia: Aid, ownership, and sovereignty, GEG Working Paper.

Golini, R., Kalchschmidt, M., \& Landoni, P. (2015). Adoption of project management practices: The impact on international development projects of nongovernmental organizations. International journal of project management, 33(3), 650-663.

Group, O. B. (2012). The Report: Papua New Guinea 2012, Oxford Business Group. 
Gulrajani, N. \& Swiss, L. (2019). Donor proliferation to what ends? New donor countries and the search for legitimacy. Canadian Journal of Development Studies/Revue canadienne d'études du développement 40(3), 348-368.

Higgins, L. \& Rwanyange, R. (2005). Ownership in the education reform process in Uganda. Compare: A Journal of Comparative and International Education 35(1), 7-26.

Hnanguie, C. T. (2003). The future of foreign aid in Papua New Guinea after 25 years of successes or failures. Building a Nation in Papua New Guinea: Views of the Post-Independence Generation, Pandanus Books, Canberra, 133-148.

Hogan, M. J. \& Hogan, M.J. (1989). The Marshall Plan: America, Britain and the Reconstruction of Western Europe, 1947-1952, Cambridge, Cambridge University Press.

Howes, S., Mako, A. A., Swan, A., Walton, G., Webster, T., \& Wiltshire, C. (2014). A lost decade? Service delivery and reforms in Papua New Guinea 2002-2012. NRI-ANU Promoting Effective Public Expenditure (PEPE) Project.

Howes, S., et al. (2014). "A lost decade? Service delivery and reforms in Papua New Guinea 2002-2012." NRI-ANU Promoting Effective Public Expenditure (PEPE) Project.

Ika, L. A., Diallo, A., \& Thuillier, D. (2010). Project management in the international development industry: the project coordinator's perspective. International Journal of Managing Projects in Business.

Journal of Development Studies 41(6): 1092-1117.

Kaiku, P. (2020). National Development Plans in PNG - How They Measure Up Against the National Goals and Directive Principles, (Working Paper).

Kim, E. M. \& Lee, J. E. (2013). Busan and beyond: South Korea and the transition from aid effectiveness to development effectiveness. Journal of international development 25(6), 787-801.

Landsverk, J., Brown, H., Chamberlain, P., Palinkas, L. A., \& Horwitz, S. M. (2012). Design and analysis in dissemination and implementation research. In R. C. Brownson, G. A. Colditz, \& E. K. Proctor (Eds.), Translating science to practice (pp. 225-260). New York: Oxford University Press.

Larmour, P. (2007). International action against corruption in the Pacific Islands: Policy transfer, coercion and effectiveness. Asian Journal of Political Science 15(1), 1-16.

Manning, C. \& Malbrough, M. (2010). Bilateral donors and aid conditionality in postconflict peacebuilding: the case of Mozambique. The Journal of Modern African Studies, 143-169. 
Martini, J., Mongo, R., Kalambay, H., Fromont, A., Ribesse, N., \& Dujardin, B. (2012). Aid effectiveness from Rome to Busan: some progress but lacking bottom-up approaches or behaviour changes. Tropical Medicine \& International Health, 17(7), 931-933.

Mawdsley, E. (2015). DFID, the private sector and the re-centring of an economic growth agenda in international development. Global Society, 29(3), 339-358.

Mawdsley, E., Murray, W. E., Overton, J., Scheyvens, R., \& Banks, G.(2018). Exporting stimulus and "shared prosperity": Reinventing foreign aid for a retroliberal era. Development Policy Review, 36, 025-043.

Mawdsley, E., Murray, W. E., Overton, J, Scheyvens, R. \& Banks, G. A. (2018) Exporting stimulus and 'shared prosperity': Re-inventing aid for a retroliberal era. Development Policy Review, 36, O25-O43

Mawdsley, E., Savage, L. \& Kim, S-M. (2014) A 'post-aid world'? Paradigm shift in foreign aid and development cooperation. Geographical Journal, 180, 12738.

Murray, W. E. \& Overton, J. (2016) Retroliberalism and the new aid regime of the 2010s. Progress in Development Studies, 16(3), 1-17

McEwan, C., Mawdsley, E., Banks, G., \& Scheyvens, R. (2017). Enrolling the private sector in community development: magic bullet or sleight of hand? Development and Change, 48(1), 28-53.

McGillivray, M. \& Morrissey, O. (2000). Aid fungibility in assessing aid: red herring or true concern? Journal of international development, 12(3), 413-428.

Michener, V. J. (1998). The participatory approach: contradiction and co-option in Burkina Faso. World Development, 26(12), 2105-2118.

Mohanty, A. (2017). Multilingualism, education, English and development: Whose development. Multilingualisms and development, 261-280.

Molenaers, N., Dellepiane, S., \& Faust, J. (2015). Political conditionality and foreign aid. World Development, 75, 2-12.

Montinola, G. R. (2010). When does aid conditionality work? Studies in comparative international development, 45(3), 358-382.

Murray, W. E. \& Overton, J. (2011). The inverse sovereignty effect: Aid, scale and neostructuralism in Oceania. Asia Pacific Viewpoint, 52(3), 272-284.

Murray, W. E. \& Overton, J. (2016). Retroliberalism and the new aid regime of the 2010s. Progress in development studies, 16(3), 244-260. 
Murray, W. E. \& Overton, J. D. (2011). Neoliberalism is dead, long live neoliberalism? Neostructuralism and the international aid regime of the 2000s. Progress in development studies, 11(4), 307-319.

Neuman, W. L. \& Wiegand, B. (2000). Criminal justice research methods: Qualitative and quantitative approaches. Boston, Allyn and Bacon.

Nunnenkamp, P., Rank, M., \& Thiele, R (2016). Aid fragmentation and donor coordination in Uganda: A district-level analysis. The Fragmentation of Aid, Springer, pp.153-164.

OECD (2008). The Paris Declaration on Aid Effectiveness and the Accra Agenda for Action, Paris, OECD, http://www.oecd.org/dac/effectiveness/34428351.pdf accessed 20 February 2014.

OECD (2011). Busan Partnership for Effective Development Cooperation, Busan.

Overton, J. (2017) The context of overall aid in the Pacific - and its effectiveness. In M. Powles (ed) China and the Pacific: The View from Oceania (pp. 161-172). Wellington, Victoria University Press.

Overton, J., Murray, W.E., Prinsen, G., Ulu, A.J., \& Wrighton, N. (2018). Aid, Ownership and Development: The Inverse Sovereignty Effect in the Pacific Islands. Abingdon, Routledge.

Overton, J., Prinsen, G., Murray, W.E. \& Wrighton, N. (2012). Reversing the tide of aid: Investigating development policy sovereignty in the Pacific. Journal de la Société des Océanistes, 135, 229-242.

Owa, M. (2011). Revisiting the Paris Declaration Agenda - An Inclusive, Realistic Orientation for Aid Effectiveness. Development in Practice, 21(7), 987-998

Ozcan, G.B. (2006). A critical analysis of decentralisation and local economic development: The Turkish case. Environment and Planning C: Government and Policy, 24(1), 117-138.

PACLII. (n.d.) Papua New Guinea Consolidated Legislation. http://www.paclii.org/pg/legis/consol_act/cotisopng534/.

Palinkas, L. A., Horwitz, S. M., Green, C. A., Wisdom, J. P., Duan, N., \& Hoagwood, K (2015). Purposeful Sampling for Qualitative Data Collection and Analysis in Mixed Method Implementation Research. Adm Policy Ment Health, 42, 533544. https://doi.org/10.1007/s10488-013-0528-y

Proctor, E. K., Landsverk, J., Aarons, G., Chambers, D., Glisson, C., \& Mittman, C. (2009). Implementation research in mental health services: An emerging science with conceptual, methodological, and training challenges. Administration and Policy in Mental Health and Mental Health Services Research, 36, 24-34. 
Montes, M. F. (2016). "Five points on the Addis Ababa action agenda." South Centre Policy Brief (24) .

Rosenström, U. \& Kyllönen, S. (2007). Impacts of a participatory approach to developing national level sustainable development indicators in Finland. Journal of environmental management, 84(3), 282-298.

Schneider, A. (2003). Decentralization: Conceptualization and measurement. Studies in comparative international development, 38(3), 32-56.

Sechrest, L. \& Sidani, S. (1995). Quantitative and qualitative methods: Is There an Alternative? Evaluation and Program Planning, 18(1), 77-87.

Shah, I. A. \& Baporikar, N. (2012). Participatory Approach to Development in Pakistan. Journal of Economic \& Social Studies (JECOSS), 2(1).

Sibanda, D. (2011). The role of community participation in development initiatives: The case of the Danga ecological sanitation project in the Zvishavane District, Zimbabwe (Doctoral dissertation, University of the Western Cape).

Singh, A. (2004). Aid Conditionality and Development. Oxford: Blackwell.

Sjöstedt, M. (2013). Aid effectiveness and the Paris declaration: A mismatch between ownership and results-based management? Public administration and development, 33(2), 143-155.

Sobhan, R. (2009). Aid effectiveness and policy ownership. The Government of Papua New Guinea, 2008. Vision 2050. Department of Prime Minster and National Executive Council.

The Government of Papua New Guinea. (2010). Development Strategic Plan 20102030. Department of National Planning and Monitoring.

The Government of Papua New Guinea. (2018). Development Cooperation Policy. Department of National Planning and Monitoring.

The Government of Papua New Guinea. (2018). Medium-Term Development Plan III 2018-2022. Department of National Planning and Monitoring.

The Government of Papua New Guinea, 2020. 2021 National Budget, Vol2a. Department of Treasury.

Thomas, J. C. (1993). Public involvement and governmental effectiveness: a decisionmaking model for public managers. Administration \& society, 24(4), 444-469.

Tierney, M. J., Nielson, D. L., Hawkins, D. G., Roberts, J. T., Findley, M. G., Powers, R. M., ... \& Hicks, R. L (2011). More dollars than sense: Refining our 
knowledge of development finance using AidData. World Development, 39(11), 1891-1906.

Van Meensel, J., Lauwers, L., Kempen, I., Dessein, J., \& Van Huylenbroeck, G. (2012). Effect of a participatory approach on the successful development of agricultural decision support systems: the case of Pigs2win. Decision Support Systems, 54(1), 164-172.

Winters, M. S. (2010). Accountability, participation and foreign aid effectiveness. International Studies Review, 12(2), 218-243. 